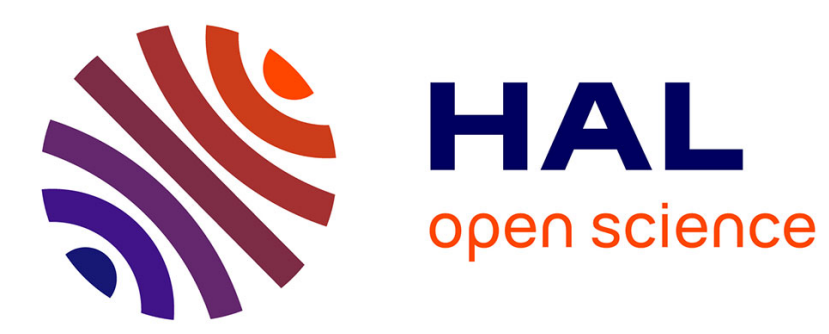

\title{
Manifested flatness predictions in thin strip cold rolling
}

Sami Abdelkhalek, Pierre Montmitonnet, Nicolas Legrand, Pascal Buessler

\section{To cite this version:}

Sami Abdelkhalek, Pierre Montmitonnet, Nicolas Legrand, Pascal Buessler. Manifested flatness predictions in thin strip cold rolling. 11th ESAFORM Conference on Material Forming, Apr 2008, Lyon, France. pp.Pages 339-342, 10.1007/s12289-008-0064-6 . hal-00510326

\section{HAL Id: hal-00510326 \\ https://hal-mines-paristech.archives-ouvertes.fr/hal-00510326}

Submitted on 18 Aug 2010

HAL is a multi-disciplinary open access archive for the deposit and dissemination of scientific research documents, whether they are published or not. The documents may come from teaching and research institutions in France or abroad, or from public or private research centers.
L'archive ouverte pluridisciplinaire $\mathbf{H A L}$, est destinée au dépôt et à la diffusion de documents scientifiques de niveau recherche, publiés ou non, émanant des établissements d'enseignement et de recherche français ou étrangers, des laboratoires publics ou privés. 


\title{
Manifested flatness predictions in thin strip cold rolling
}

\author{
S. Abdelkhalek ${ }^{1}$, P. Montmitonnet ${ }^{1}$, N. Legrand ${ }^{2}$, P. Buessler ${ }^{2}$ \\ ${ }^{1}$ Ecole des Mines de Paris-ParisTech- CEMEF - UMR CNRS 7635 - BP 207 - 06904 Sophia-Antipolis - \\ Cedex - France \\ URL: www-cemef.cma.fr \\ e-mail: sami.abdelkhalek@ensmp.fr ; pierre.montmitonnet@ensmp.fr
}

2 ArcelorMittal Research, R\&D Industrial Operations - BP 30320 - Voie Romaine 57283 Maizieres Les Metz -Cedex-France

URL: www.arcelormittal.com

e-mail: nicolas.legrand@arcelormittal.com

\begin{abstract}
The paper deals with flatness defects prediction in thin plates which appear during rolling. Their origin is the roll stack thermo-elastic deformation. The combination of the elastic deflection, the thermal crown and the roll grinding crown results in a non-parallel bite. If the transverse roll profile is not an affinity of the incoming strip profile, differential elongation results and induces high stresses in the outgoing strip. The latter combine with the imposed strip tension force, resulting in a net post-bite stress field which may be sufficiently compressive locally to promote buckling. A variety of non-developable shapes may result, generally occurring as waviness, and classified as flatness defects (center waves, wavy edges, quarterbuckles...). The purpose of the present paper is to present a coupled approach, following [1] : a simple buckling criterion is introduced in the FEM model of strip and roll deformation, LAM3 / TEC3 [2]. The postbite stress field is in much better agreement with experiments if this treatment is used, as will be demonstrated.
\end{abstract}

Key words: Sheet metal; Rolling; Flatness defects; Residual stresses; Buckling;

\section{INTRODUCTION}

Flatness defects are one of the major problems encountered in strip rolling. Their origin is out-ofbite stress gradients resulting in buckling in the compressive stress areas. Depending on the stress component involved and the location of compressive areas, waves in the longitudinal, transverse or oblique directions can be found, at diverse locations (Long edge / centre, quarter-buckles... see figure 1). In turn, these pre- and post-bite stress gradients have their origin in the differential elongation due to the combination of incoming strip crown and work roll (WR) active profile. The latter is a combination of grinding crown, thermal crown, and elastic roll stack and stand deformation.

During the rolling process, the strip is under tension from coilers or neighbouring stands. Hence, defects can be more or less dissimulated, but can be measured through the heterogeneity of stress distributions: latent defect. The latter becomes a manifested defect, or a manifested defect may amplify, when the strip tension is relaxed.

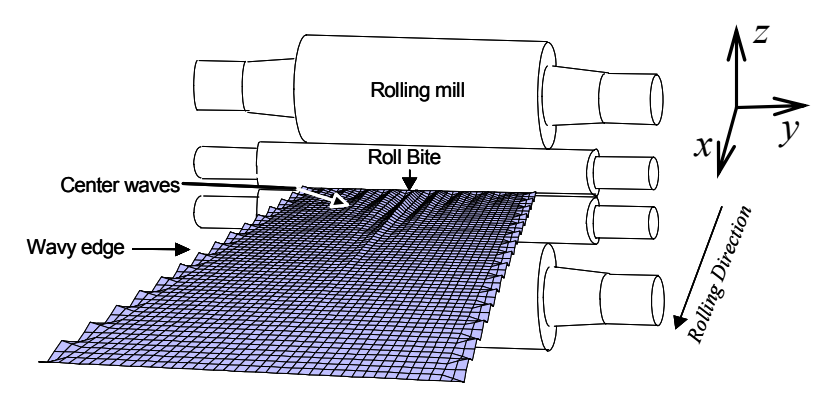

Figure 1. Schematic illustration of flatness defects [1].

\section{SCIENTIFIC STAKES}

The prediction of the occurrence and of the characteristics (wavelength, amplitude) of flatness defects is therefore a big challenge. A precise roll stack deformation model must be used; its input data, the strip / Work roll contact pressure field, must be accurate. This leads to favour thermo-mechanical, strip / roll stack coupled model. LAM3, a software developed by Cemef, Transvalor, Arcelor Research and Alcan [3], solves the strip elastic-viscoplatic 
strain by 3D FEM, and the roll stack elastic deformation by semi-analytical models.

It must be realized that defects are generally nonsymmetric, neither in the vertical nor in the transverse direction, and non-steady state: waves formed at bite exit, in a region of large stress gradients due to fast reorganization of the velocity field, are transported with the material velocity.

Moreover, manifested flatness defects imply thorough stress reorganization, because stresses always saturate in buckled areas. This complete rearrangement of the stress field in the post-bite strip can be viewed as a change in the boundary conditions of the plastic deformation in the bite. Hence, in-the-bite and out-of-bite stress fields may be strongly coupled. This makes questionable those models of flatness defects, in which a post-bite zone at some distance away from the roll gap is considered, where the stress field is quite moderate. The latter is first computed by an adequate FEM strip rolling model, then transferred to a structural, completely decoupled analytical or FEM model where buckling is analyzed [4] [5] [6].

A fully convincing model should therefore take into account all couplings: strip in the bite, buckling outof-bite, roll stack, with mechanical and thermal fields. At this stage, a simple steady-state coupled model has been used [1]; but in this case, due to the non-steady state character of the waves, only the occurrence of waves can be predicted with a certain degree of certainty, not their severity.

\section{SIMPLE COUPLED MODEL OF BUCKLING USED (COUNHAYE'S MODEL)}

Following [1], we have introduced in LAM3 (steady state version) a stress-relaxation algorithm when a simple plate buckling criterion is met :

$$
\sigma_{c}=\frac{\pi E h^{2}}{3 \delta^{2}}
$$

$E$ is Young's modulus, $h$ the strip thickness, and $\delta$ the wavelength (assumed similar to the compressive stress area dimensions). Wherever a principal stresses $\sigma_{I}$ or $\sigma_{I I}$ reaches $\sigma_{c}$, we assume buckling will shorten a material element in the corresponding direction by :

$$
\begin{aligned}
& \lambda_{I}=\frac{\sigma_{I}-\sigma_{c}}{k \times E} \\
& \lambda_{I I}=\frac{\sigma_{I I}-\sigma_{c}}{k \times E} \\
& k<<1
\end{aligned}
$$

$k$ is a parameter presenting the ratio between the material "buckling stiffness" and the Young modulus.

This decreases the strain sent back after each Newton-Raphson iteration to the constitutive model solver, and therefore the compressive stresses (and as a consequence, the stresses in the tensile area, to maintain mechanical equilibrium). This tends to force iteratively the stress field to respect the criterion.

Remark: $\lambda_{i}(i=1,2)$ can also been defined as a a deformation recovered by buckling, so it can be given by :

$$
\lambda_{i}=\ln \left(\frac{\tilde{L}_{i}}{\bar{L}_{i}}\right),(i=1,2)
$$

where $\tilde{L}_{i}$ and $\bar{L}_{i}$ are respectively the developed length of the buckled line and its projection on $(x, y)$ plan.

Although buckling does not occur at element scale, here it is treated locally on each element reaching the critical stress estimated in (1). However, despite the simplicity of this model, figure 2 shows, for particular rolling conditions (Table 1), that the impact of buckling on the final stress state is to bring it closer to experiments (tensiometer roll). Furthermore, we note an insignificant dependence of results on $\sigma_{c}$ value. This supports the criterion (1) in spite of its simplicity.

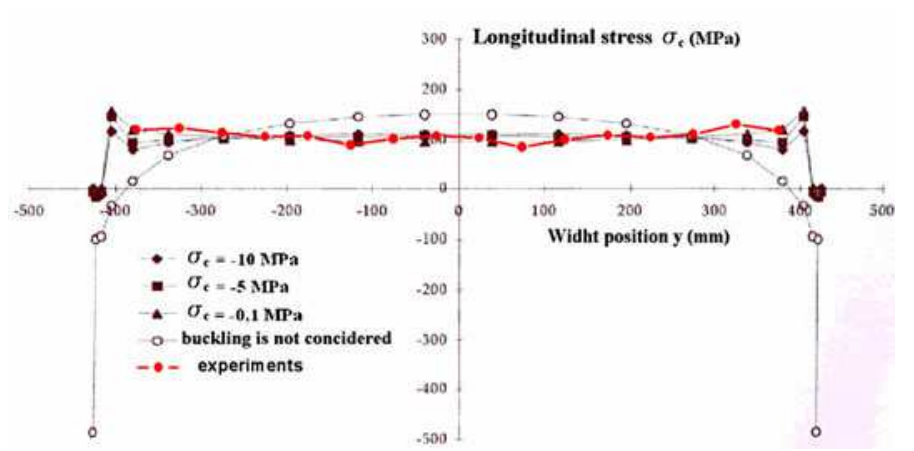

Figure 2. Comparison of stress profiles computed with and without accounting for stress relief by buckling, and measured in experiments [1] (far away enough from the bite).

\begin{tabular}{|l|l|}
\hline Friction law & Coulomb : $\mu=0.033$ \\
\hline width & $851 \mathrm{~mm}$ \\
\hline Entry thickness & $0.355 \mathrm{~mm}$ \\
\hline Looked thickness for & $0.225 \mathrm{~mm}$ \\
\hline Upstream imposed tension & $170 \mathrm{MPa}$ \\
\hline downstream imposed tension & $100 \mathrm{MPa}$ \\
\hline Rolling velocity & $22 \mathrm{~m} . \mathrm{s}-1$ \\
\hline Work roll diameter & $555 \mathrm{~mm}$ \\
\hline & $\begin{array}{l}\text { Young modulus } \mathrm{E}=210 \mathrm{GPa} \\
\text { Poisson's ratio } v=0.3 \\
\sigma_{0}=(470.5+175.4 \times \bar{\varepsilon}) \\
\text { Behaviour law }\end{array}$ \\
& $\quad \times\left(1-0.45 \times e^{-8.9 \bar{\varepsilon}}\right)-175$ \\
\hline
\end{tabular}

Table 1. Simulated rolling operation description. 


\section{GENERAL FEATURES OF THE STEADY- STATE FINITE ELEMENT MODEL (LAM3/TEC3)}

The global algorithm of thermomechanical computing is presented in figure 3. As the steady state model requires an integration of the stress history along material streamlines, a structured mesh composed of hexahedral (8-node brick) elements is used. It consists of a series of cross sectional meshes (4-node quadrilateral elements) with identical topology, progressing in the rolling direction. The streamline updating step (of both free surface and internal nodes) ensures that lines of nodes are located on streamlines.

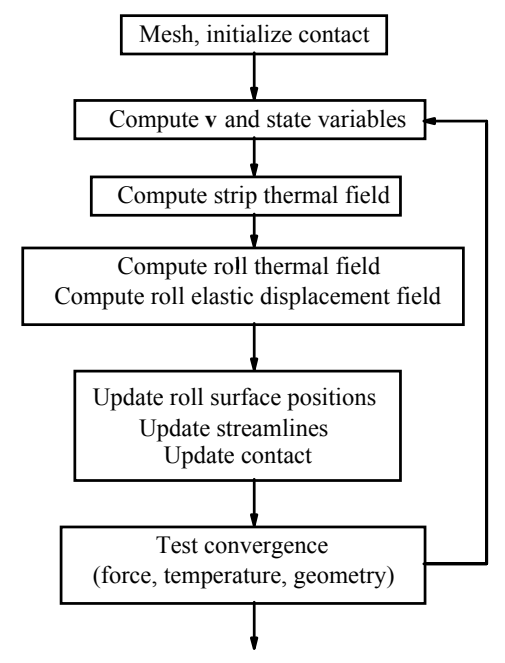

Figure 3. Global flow chart of the model.

In the second step ("Compute velocity $\mathrm{v}$ and state variables") it is assumed that integration points as well as nodes are aligned along streamlines, so that the stress integration may be performed from integration point to integration point.

In the iterative process pictured in figure 4 , stress and strain are updated to respect the equilibrium equation on each integration point. At this stage, the simple buckling model has to be implemented in order to respect the buckling criterion given by (1) as exposed in figure 5.

\section{RESULTS AND DISCUSSION}

Several cases of steel and aluminium strip rolling were observed presenting comparable results. The case which was presented previously (table 1) has been reproduced in order to evaluate the validity of the model.

Similar to results exposed on figure 2, figure 6 shows that considering buckling brings our results closer to experiments.

As shown by figures 7 and 8 , considering buckling does not change the contact stress in the bite (figure 7 ), nor the rolled strip profile (figure 8). Hence, at this stage of this study the bite/out-of-bite coupling does not seem so necessary. Further work will be devoted to this point.

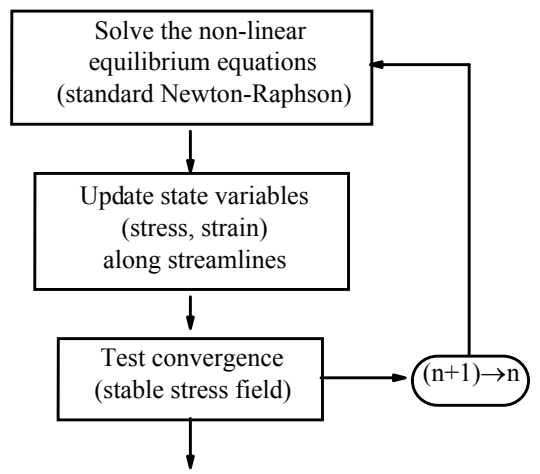

Figure 4. Flowchart for velocity field and stress field computation.

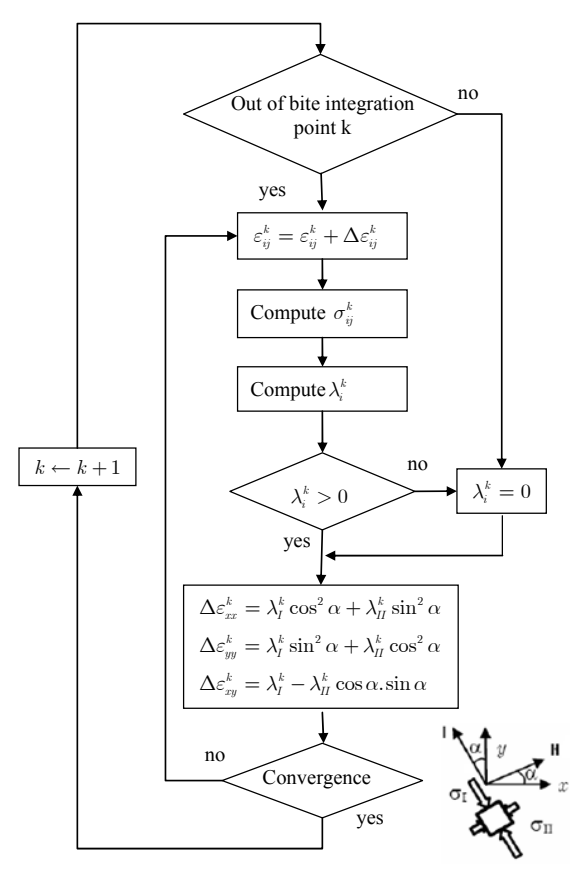

Figure 5. Algorithm of coupling Lam3/tec3 with a steady state simple buckling model: $\varepsilon_{\mathrm{ij}}$ and $\sigma_{\mathrm{ij}}$ are respectively the strain increment tensor and the stress components, $\alpha$ defines the principal directions $I$ and $I I$ in the laboratory reference frame.

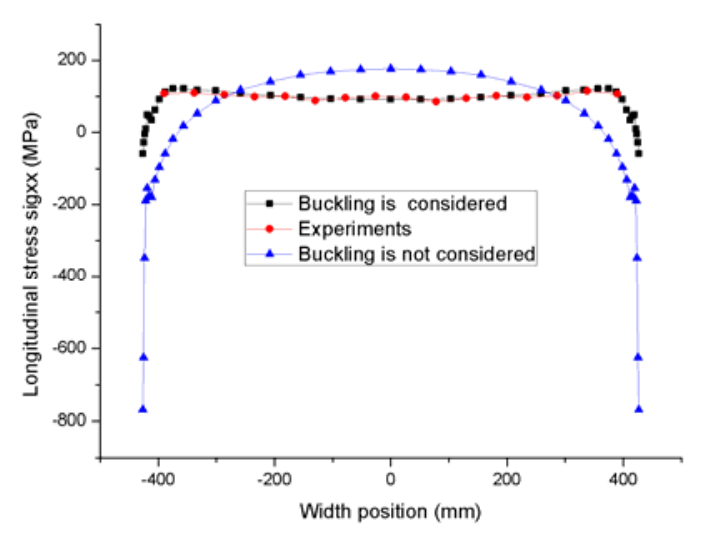

Figure 6. Longitudinal stress at enough distance away from the bite (case data: table 1) $: \sigma_{\mathrm{c}}=-10 \mathrm{MPa}$. 


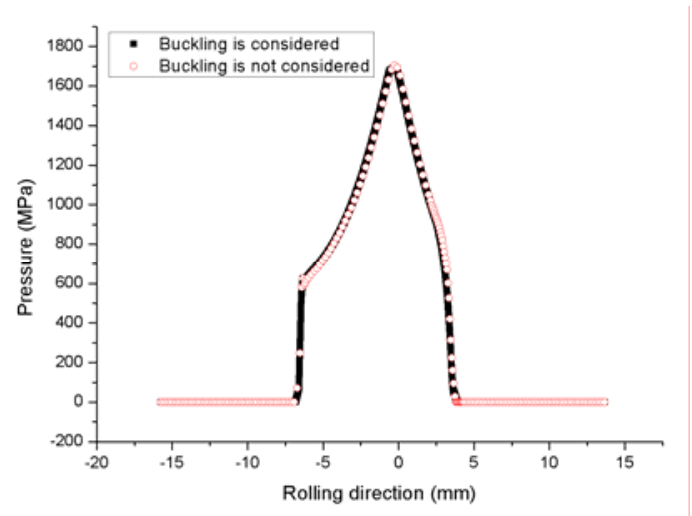

Figure 7. Centre line normal pressure in the bite (case data: table 1).

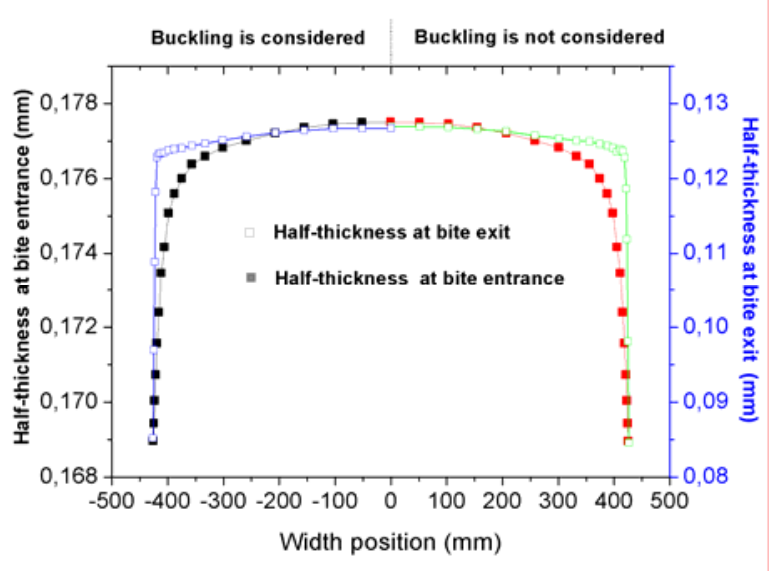

Figure 8. Rolled strip geometry at the exit and the inlet of bite (case data: table 1).

Therefore, a decoupled approach using a more sophisticated and general approach, the asymptotic numerical shell element model (ANM) [7], proves interesting. Several strip rolling cases have been modelled, one of them is presented in figure 9. The displayed strip shape at bite exit shows longitudinal stationary waves near the centreline. The ANM thus looks more promising, being a much more precise and predictive buckling model, in particular allowing modelling of post-buckling.

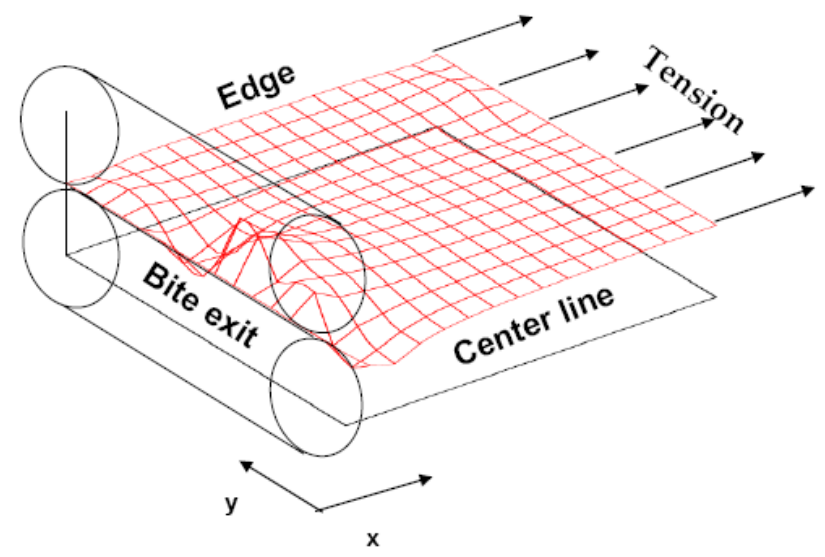

Figure 9. Uncoupled computed flatness defect for the case presented on table 1 .

\section{CONCLUSIONS}

Lam3/Tec3 has been complemented with a simple buckling model, so that stresses are closer to experiments. Fortunately, the fact that the buckling has no influence on the bite, might avoid the difficult point of coupling Lam3/Tec3 (bite zone) and the ANM model. Yet, this finding has to be confirmed through numerical testing. Furthermore, if non stationary wavy edge defects are to be modelled completely, this coupling will probably prove necessary.

\section{ACKNOWLEDGEMENTS}

The authors are grateful to ArcelorMittal for its financial support, and for authorization to publish this work. We also address special thanks to $\mathrm{M}$. Potier-Ferry and $\mathrm{H}$. Zahrouni for sharing their expertise and their software of shell buckling.

\section{REFERENCES}

1. C. Counhaye "Modélisation et contrôle industriel de la géométrie des aciers laminés à froid" (modelling and industrial control of the geometry of cold rolled steels), PhD Thesis, Université de Liège (2000) (in French).

2. P. Montmitonnet "Hot and cold strip rolling processes" Comput. Meth. Appl. Mech. Engng 2006, Vol.195, p.6604-6625.

3. A. Hacquin, " Modélisation thermo $\neg$ mécanique tridimensionnelle du laminage: couplage bande -cylindres. » (3D thermomechanical modelling of rolling processes : coupling strip and rolls). $\mathrm{PhD}$ Thesis, Ecole des Mines de Paris (in French).

4. H. Marchand, "Modélisation de la planéité en sortie de laminage des produits plats. » (Modelling flatness in flat rolling). PhD Thesis, Ecole des Mines de Paris (in French).

5. A. Bush., R. Nicholls., J. Tunstall, "Stress levels for elastic buckling of rolled strip and plate.", Ironmaking and Steelmaking 2001, Vol. 28 No. 6 pp. 481-484.

6. F.D. Fischer, F.G. Rammerstorfer, N. Friedl, "Residual stress induced centre wave buckling of rolled strip metal", J. Appl. Mech. 70 (2003) pp.84-90.

7. H. Zahrouni, « Méthode Asymptotique Numérique pour les coques en grandes rotations. » (Numerical Asymptotic Method for shells in large rotation), PhD, LPMM, Université de Metz (in French). 


\title{
Irregularity in Friction Hills during the Cold Rolling of Materials
}

\author{
H. Abdollahi Ali Beik ${ }^{1}$, K. Dehghani ${ }^{1}$ \\ ${ }^{1}$ Department of Mining and Metallurgical Engineering, Amirkabir University of Technology, 424 Hafez Ave., \\ P.O. Box 15875-4413, Tehran 15914, Iran \\ e-mail: habdollahi2002@yahoo.com,dehghani@aut.ac.ir
}

ABSTRACT: Among the cold rolling parameters, the pressure distribution or friction hill within the roll gap is one of the most significant one. Almost all of the previous works in this regard are based on laboratory simulations rather than industrial mill conditions though the situations can be completely different. In this study, following determination the coefficient of friction (COF), the friction hills for the real industrial mills were obtained by Matroll software. After carrying out various industrial cold-roll passes on 3003 aluminum alloy and low carbon steel, the friction hills were plotted for industrial cases. The new findings indicate that there are some kinds of irregularities in the real industrial friction hills that are different from those reported for laboratory cases. The results show that this happens when the COF values during industrial rolling are too low.

Key words: Friction hill, Cold rolling, Coefficient of friction, Steel and aluminium rolling

\section{INTRODUCTION}

Without the knowledge of the effectiveness of the coefficient of friction (COF), the satisfactory operation of commercial rolling facilities is very difficult to achieve. Moreover, it may become more difficult to use mathematical models of the cold rolling process for engineering purposes [1-4].

In the cold rolling process, friction along the arc of contact at the roll-strip interface is necessary for the transmission of deformation energy from the work rolls to the strip. If the frictional forces are too small, the peripheral speed of the roll will exceed the exit speed of the strip. In other words, the rolls will skid in this case. By contrast, larger coefficients will result in a forward or positive slip of the strip, in fact in such a case, the exit speed of the strip in excess of the peripheral speed of rolls.

The surface quality of sheet is another property influenced strongly by the changes occurred in the COF; in general, the brightness of sheet increases as the effective COF increases and vice versa [5]. In other words, a high value of COF, by employing the poorer types of lubricants, enhances the luster of the rolled strip. However, with poor lubricants, detritus may become embedded in the rolls (i.e. roll pick-up). If this happens, it can degrade the appearance of rolled strip. That is because, in case of high value of COF, e.g. employing poor lubricants, the rolls become worn through the processing of strip so that, if they are initially rough, they tend to become smoother. By contrast, when the COF is low, e.g. using good lubricants, of course, the wear rate is minimized. It should be mentioned that poor lubricity can also damage the work roll surface, resulting in forming a micro-uneveness of the work roll surface. This is attributed to different wear rates on the surface on a microscopic scale [6]. Therefore, a strong correlation exists between the general appearance of the rolled strip and the COF changes in the roll bite.

Regarding the other rolling parameters, increasing the friction in rolling increases the degree of nonuniformity in the deformation zone of rolled stock, increases the rolling force and rolling power as well as the forward slip. The increased rolling force, attributed to the excessive friction in the roll bite, increases the frictional energy dissipation along the arc of contact as well as the bearing losses associated with the mill. To some extent, however, this increased energy supplied by spindles is offset by slightly increased throughout of the mill stand due to the increased forward slip of the strip as it emerges from the roll bite [7].

In the present work, an attempt has been made to study the irregularities observed in friction conditions and friction hills during the industrial cold rolling of aluminum and steel.

\section{TECHNICAL PROCEDURE}

The Matroll software, developed by authors $[8,9]$, is based upon years of practical and experimental observations from cold rolling of metal strips especially aluminium. This software has the capability to operate on windows since it is developed using Visual Delphi 6. During the software operation, the rolling equations pertaining to about 25 parameters are solved using a numerical approach.

One of the significant features of the Matroll is that, contrary to the other models, none of input parameters owns presumed value. In other words, all 
the rolling parameters are calculated or measured according to the constitutive equations of rolling theory. This led to the complexity as well as widespread of the algorithm used in Matroll software. To provide the accurate result, the real conditions of industrial rolling process are considered in the software. For example, as the strip rolling process is a plane strain deformation (i.e. no lateral spread), it was necessary as the first step to obtain the flow stressdraught curves, so called S-r diagrams. To do this, the plain-strain compression tests (Ford test) were carried out. The results are then fed into the software as subprograms. For instance, to obtain the flow-stress of workpiece after a few passes, Matroll goes back to subprograms in order to calculate the equivalent reduction and then refers to S-r curve so as to determine the flow stress corresponding to the total reduction of workpiece. Therefore, the S-r curves, which are considered in Matroll, are of the most important requirements for simulating flat-rolled products.

For saving the space, only are the characteristics of industrial mill for aluminium rolling mentioned here. These are as follows:

Aluminum Mill: Industrial four-high reversing mill Back up diameter: $1000 \mathrm{~mm}$

Work roll diameter: $400 \mathrm{~mm}$

Lubricant: light mineral oil with $4 \%$ additives Entry and exit gauges: $7 \mathrm{~mm}$ and $0.3 \mathrm{~mm}$ respectively Rolling speed: $\quad 0$ to $400 \mathrm{~m} / \mathrm{min}$

Using Matroll software, the COF values and friction hills were obtained for many passes carried out on the industrial mills. These were done for rolling both aluminium alloy 3003 and low carbon steel.

As for obtaining the COF, Avitzur [10] suggests the following equation. Compared to other methods to calculate the COF [11-16], this equation is believed that is more completed one, including more important parameters affecting the rolling process and COF. Avitzur's equation used in Matroll is as follows:

$$
\begin{aligned}
& \frac{1}{2} \sqrt{\frac{h_{f}}{R^{\prime}}}\left[\ln \left(\frac{h_{f}}{h_{0}}\right)+\left(\frac{1}{4} \sqrt{\frac{h_{f}}{R^{\prime}}} \sqrt{\frac{h_{0}}{h_{f}}-1}\right)+\frac{t_{0}-t_{f}}{\frac{2}{\sqrt{3}} \sigma}\right] \\
& \left\{\left(\ln \frac{h_{0}}{h_{f}}-1\right) \times \frac{\left(t_{f}-t_{0}\right)}{\frac{2}{\sqrt{3}} \sigma \sqrt{\frac{h_{f}}{h_{0}}-1}}\right]-\left[\frac{\left.\left.\left.\left(\frac{1}{\frac{2}{\sqrt{3}} \sigma}\left(t_{f}-\frac{t_{f}-t_{0}}{\frac{h_{f}}{h_{0}}-1}\right)-1\right) \cdot \tan ^{-1} \sqrt{\frac{h_{0}}{h_{f}}-1}\right]\right]\right\}}{\}}\right.
\end{aligned}
$$

front tensions, $\mathrm{R}^{\prime}$ is the flattened roll radius and $2 / \sqrt{ } 3 \sigma$ is the flow stress of the strip being rolled.

\section{RESULTS}

The industrial amounts of COF determined by Matroll software for both aluminium and steel are summarized in Table I. The friction hills plotted also by Matroll software for industrial steel mills are shown in Figures 1 to 3 . As it is observed, for the passes that COF value is almost reasonable, the friction hills show their normal trend, whereas in cases that this amount is low, there are some kinds of irregularities in the pressure distribution curves. It is interesting that the same happened for real industrial rolling of aluminium, Figures 4 to 6 . Regarding the irregularities in friction hills, while the workpiece is being rolled, any instantaneous changes in rolling conditions that consequently results in lowering the COF values are most likely responsible for the observed abnormalities. Among these changes in the roll gap or deformation zone during rolling can be variations in lubricity conditions, roll temperatures or thermal crowns, roll bending, front and back tensions and roll force. To compensate for any of these changes, the operator should take measures so as to increase the effective $\mathrm{COF}$, i.e. by varying the mentioned parameters in the way of increasing COF.

Table I - The industrial amounts of COF determined by Matroll software.

\begin{tabular}{||c|c|c|c||}
\hline & PASS 1 & PASS 2 & PASS 3 \\
\hline COF vales of Steel & 0.048 & 0.027 & 0.025 \\
\hline COF vales of Aluminum & 0.052 & 0.022 & 0.031 \\
\hline
\end{tabular}

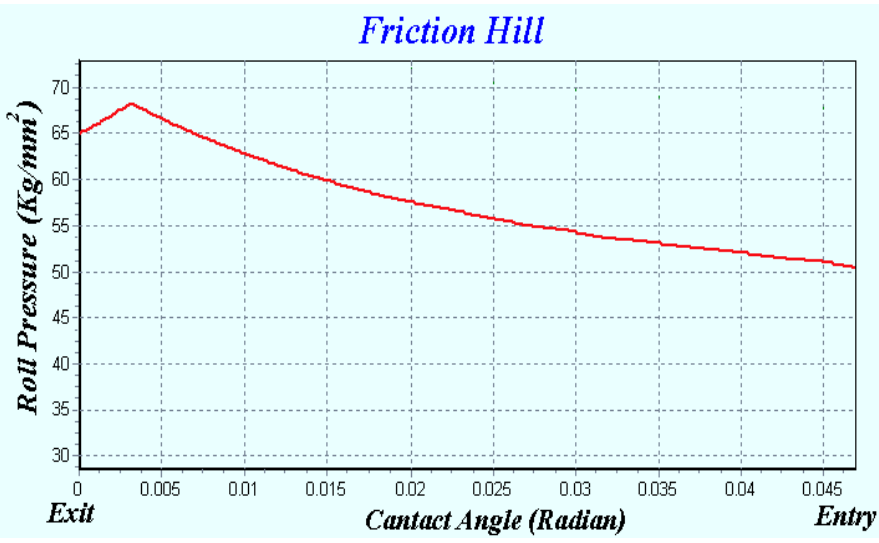

Fig.1. Friction hill for the first pass of steel rolling 


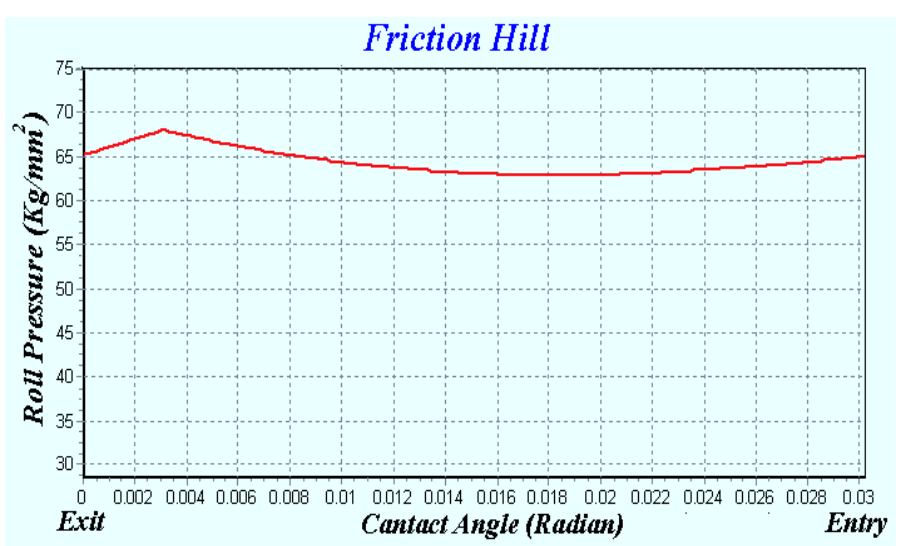

Fig.2. Friction hill for the second pass of steel rolling

\section{Friction Hill}

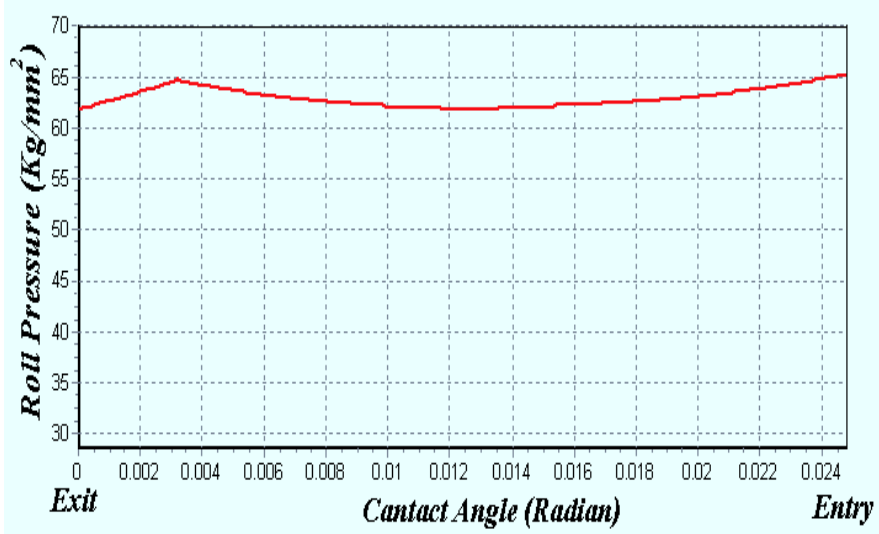

Fig.3. Friction hill for the third pass of steel rolling

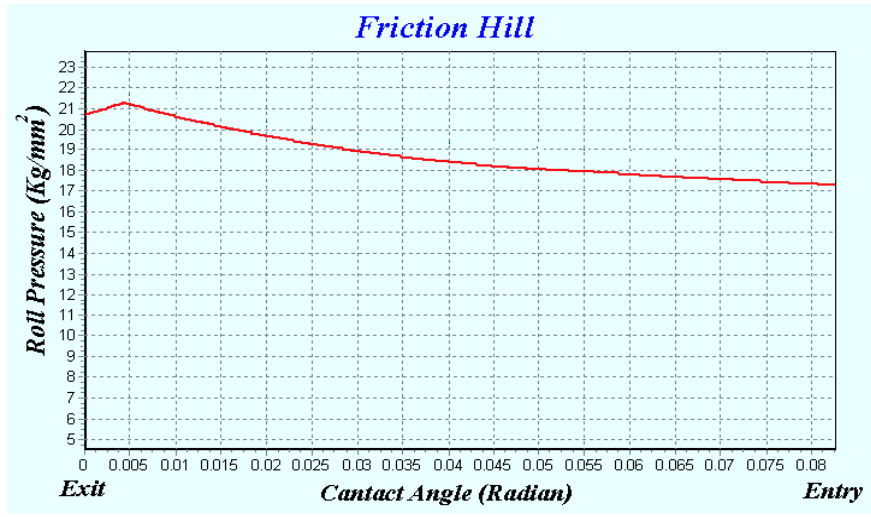

Fig.4. Friction hill for the first pass of aluminium rolling

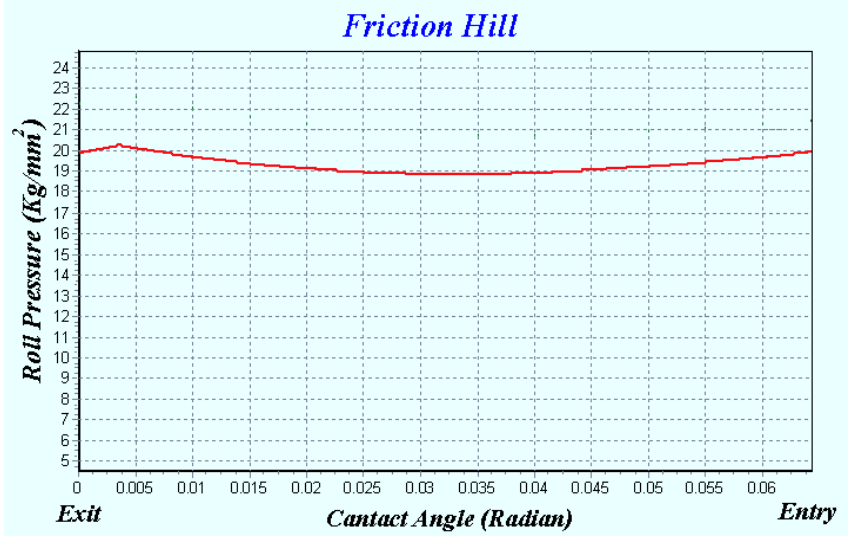

Fig.5. Friction hill for the second pass of aluminium rolling

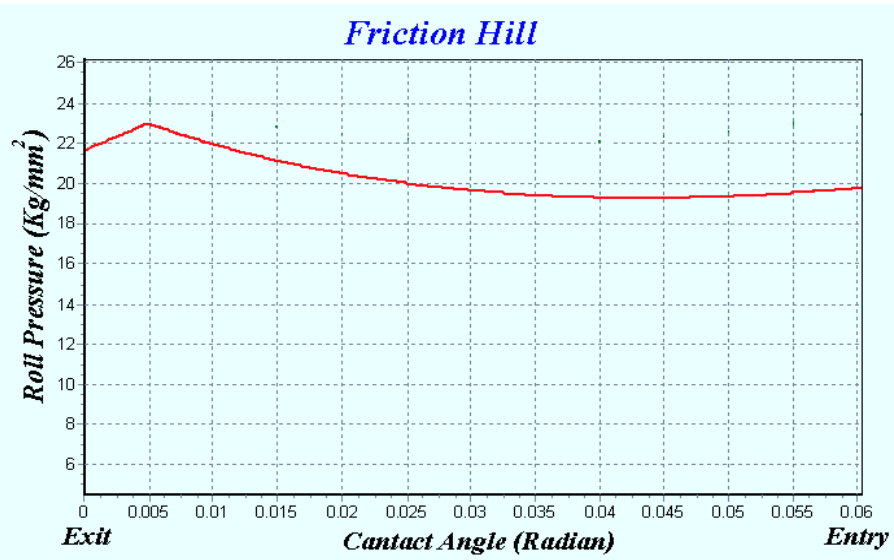

Fig.6. Friction hill for the third pass of aluminium rolling

\section{DISCUSSION}

Referring to Figures 2, 3, 5 and 6, the diagrams of pressure distribution (i.e. the friction hills) over the entry side of the arc of contact exhibit interesting features. As shown for curve 2 in Figure 7, in the entry zone, there is a segment over which the angles of contact are greater than the angle of friction, i.e. tan $\varphi>\mu$. In other words, in this specific region, the friction hill is characterized by a fall rather than by a rise, i.e. a lower COF. By contrast, for curve 1 that represents the theoretical friction distribution, the changes in friction follow the general condition $(\tan \varphi<\mu)$ along the whole contact arc. Therefore, the abnormal friction distribution $(\tan \varphi>\mu)$ may take place at the beginning of the contact arc in a real industrial mill, i.e. in the entry zone of Figures 2, 3, 5 and 6. These findings are in agreement with those reported by Tselikove [17]. Thus, it can be concluded here that the real pressure distribution or friction hill for an industrial level is not necessary the same as the theoretical or predicted one, at least for some cases. This is another finding that confirms, during industrial rolling, the $\mathrm{COF}$ is not constant over the whole arc of contact.

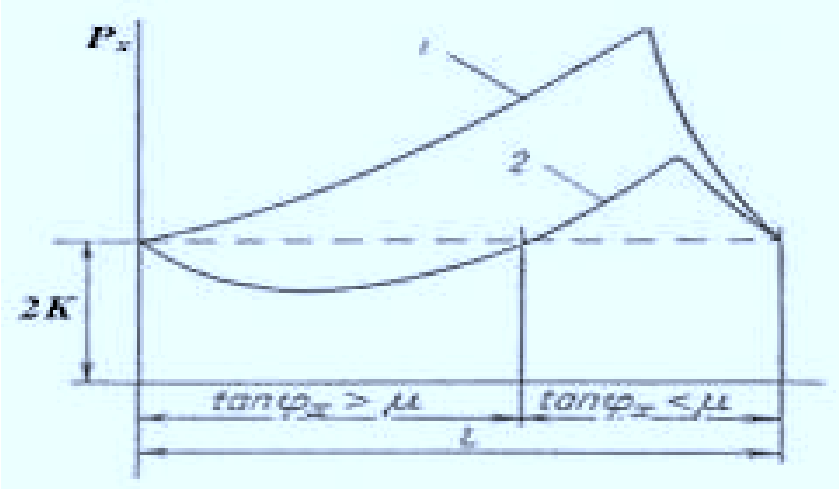

Fig. 7.Depending theoretical friction hills on the friction angle; 1) $\tan \varphi<\mu$ along the whole contact $\operatorname{arc}, 2) \tan \varphi>\mu$ at the beginning of the contact arc [17]. 
If the frictional forces are considerably in excess of those corresponding to minimal frictional requirements, then difficulties may be encountered in obtaining satisfactory rolling conditions in that the rolling forces may be so large that employing roll bending gives the rolled strip a poor shape or an inadequate degree of flatness. Moreover, the dissipation of the excessive frictional energy may result in abnormally high roll and strip temperatures. In the case of former, nonuniform heating of the rolls may affect the ease of attaining satisfactory rolled strip shape, whereas the latter may be detrimental with respect to the quality of the strip if used for the critical applications [9].

In addition, increased friction also produces a more lustrous finish on the rolled strip, on account of the increased buffing action of the rolls on the strip surfaces.

Regarding the general appearance of rolled strip (reflectivity, gloss, lustre or shininess etc.), one can conclude that the surface finish of the strip is, in part, dependent on changes in COF during rolling. That is because, the changes in friction in the roll gap affects the amount of buffing the strip receives from the roll surface prior to its emergence from the roll bite.

With respect to lubricity, the ability of a lubricant film to resist an applied pressure without rupture is defined as the lubricant film strength. During rolling, severe stresses may arise from roll flattening, thermal changes and wear. These can readily lead to rupturing the lubricant film. Consequently, a high value of COF is obtained because of direct contact between the roll surface and strip. By contrast, any change that occurs in the reverse direction tends to lower the COF during rolling. Therefore, the load bearing capacity or the strength of lubricant film plays an important role in the COF provided in the roll gap [16].

Concerning the tensions, any change in the strip tensions during rolling, of course to some extent, can change the strip surface quality by affecting the COF values. This is due to the fact that the position of neutral point, and in turn the COF values, is affected by changes in the ratio of the back to the front strip tensions. It is believed that increasing this ratio during rolling moves the neutral point towards the exit plane, i.e. towards decreasing the COF that in turn results in a duller strip. By contrast, decreasing the ratio has an inverse effect that tends to produce brighter strip, i.e. increasing the $\mathrm{COF}$ amounts by moving the neutral point in the opposite direction.

\section{CONCLUSIONS}

1. Irregularities were observed in friction hills of industrial rolling of steel and aluminium. These happen when any changes in a given set of rolling conditions causes a decrease in COF.

2. For the industrial passes that COF value is almost reasonable, the industrial friction hills show their normal trend, whereas in cases that this amount is low, there are some kinds of irregularities in the pressure distribution curves.

\section{References}

1. Z.Y. Jiang and A.K. Tieu, A 3-D Finite Element Method Analysis of Cold Rolling of Thin Strip with Friction Variation. Tribology International. 37 (2004) 185-191.

2. Z.Y. Jiang, A.K. Tieu, X.M. Zhang, C. Lu and W.H. Sun, Finite Element Simulation of Cold Rolling of Thin Strip. Journal of Materials Processing Technology. 140 (2003) 542-547.

3. J. Larkiolda, P. Myllykoski, J. Nylander and A.S. Korhonen, Prediction of Rolling Force in Cold Rolling by using Physical Models and Neural Computing. Journal of Materials Processing Technology, 60 (1996) 381-386.

4. H. Keife and C. Sjögren, A Friction Model Applied in the Cold Rolling of Aluminum Strips. Wear 179 (1994) 137-142.

5. H. L. Murphy, J.P. Bressanelli and K.E. Pinnow, Method for Rolling Stainless Steel. U.S. Patent 3496746, (1974).

6. V.A. Nikolaev et al., Wear on the Surfaces of the Work Rolls of a Reversing Cold Rolling Mill. Stal in English. (1969) 196-198.

7. W.L. Roberts, R.J. Bentz and D.C. Litz, Cold Rolling Carbon Steel Strip to Minimum Gage. Iron and Steel Engineer Year Book. (1970) 413-420.

8. H. Abdollahi and K. Dehghani, 'A new software (Matroll) to determine the coefficient of friction and to plot the friction hill during the cold rolling of aluminum' Proceedings of the Int. Conf COM 2005, Calgary, Canada, (2005) 319-333.

9. K. Dehghani, Measurement the Coefficient of Friction during the Cold Rolling of Industrial Aluminum Mill, Master Thesis, Tehran University, (1990) 141-157.

10. B. Avitzur, Metal Forming: Processes and Analysis, McGraw Hill Book Company, New York, NY, USA, (1979).

11. S. Kondo, Improving Rolling Stability during Cold Rolling of Aluminum, Light Metal Age, December, (1974), 5-7.

12. S. Jianlin and Z. Xinming, Evaluation of Lubricants for Cold Rolling Aluminum Strips, Journal of Central South University of Technology, 4 (1997), 65-68.

13. P.M. Lugt, A.W. Wemekamp, W.E.T. Napel, P. V. Liempt and J.B. Otten, Lubrication in Cold Rolling, Wear, 166 (1993), 203-214.

14. S. Zhang and J. G. Lenard, The Effects of the Reduction, Speed and Lubricant Viscosity on Friction in Cold Rolling, Journal of Materials Processing Technology, 30 (1992), 197-209.

15. R. Lazic, R. Dodok and V. Milenkovic, Influence of Front and Back Tensions in Friction in the High Speed Cold Rolling of Aluminum Strip, Aluminum, 59 (1983), 381-384.

16. L.B. Sargent, Lubricants for Cold Rolling Aluminum Alloys- a Laboratory Appraisal, Light Metal Age, (1975), 15-17.

17. Tselikove, Stress and Strain in Metal Rolling, MIR Publishers, Moscow, Russia, (1967) 60-80. 


\title{
Production of structure components with selective properties by means of action media based cold forming
}

\author{
B.-A. Behrens, T. Hagen, J. Mielke, K.B. Sidhu \\ Institute of Metal Forming and Metal-Forming Machines, Leibniz Universität Hannover, An der Universität \\ 2, 30823 Garbsen, Germany \\ URL: www.ifum.uni-hannover.de \\ e-mail: hagen@ifum.uni-hannover.de
}

\begin{abstract}
Minimising a metallic component's weight can be achieved by either using lightweight alloys or by improving the component's profile properties. In both cases, the material formability affects the utilisability for mass production processes. Most of the high-strength materials show a material-restricted formability and are difficult to forge. The formability of a material is described by its maximum forming limit. Large plastic strains lead to mechanical damage within the material. The greater the tensile strength rate in relation to total tension rate, the faster raises the damage value. A promising approach of handling low ductile, high-strength alloys within a forming process is forming with a superimposed hydrostatic pressure by active means $[1,2,3]$.
\end{abstract}

In preliminary examinations [4], the influence of superimposed hydrostatic pressure on the flow stress was analysed as well as the formability for different sample geometries at different hydrostatic pressure and temperature levels. The superimposed pressure has no influence on the plastic deformation, nor does a pressure dependent near-surface material hardening occur. Nevertheless, the formability increases with rising hydrostatic pressure. The relative gain at ambient temperature and an increase of the superimposed pressure from 0 bar to 600 bar for tested materials was at least $140 \%$ and max. $220 \%$. Therefore, within the described project, it is intended to develop a cold forming process with superimposed pressure for forming structure components with selective properties. For example, the increase in formability is to be used to increase local plastic strains to higher limits resulting in higher local strain hardening and hardness. This offers new design possibilities with selectively adjusted local structure or structure component properties, especially adapted to their technical application. Additionally, by applying damage models, Finite-Element-Analysis is used in order to predict damage occurring within the cold forming process with superimposed hydrostatic pressure for various sample geometries.

Key words: Locally induced strain hardening, Cold forming, Brittle alloys, Active means, Superimposed hydrostatic pressure, Increase in formability, Near net shape extrusion, Damage model, Heatless hardening

\section{INTRODUCTION}

Since the introduction of high strength materials in modern production engineering, the group of metal forming techniques is facing great challenges. The common production processes are often not suitable to utilize the full potential which these materials may offer. This is due to the low material formability which results in ductile damage during the conventional forming process. It is known that compressive forming processes are better to those under tensile conditions as far as their forming capability is considered. The single particles of the material are under a mutual pressure during the deformation, which reduces the sensitivity of forming material towards of crack initiation and growth.

Therefore, a promising new approach to enhance material formability is using superimposed hydrostatic pressure during the forming process which is achieved by means of a liquid active media 
such as oil $[1,2]$.

\section{BULK FORMING WITH SUPERIMPOSED HYDROSTATIC PRESSURE}

\subsection{Basic tool concept}

In former projects [4] based on theoretical knowledge and experimental analysis, four aluminium alloys were investigated by using an innovative tool concept to demonstrate forming by active media. The fundamental principle of the developed forming tool, as shown in figure 1, is based on a cylinder (lower tool) and a ram which represents the upper tool. The ram moves down into the cylinder which is filled with an active media such as castor oil.

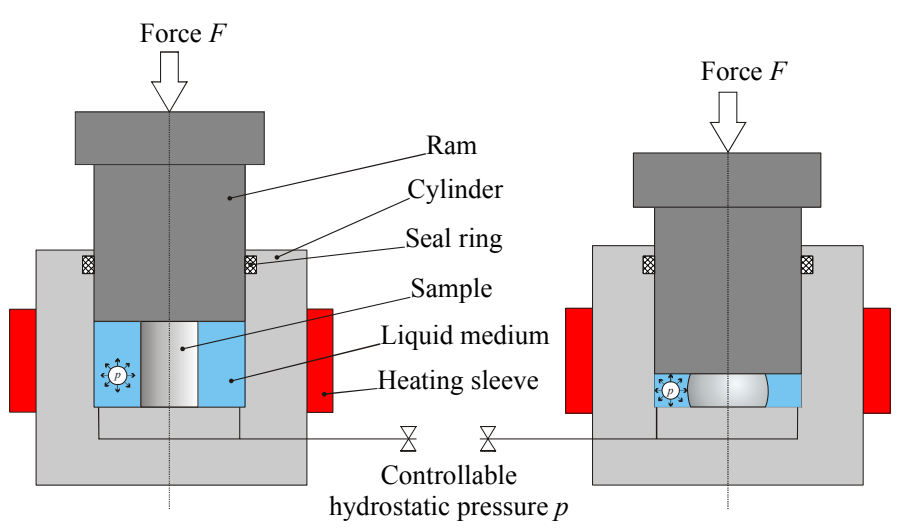

Fig. 1. The developed forming tool for forming with superimposed hydrostatic pressure

When the ram passes the seal ring, a hydrostatic pressure is built up in the cylinder. Due to the movement of the ram, the oil is displaced through a pressure pipe. It is ensured that the pressure in this system will always remain constant all the time. As soon as the ram strikes the sample, the forming operation starts with superimposed hydrostatic compressive stresses. For forming operations at high temperatures, the cylinder and the castor oil will be heated up externally to the temperature of the sample.

\subsection{Improved tool concept for active superimposing pressures up to 2000 bar}

The lower the forming temperatures the higher the value of superimposed pressure has to be to gain a significant increase in formability [4]. For cold forming processes superimposed pressure levels up to 2000 bar are considered reasonable. The increase in formability will be used to induce large local plastic strains which lead to an increase in strain hardening. Therefore, based on figure 1 the tool concept was redesigned for superimposed pressures up to 2000 bar and complex geometries as shown in figure 2 .

To keep the expected hardening effects, the thermal activation processes have to be avoided by e.g. using the hydraulic circle for system cooling. Unlike the former passive pressure set-up concept the new tool system will be supplied by an external hydraulic power unit.

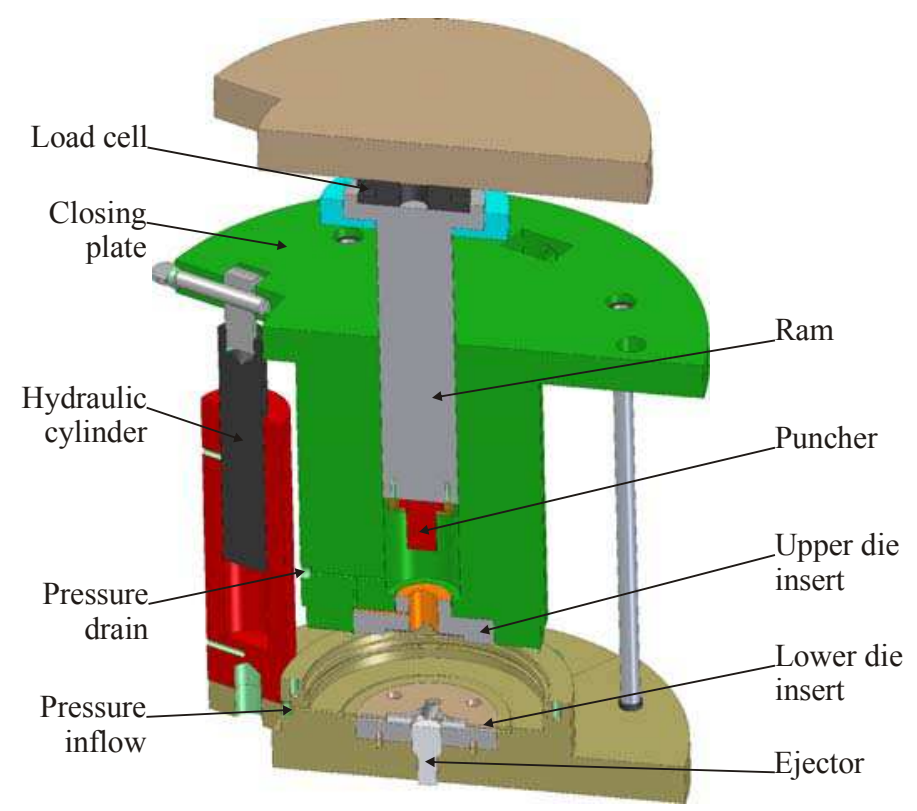

Fig. 2. Redesigned tool concept for superimposing hydrostatic pressures up to 2000 bar

The forming operation can be divided into the following steps:

1. Inserting the sample

2. Closing the tool system by pulling the closing plate using four hydraulic cylinders

3. Setting-up superimposed hydrostatic pressure by an external hydraulic power unit

4. Driving the ram down

5. Running the forming operation

6. Controlling the amount of superimposed pressure

7. After finishing forming operation pressure release and evacuation of the tool system

8. Backtrack of the ram, accompanied by backtracking the closing plate and

9. Ejection of the workpiece.

Because of the high pressure amounts of up to $2000 \mathrm{bar}$, the sealing of the tool system is a challenge. To avoid dangerous leakage the sealing gap is limited to a maximum of $0.15 \mathrm{~mm}$. The surface in the near area of the sealings has to be polished and of minimum $65 \mathrm{HRC}$. 
The demand on a high flexible tool is implemented by the modular tool design. It allows changing the workpiece geometry by using die inserts, which can be easily mantled into the basic dies. Some of the intended forming geometries for upsetting and lateral extrusion tests are shown in figure 3.

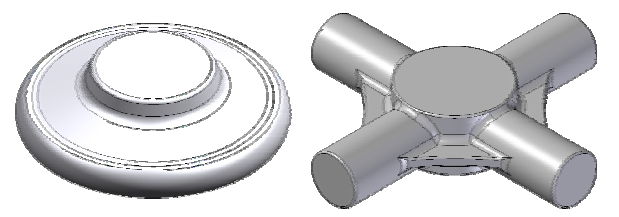

Fig. 3. Forming geometries for lateral extrusion tests

Besides, the ejector offers good handling of forming geometries with deep engravings and reduces the lifting bevels' angles.

By supplying the media pressure through various ducts in $\mathrm{x}, \mathrm{y}, \mathrm{z}$-directions, the superimposed pressure can be obtained and maintained at the actual noncontacted surfaces during forming operation. Also, the ducts are used for deaerating the system before setting-up hydraulic pressure.

\section{SIMULATION OF THE FORMING PROCESS}

Using FEA minimises the quantity of cost and time intensive empirical testing to verify and validate the tool concept and the forming process. Forming behaviour like material flow, form filling, forming laps and forming force can be predicted [5] as well as thermal and mechanical loads charging the tool.

Supporting the tool design process FEA was used to simulate the forming process with various parameters such as different forming geometries, amounts of superimposed pressure and different aluminium alloys.

Therefore, it was essential to develop a numerical model in order to simulate the superimposed hydrostatic pressure forming, and further be able to predict ductile damage during the process.

Damage occurring during the forming operation can be predicted by several damage models [6] such as the Cockroft-Latham, $\mathrm{Oh}$ and Kobayashi, McClintock, Lemaitre etc. approaches.

Here, the local damage value $D$ is predicted by using a model, which uses the maximum principal stress $\left(\sigma_{T}\right)$ and the effective stress $(\bar{\sigma})$ as described in Equation 1 and 2.

$D=\frac{\sigma_{T}}{\bar{\sigma}}$, if $\quad \frac{\sigma_{T}}{\bar{\sigma}} \geq 0.5$
$D=0$, if $\frac{\sigma_{T}}{\bar{\sigma}}<0.5$

The FE-model with the boundary conditions is shown in figure 4 . The effect of hydrostatic pressure in the experiment is implemented in FE-model through normal pressure on each boundary element of the workpiece.

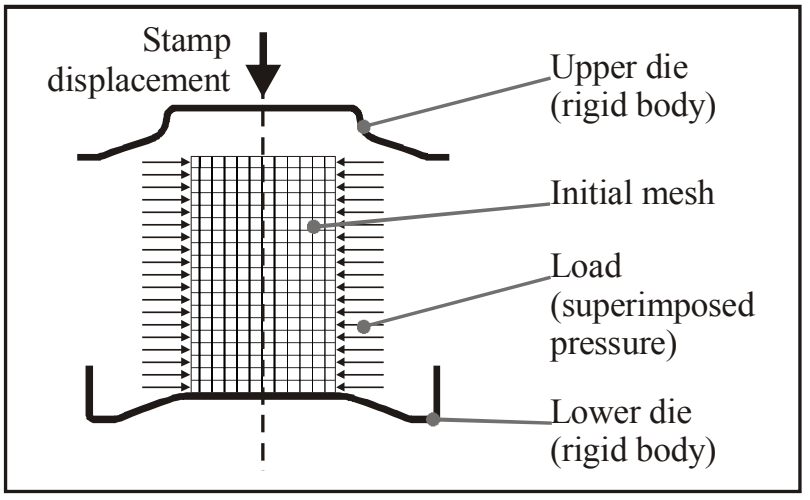

Fig. 4. FE-model with boundary conditions

Due to the high deformation of workpiece during the process, the remeshing was required. Therefore, in order to define the pressure boundary condition on the workpiece it was necessary to program subroutines which were used for get updated information of boundary nodes after every increment, and further to apply the required pressure boundary condition. The damage results for upsetting with and without superimposed hydrostatic pressure are shown in figure 5.

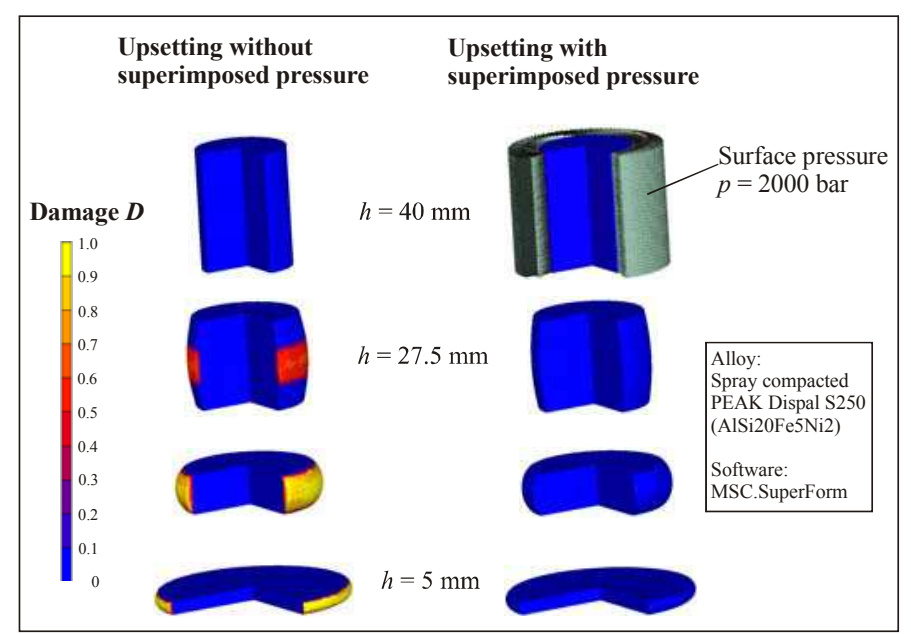

Fig. 5. Predicted damage for upsetting tests with (right) and without (left) superimposed pressure

For upsetting damage occurs at $12.5 \mathrm{~mm}$ compression when forming without superimposed pressure. For a superimposed hydrostatic pressure $p$ of 2000 bar there was no damage predicted until a faultless height $h_{\min }$ of $5 \mathrm{~mm}$. 
For the extrusion geometry damage was predicted by FEA as well (see figure 6). Here, only some forming steps at the beginning of form filling are demonstrated. In further forming steps these cracks lead into forming gaps and yet cannot be displayed correctly by the FE-model.

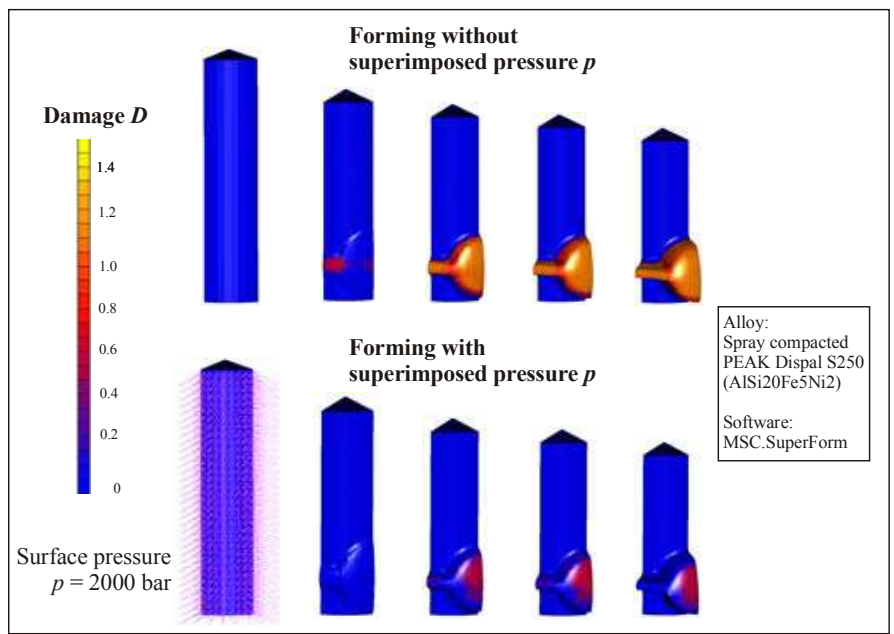

Fig. 6. Predicted damage for extrusion tests with (bottom) and without (top) superimposed pressure

Nevertheless, the positive effect on formability of the superimposed hydrostatic pressure on cold forming processes could be displayed by FEA also for the complex cross geometry.

\section{OUTLOOK}

The main objective of this research project is the development of a technically usable near net shape production process. In the future the fabrication of high complex components could be optimized by locally hardening effects induced by means of active media forming processes. Simultaneously, the numerical analysis is to be advanced, in order to reduce the number of experimental tests as well as the determination of optimal process parameters with the prediction of material failure and the expected local strain hardening.

The strengthening achieved by selective induced strain hardening can additionally be used to reduce the number of processing steps as well as for "heatless hardening". Through this, a more efficient use of energy resources is made possible.

\section{ACKNOWLEDGEMENTS}

The authors would like to thank German research foundation (DFG) for funding this Collaborative Research Center 675 (SFB 675) - "Creation of high strength metallic structures and joints by setting up scaled local material properties".

\section{REFERENCES}

1. T. Minghetti, K. Steinhoff, Nastran et al.: Advanced forming techniques for aluminium-based metal matrix composites, 4th International ESAFORM Conference on Material Forming, Belgium, Issue 1/2001, (2001) p. 135138.

2. O. Pawelski and W. Lorrek: Großer hydrostatischer Druck verbessert Umformvermögen von Metallen, Maschinenmarkt, Volume 81, Issue 9/1975, Germany, (1975) p. 1784-1786.

3. O. Pawelski: Hydrostatisches Stauchen - ein neues Verfahren zur Formgebung schwer umformbarer Werkstoffe, Technik und Forschung, Germany, (1967), p. 682-686.

4. F. Meiners: Untersuchungen zur wirkmedienbasierten Massivumformung von Aluminiumwerkstoffen, Ph.D. Thesis, Leibniz Universität Hannover, Germany, (2004).

5. H.-W. Raedt: Herausforderungen in der Simulation des Warmumformverhaltens von AFP-Stählen; Konferenzbericht: Moderne thermomechanische Prozessstrategien in der Stahlumformung, 10./11. Mai 2007, Düsseldorf, Germany, (2007)

6. B. Buchmayr: Simulation der Umformung und Schädigung in der Massivumformung, Tagungsband 6. Industriekolloquium "Hochfeste Strukturen", Sonderforschungsbereich 675, Heinz Palkowski, Clausthal-Zellerfeld, Germany, (2007), p. 125-132 


\title{
2D asperity deformation of stainless steel strip in cold rolling
}

\author{
A. Belotserkovets ${ }^{1}$, A. Dubois ${ }^{1}$, M. Dubar ${ }^{1}$, L. Dubar ${ }^{1}$, R. Deltombe ${ }^{1}$, \\ H. Vandekinderen ${ }^{2}$, J.M. Damasse ${ }^{2}$ \\ ${ }^{1}$ Laboratoire d'Automatique, de Mécanique et d'informatique Industrielles et Humaines, UMR 8530, \\ University of Valenciennes, F-59313 Valenciennes Cedex 9, France \\ URL: www.univ-valenciennes. fr/LAMIH \\ e-mail:andre.dubois@univ-valenciennes.fr \\ ${ }^{2}$ Ugines \& Alz research center, Arcelor-Mittal group, BP 15, F-62330 Isbergues, France \\ URL: http://www.ugine-alz.com \\ e-mail:hendrik.vandekinderen@ugine-alz.arcelor.com
}

\begin{abstract}
A sequential fluid-structure weak coupling approach is developed in order to compute the deformation of 2D asperities in mixed lubrication regime. The cold rolling model involves the strip with its asperities, the lubricant and the working roll. Reynolds equations are solved at the asperity level and lead to the evaluation of the fluid pressure acting on the asperity sides. Then solid finite element models, where the top of the asperity are in contact with the working roll and the fluid pressure is applied on asperity sides, are performed. Reynolds solving and finite element computations are performed on an asperity, from the entry to the exit of the roll bite. The methodology is applied to quantify effect of shot blasting on asperity flattening.
\end{abstract}

Key words: cold rolling; stainless steel; mixed lubrication; fluid-structure weak coupling

\section{INTRODUCTION}

In order to reduce friction and to better control workpiece final roughness, most metal forming processes require mixed lubrication regime at tool work-piece interface [1]. The main peculiarity of the mixed lubrication regime is that the contact pressure between tools and workpieces is partly managed by the contact between asperities, and partly by the lubricant. The top of work-piece asperities are then upset by the tools, when the asperity sides are deformed by the pressurized lubricant.

The mixed lubrication regime has been widely studied, more particularly in the field of cold rolling [2-4]. Recent studies were based on a coupling between fluid mechanic equations and a flattening asperity model $[5,6]$. The total pressure at the rollstrip interface $\mathrm{P}$ is expressed as a function of the pressure at asperity tips $\mathrm{Pa}$, the fluid pressure in the valley $\mathrm{Pb}$ and the real area of contact $\mathrm{A}$ :

$\mathrm{P}=\mathrm{A} \cdot \mathrm{Pa}+(1-\mathrm{A}) \cdot \mathrm{Pb}$

The total pressure $\mathrm{P}$ is identified from equilibrium equations of the process. Relation between the pressure $\mathrm{Pa}$ and the real area of contact comes from flattening asperity models [7]. Fluid pressure $\mathrm{Pb}$ is identified by solving Reynolds equations along the contact surface. These analyses are very useful to compute the contact pressure along the roll bite, identify roll separating forces, lubricant film thickness and frictional stress, but can not determine with accuracy the shape of the deformed asperities, which are given by the flattening asperity model.

The present paper deals with a sequential fluidstructure weak coupling approach in order to circumvent the problem. The cold rolling model involves the strip with its asperities, the lubricant and the working roll. The strip asperities are modeled in 2D (trapezoidal shape in the present study). Reynolds equations are solved at the asperity level and lead to the evaluation of the fluid pressure acting on the asperity sides. Then solid finite element models, where the top of the asperity are in contact with the working roll and the fluid pressure is applied on asperity sides, are performed. Reynolds solving and finite element computations are performed on an asperity, from the entry to the exit of the roll bite. 


\section{THE ROLLING PROCESS}

The studied rolling process is used to reduce stainless steel strip from 3 to $0.49 \mathrm{~mm}$. The rolling machine is a Sendzimir mill made up of two work rolls, four first intermediate rolls, six second intermediate rolls and height backup rolls. Work rolls have diameter lower than $100 \mathrm{~mm}$. During the rolling process, a roll separating force (RSF) and a torque $(\mathrm{C})$ are applied on the rolls to maintain pressure on the strip and to reduce its thickness. A rear tension (RT) and a front tension (FT) are applied on the strip in order to guide it correctly at the mill entry (figure 1). The peripheral roll speed ranges from 300 to $650 \mathrm{~m} / \mathrm{min}$. The forward slip ranges from 0 to $20 \%$. Mineral oil is used as lubricant.

The final thickness is obtained after 10 rolling passes, with reduction ration decreasing from $25 \%$ to $10 \%$.

The strip is shot blasted before cold rolling. The shot blasting is performed to clean the strip and provide a given initial roughness that facilitates the lubricant inflow through the roll gap. The initial arithmetical average roughness $\mathrm{Ra}$ is equal to $2.7 \mu \mathrm{m}$ in the present work.

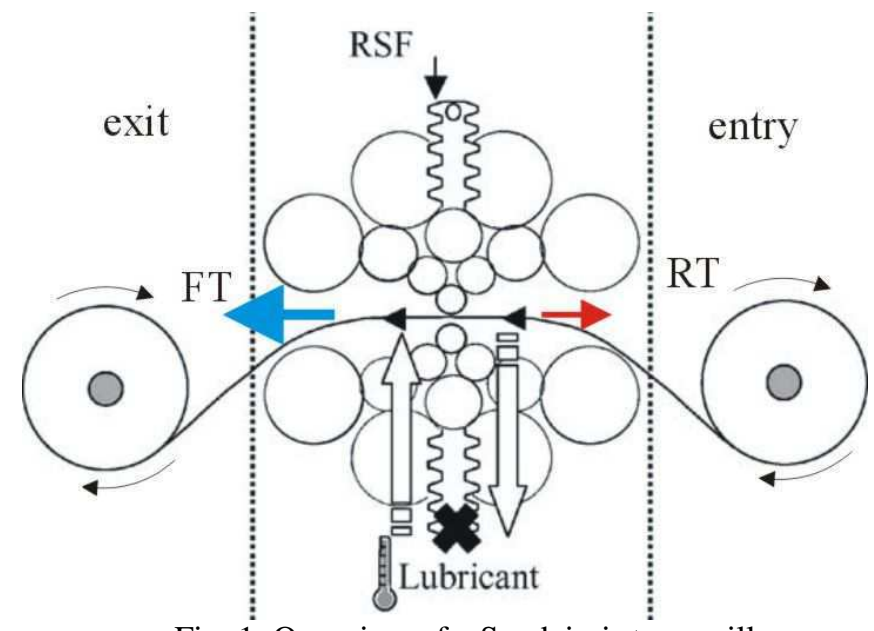

Fig. 1. Overview of a Sendzimir type mill

\section{METHODOLOGY}

The roll bite is divided in a given number of "steps". For each step, i.e. for each position of the asperity along the roll bites, a fluid-structure weak coupling is performed. The first solid finite element computation is run to compute the contact pressure at the strip/roll interface. No fluid pressure is applied on asperity sides. The resulting pressure values are used as initial conditions to solve Reynolds equations. Then a second solid computation is performed with pressure on asperity sides. New values of contact pressures are obtained on asperity tops, leading to new initial conditions to solve Reynolds equation. A loop is performed until contact pressures converge.

\subsection{Finite element model}

ABAQUS/Standard is used to perform the finite element computations. This is an implicit code that has convergence checking at each increment step to ensure the equations are solved accurately. The strip is modelled by 1212 four node plane strain full integration elements. The mesh is refined at the strip surface and in the vicinity of the asperities (figure 2). A total of 5 asperities are meshed. The work roll is supposed to be non deformable and is modelled by a rigid surface.

Strip bulk behaviour is characterized by a Young modulus equal to $210 \mathrm{MPa}$, a Poisson's coefficient equal to 0.3 and an initial yield stress equal to 560 MPa.

\subsection{Lubricant pressure}

The fluid pressure is obtained by solving the average Reynolds equation introduced by Patir and Cheng [8]:

$\frac{\mathrm{d}}{\mathrm{dx}}\left(\Phi_{\mathrm{x}} \frac{\mathrm{h}_{\mathrm{t}}^{3}}{12 \eta} \frac{\mathrm{dp}_{\mathrm{b}}}{\mathrm{dx}}\right)=-\left(\frac{\mathrm{u}_{\mathrm{r}}+\mathrm{u}_{\mathrm{w}}}{2} \frac{\mathrm{dh}_{\mathrm{t}}}{\mathrm{dx}}+\frac{\mathrm{h}_{\mathrm{t}}}{2} \frac{\mathrm{du}_{\mathrm{w}}}{\mathrm{dx}}\right)(2)$

where $\mathrm{u}_{\mathrm{w}}$ and $\mathrm{u}_{\mathrm{r}}$ are respectively the strip and the roll surface velocities, $h_{t}$ is the average film thickness, $\eta$ is the oil viscosity, $\mathrm{x}$ is the distance from the exit of the roll bite and $\Phi_{\mathrm{x}}$ is a flow factor, function of the root mean square roughness. Equation (2) is solved using the finite difference method with a GaussSeidel iterative scheme [9]. The fluid pressure is then given by:

$$
\mathrm{P}_{\mathrm{fi}}^{\mathrm{next}, \mathrm{k}+1}=\frac{\mathrm{X}_{\mathrm{i}}^{+} \mathrm{P}_{\mathrm{fi}+1}^{\mathrm{k}}+\mathrm{X}_{\mathrm{i}}^{-} \mathrm{P}_{\mathrm{fi}-1}^{\mathrm{k}+1}-12 \eta \mathrm{X}_{\mathrm{i}} \Delta \mathrm{x}^{2}}{\mathrm{X}_{\mathrm{i}}^{+}+\mathrm{X}_{\mathrm{i}}^{-}}
$$

with

$$
\left\{\begin{array}{l}
\mathrm{X}_{\mathrm{i}}^{-}=\left(\Phi_{\mathrm{xi}-1}+\Phi_{\mathrm{xi}}\right)\left(\mathrm{H}_{\mathrm{ti}-1}^{3}+\mathrm{H}_{\mathrm{ti}}^{3}\right) \\
\mathrm{X}_{\mathrm{i}}^{+}=\left(\Phi_{\mathrm{xi}+1}+\Phi_{\mathrm{xi}}\right)\left(\mathrm{H}_{\mathrm{ti}+1}^{3}+\mathrm{H}_{\mathrm{ti}}^{3}\right) \\
\mathrm{X}_{\mathrm{i}}=\left(\frac{\mathrm{u}_{\mathrm{r}}+\mathrm{u}_{\mathrm{wi}}}{2}\right) \frac{\mathrm{H}_{\mathrm{ti}+1}+\mathrm{H}_{\mathrm{ti}-1}}{2 \Delta \mathrm{x}}+\frac{\mathrm{H}_{\mathrm{ti}}}{2} \frac{\mathrm{u}_{\mathrm{wi}+1}-\mathrm{u}_{\mathrm{wi}-1}}{2 \Delta \mathrm{x}}
\end{array}\right.
$$


a)

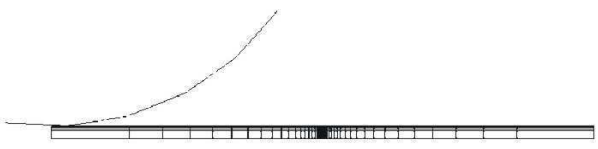

b)
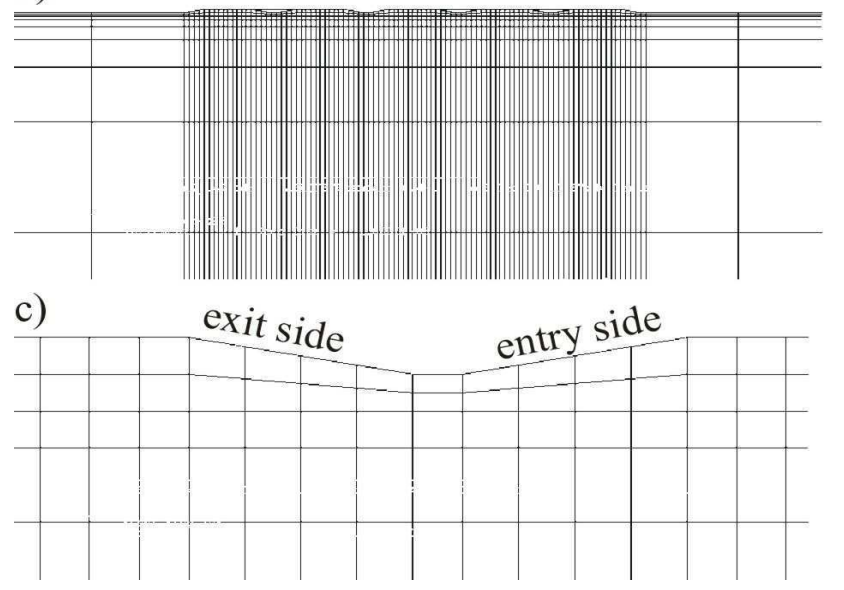

Fig. 2. Finite element mesh. a) finite element mesh b) zoom on the refined area, c) zoom on an asperity

and where $\mathrm{k}$ is the iterative index-number, $\mathrm{i}$ the node number, $\mathrm{P}_{\mathrm{f}}$ the dimensionless fluid pressure $\left(\mathrm{P}_{\mathrm{f}}=\right.$ $\left.\mathrm{p}_{\mathrm{f}} / \sigma_{0}\right)$ and $\mathrm{H}_{\mathrm{t}}$ the dimensionless film thickness $\left(\mathrm{H}_{\mathrm{t}}=\mathrm{h}_{\mathrm{t}} / \mathrm{R}_{\mathrm{q}}\right)$.

\subsection{Asperity geometry}

The shot blasting of the strip before the first pass lead to an initial surface profile where the asperity tips are flattened. Asperities can not be schematized by triangle are then modelled as trapezoids which geometrical characteristics are the valley length $\mathrm{Lv}$, plateau length Lp, height Rt and angles $\alpha$ and $\beta$ (figure 3a). For the studied strip, $\alpha$ and $\beta$ are equal to $10^{\circ}$, Rt ranges from 6 to $10 \mu \mathrm{m}, \mathrm{Lv}$ from 5 to 20 $\mu \mathrm{m}$ and $\mathrm{Lp}$ from 50 to $200 \mu \mathrm{m}$. A comparison between true and simplified surface profiles is presented in figure $3 b$.

\section{RESULTS}

Two finite element computations are performed to study the influence of the shot blasting. In the first computation only the surface geometry resulting from the shot blasting is considered. The surface profile is the one measured on the real steel strip and presented in figure $3 \mathrm{~b}$. The same bulk behaviour law is associated to the 1212 finite elements of the model. In the second computation, the effect of shot blasting on the strip behaviour is also taken into account. An inverse method of identification based

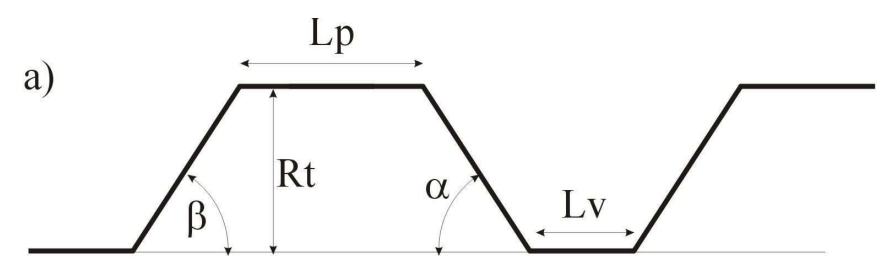

b)

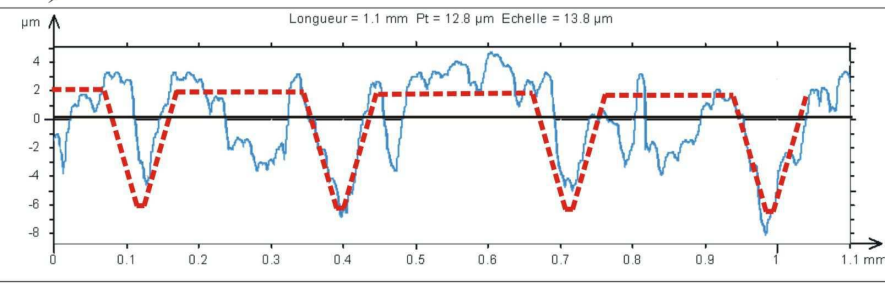

Fig. 3. Asperity profile. a) Geometrical parameter b) true surface profile (blue), simplified profile (red)

on Vickers indentations was used on the real strip to identify the bulk behaviour in the surface vicinity so that the strip thickness affected by the shot blasting operation [10].

The second finite element model involves a first bulk behaviour law for the elements in core of the strip, and a second behaviour law for the element in surface of the strip. The initial yield stress in core equals $565 \mathrm{MPa}$, the initial plastic stress in surface equals $702 \mathrm{MPa}$.

Figure 4 presents the asperity valley deformation in the case of single bulk behaviour computation. The fluid pressure acting on valley sides leads to a non symmetrical deformation of the asperities. The "entry" side of valleys tends to folds on the roll surface when the elongation of the strip leads to the stretching of the "exit" side. The slopes of asperity sides are then changed and angles $\alpha$ and $\beta$ are no more equal.

Taking into account the hardening of the strip surface due to shot blasting does not greatly modified the profile of the deformed asperities. Nonetheless, the reduction in height is greatly modified. When considering only geometrical aspects of shot blasting, the first rolling pass reduces the asperity height by $20 \%$, from 8 to $6.4 \mu \mathrm{m}$. When strain hardening is consider, asperity height are only reduced by $8 \%$, from 8 to $7.4 \mu \mathrm{m}$.

\section{CONCLUSIONS}

A fluid-structure weak coupling is proposed to study the flattening of steel strip asperity during a cold rolling sequence. First the fluid pressure is obtained by solving the average Reynolds equation. Then the 
fluid pressure is applied on asperity sides in a "solid" finite element model. The proposed methodology is applied to quantify the effect a shot blasting on the strip surface profile after rolling. Two computations are run, one taking into account only the geometry generated by the shot blasting operation, another taking into account the geometry and the strain hardening of the strip surface. Results show that, for a given surface profile, strain hardening due to shot blasting reduces asperity flattening. More lubricant can then carried through the roll bite for the next rolling pass.

a)

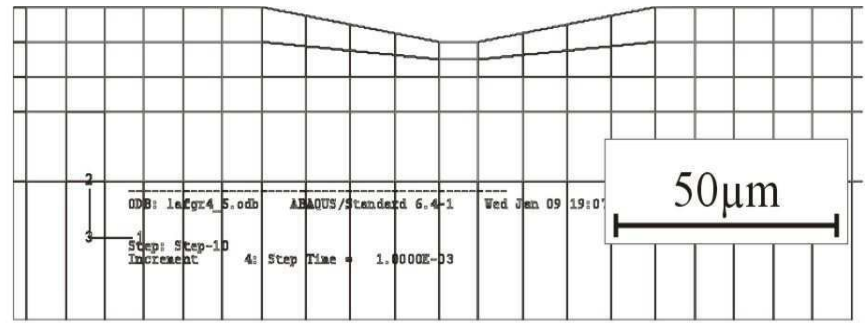

b)

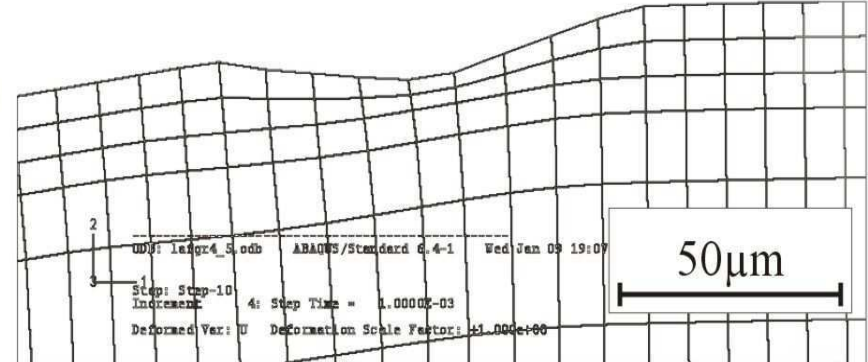

c)

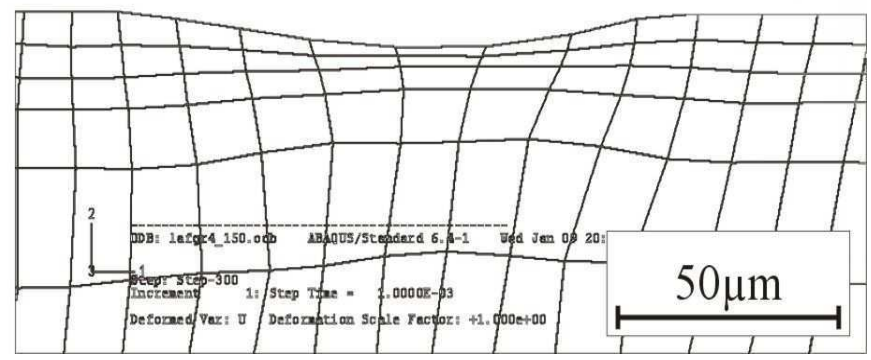

Figure 4. a) initial asperity mesh b) deformed mesh at roll bite entry c) deformed mesh at roll bite exit

\section{ACKNOWLEDGEMENTS}

The present research work has been supported by the European Community, the Délégation Régionale à la Recherche et à la Technologie, the Ministère de l'Education Nationale, de la Recherche et de la technologie, The Région Nord-Pas de Calais, the Centre National de la Recherche Scientifique. The authors gratefully acknowledge the support of these institutions and industrial partners.

\section{REFERENCES}

1. J.A. Schey, Tribology in Metal Forming, friction, lubrication and wear, Edt. Metal Parks Ohio, ASM (1983) ISBN: 0871701553

2. D.Dowson, M. Priest, G. Dalmaz and A.A. Lubrecht (Eds), Lifecycle tribology, Elsevier (2005) ISBN: 0-44451687-5.

3. D. Dowson et al. (Edt), Boundary and mixed lubrication, proceedings of the 28th Leeds-Lyon Symposium on Tribology, (2002) ISBN: 0-444-50969-0

4. P. Montmitonnet. 'Plasto-hydrodynamic lubrication (PHD), application of lubrication theory to metal forming processes', C. R. Acad. Sci. Paris, t. 2, Série IV (2001) 729-737

5. M. Saniei and M. Salimi. 'Development of a mixed film lubrication model in cold rolling', J. of Mat. Proc. Technol., 177, (2006) 575-581

6. Stephany and J.P. Ponthot. 'Improvement of an Iterative and Staggered Approach for a Model of MixedLubrication in Cold Rolling', in Materials processing and design: Modelling, simulation and applications NUMIFORM 2004, Eds S.Ghosh, J.M. Castro and J.K. Lee, American Institute of Physics (2004) 406-411

7. W.R.D. Winson and S. Sheu. 'Real area of contact and boundary friction in metal forming', Int. J. Mech. Sci. Vol. 30, No. 7 (1988) 475-489

8. N. Patir, H.S. Cheng, 'Application of average flow model to lubrication between rough sliding surfaces', J. Lub. Tech. ASME 101 (1979) 220-229.

9. A. Stephany, J.P. Ponthot, C. Collette and J. Schelings, 'Efficient algorithmic approach for mixed-lubrication in cold rolling', J. Mater. Process. Technol., Vol 153-154 (2004) 307-313

10. L. Dubar, B. Hauw, A. Dubois and J. Oudin, 'Numerical identification of coating bulk behaviour in metal forming', Computers \& Structures, 79-10 (2001) 1027-1037 


\title{
Finite Element Modeling of Tube Piercing and Creation of a Crack
}

\author{
${\text { Yvan } \text { Chastel }^{1} \text {, Aliou Diop }}^{1}$, Silvio Fanini ${ }^{2}$, P.O. Bouchard ${ }^{1}$, Katia Mocellin ${ }^{1}$ \\ ${ }^{1}$ Centre de Mise en Forme des Matériaux, CEMEF (ENSMP) - rue Claude Daunesse, 06904 Sophia- \\ Antipolis, France \\ URL: http://www-cemef.cma.fr \\ e-mail:yvan.chastel@ensmp.fr
}

${ }^{2}$ DIMEG, University of Padova, Via Venezia 1 - 35131 Padova, Italy

ABSTRACT: A 3D simulation of Mannesmann tube piercing is performed using the finite element software Forge $2005 \AA$. The sensitivity of the simulation results to numerical methods and physical parameters is discussed. Advanced numerical schemes and refined time discretizations are required to obtain correct descriptions of the material flow. In this study, one concentrates on the stress state and damage development before the material comes in contact with the plug. Indeed, the crack is to appear prior to the action of the plug. The description of the material behaviour is found to be a key information to predict the crack development. Predictions based on a modified Lemaitre damage law and a normalised Latham and Cockroft criterion are compared.

Key words: Tube piercing, Mannesmann effect, damage

\section{INTRODUCTION}

The Mannesmann tube piercing is a hot temperature process in which a solid bar is deformed in between two rotating bi-conical rolls. The process relies on the cyclic mechanical loading of the material caused by the conical shape of the rolls and their rotation. The material is pulled-in along a helical trajectory and a depressive mode causes a hole to form and develop in the billet (Figure 3).

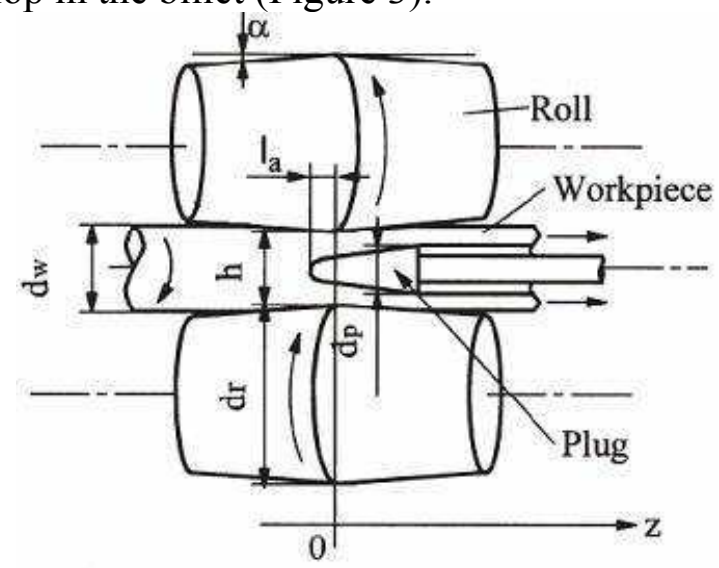

Fig. 1: Schematics of the process and of the tools [1]

The crack starts along the central axis, then expands and propagates. A plug is placed downstream to guide the material outward that a seamless tube can be produced.

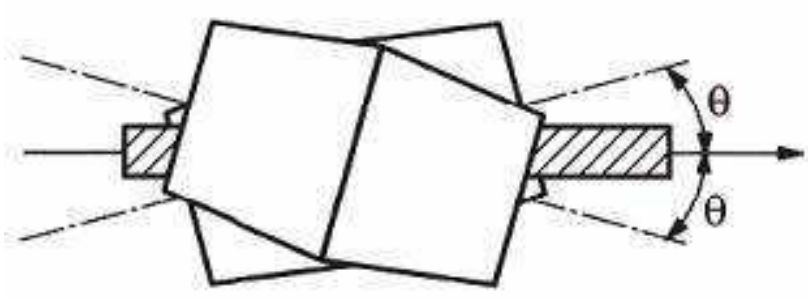

Fig. 2: Orientation of the rolls with respect to the billet [1]

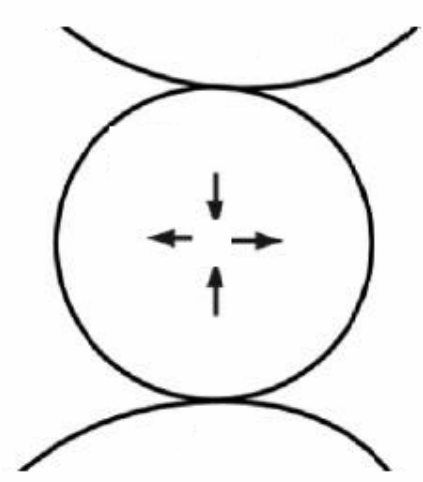

Fig. 3: Stress state in the center of the billet 
The numerical simulation of this process is complex because of the kinematics of the rolls which forces the billet to rotate. A numerical model of the process is presented in this paper. The induced strains are very large. Shear, tensile and compressive modes are combined. One central phenomenon in the process is damage. Rheological models with damage have to be included to track the crack growth and to study the radial expansion which leads to the shaping of the tube. An optimal position is looked for which should take into account the oxidation of the billet material and the progressive wear of the plug (Figure 4). These features are not explicitly included in this paper.

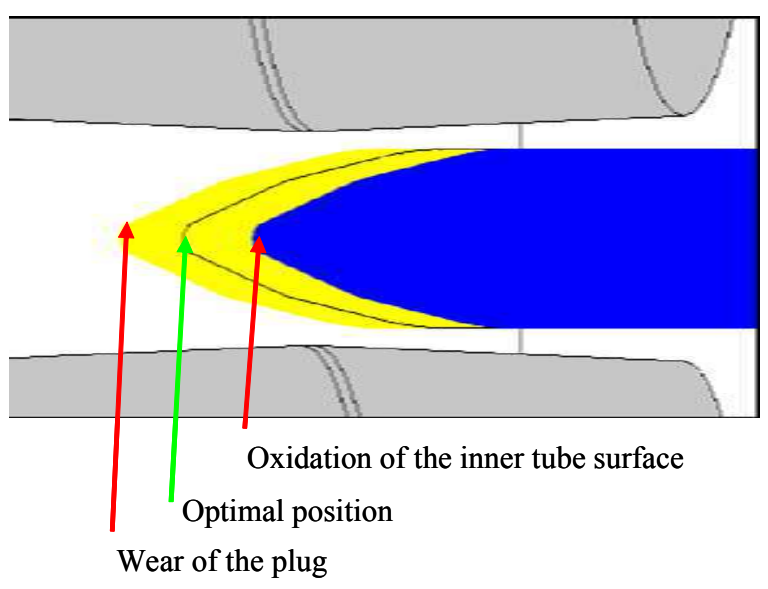

Fig. 4: Positions of the billet and of the plug

\section{THE NUMERICAL MODEL}

The software FORGE2005® is used as the basis for modelling the process. Six tools are included in the model: a pusher, two rolls, two guides and a plug, as depicted in Figure 5. The two rolls are rotating at 70 rotations/minute, and their axes form a $6^{\circ}$ angle. The diameter of the billet is $200 \mathrm{~mm}$ and it is assumed to be at $1250^{\circ} \mathrm{C}$ as it enters the roll bite. At the beginning of the deformation, the temperature of the rolls is taken as $200{ }^{\circ} \mathrm{C}$ and the plug is $800^{\circ} \mathrm{C}$. The constitutive law for the steel grade of interest writes:

$$
\sigma=A \exp \left(T m_{1}\right) \varepsilon^{m_{2}} \dot{\boldsymbol{\varepsilon}}^{m_{3}}
$$

The material parameters are obtained from experimental tests:

$$
\begin{aligned}
& \mathrm{A}=10642 \mathrm{MPa} . \mathrm{s} 3 \\
& \mathrm{~m} 1=-0.004 /{ }^{\circ} \mathrm{C} \\
& \mathrm{m} 2=0.164 \\
& \mathrm{~m} 3=0.119
\end{aligned}
$$

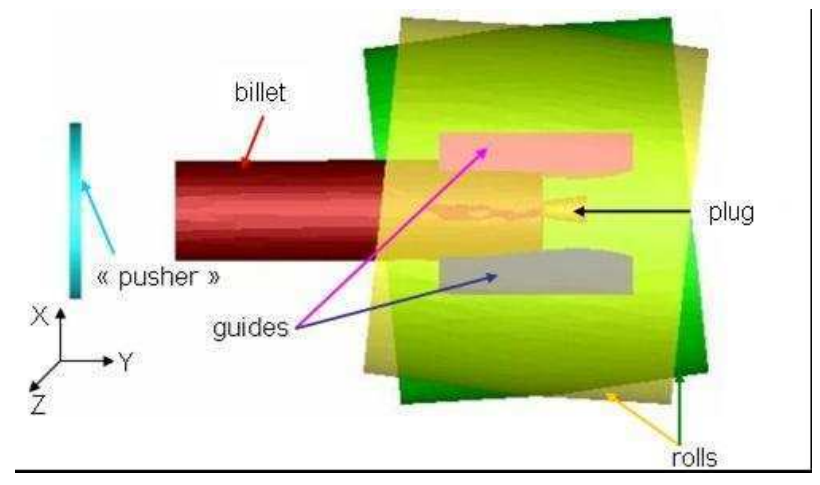

Fig. 5: Position of the tools in the numerical model

The contact with the billet and the rolls is assumed to be close to sticking friction. Sliding modes are applied to model the contacts between the billet and the guides.

\section{NUMERICAL SENSITIVITY ANALYSES}

\subsection{Time discretization}

The billet rotates all along the deformation stage. In updated Lagrangian formulations, large rotations are known to cause numerical volume increase which is artificial and leads to significant errors. The classical update, the explicit Euler scheme, can be written writes as in (2) for an update of the material position $\mathrm{X}$ moving at a velocity $\mathrm{V}$ over a time step $\mathrm{dt}$ :

$$
X_{t+d t}=X_{t}+V_{t} \times d t
$$

For such processes, the second order Runge Kutta scheme as expressed with equations (3) and (4) proves better (see sketch in Figure 6) :

$$
\begin{aligned}
& X_{t+\frac{d t}{2}}=X_{t}+V_{t} \times \frac{d t}{2} \\
& X_{t+d t}=X_{t+\frac{d t}{2}}+V_{t+\frac{d t}{2}} \times \frac{d t}{2}
\end{aligned}
$$

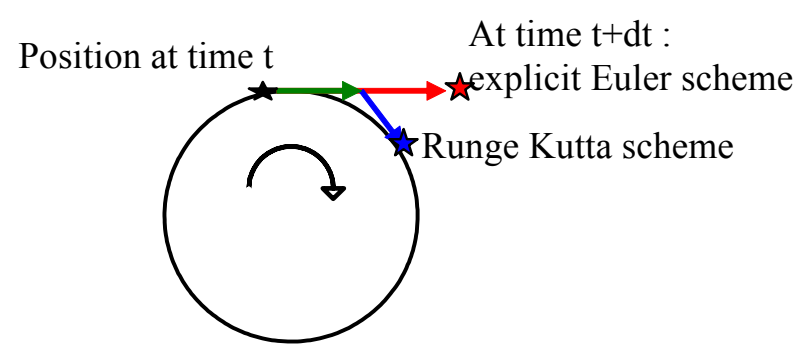

Fig. 6: Numerical update of the configuration over a time step 
In the real tube piercing process, the total deformation time for each material volume is about 5 seconds. Even with a second order Runge Kutta integration scheme, some numerical volume increase is observed. Figure 7 shows a sensitivity study of this volume increase with the time step.

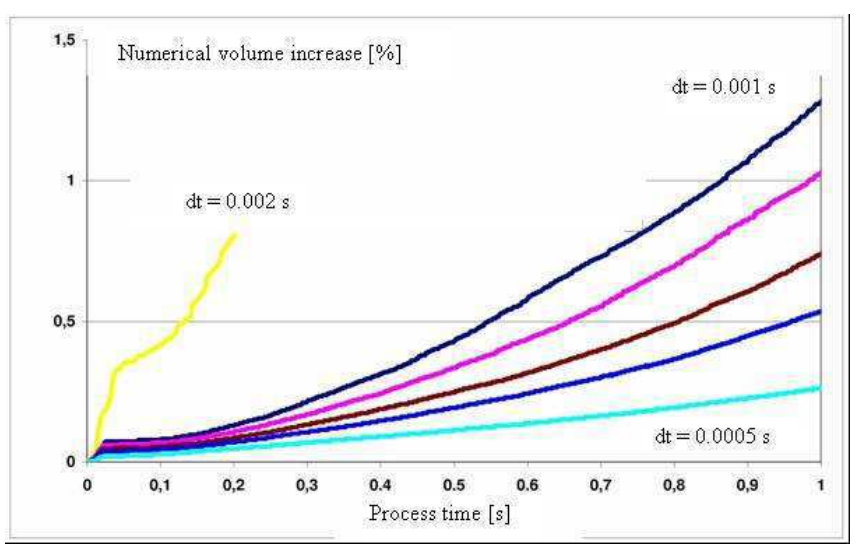

Fig. 7: Volume increase in the numerical simulation during the first second of the process for various time steps

An artificial and excessive shearing at the contact zone with the guiding tools can also be obtained in the numerical simulation at the outer surface of the billet (Figure 8).

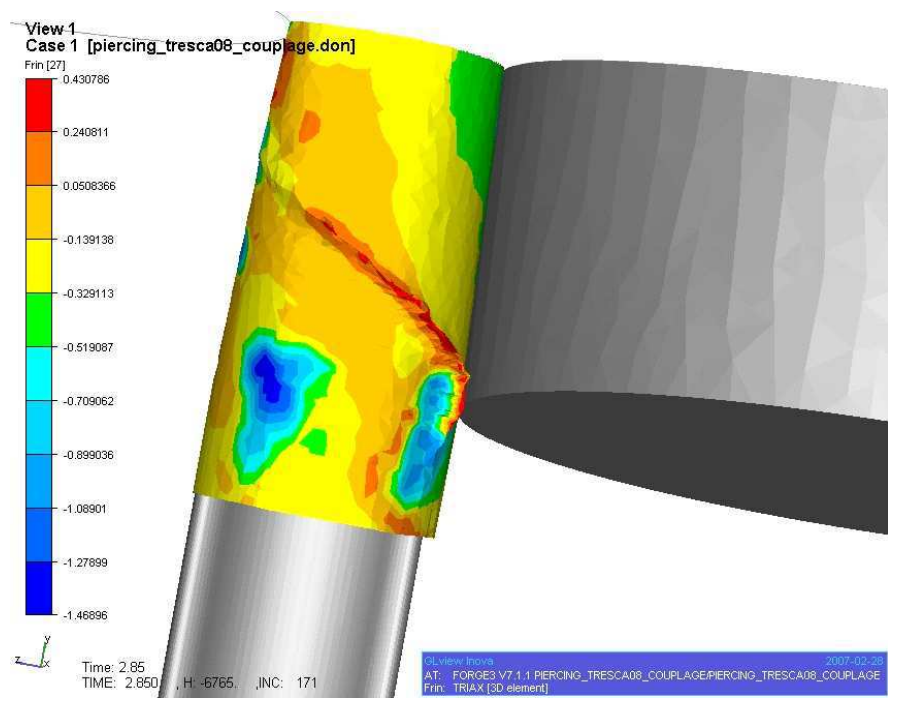

Fig. 8: Stress state in the center of the billet

A small time step can prevent these errors. But, reducing the time step leads to an increase in the required CPU time (Figure 9).

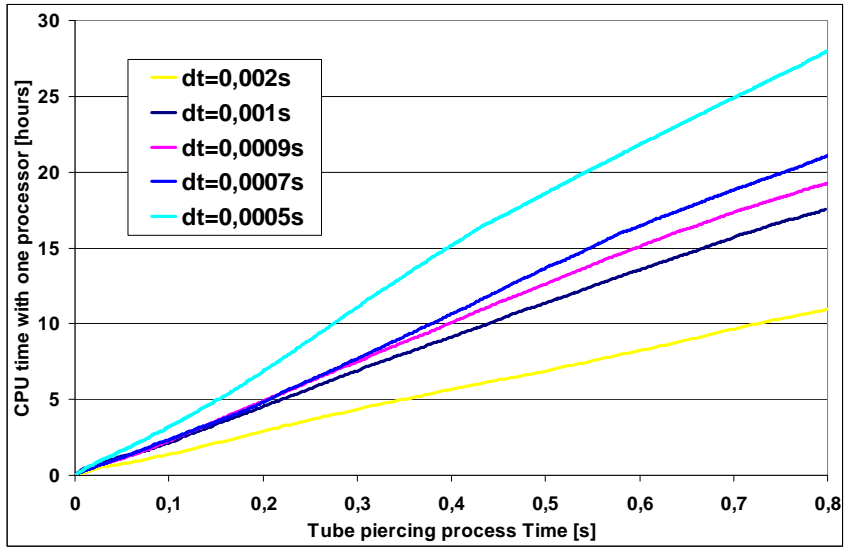

Fig. 9: CPU time required with one processor

\subsection{Stability of the process}

Given the kinematics of the rolls, the billet tends to twist. This is observed in practice. It makes the simulation very difficult since the position is then very sensitive to the friction model for instance. We concentrate on a configuration which would give a stable flow i.e. a flow with a fixed longitudinal axis of the billet as it goes into the roll bite. To enforce this stable motion of the billet in the numerical model, the shape of the two guiding tools is modified (Figure 10).

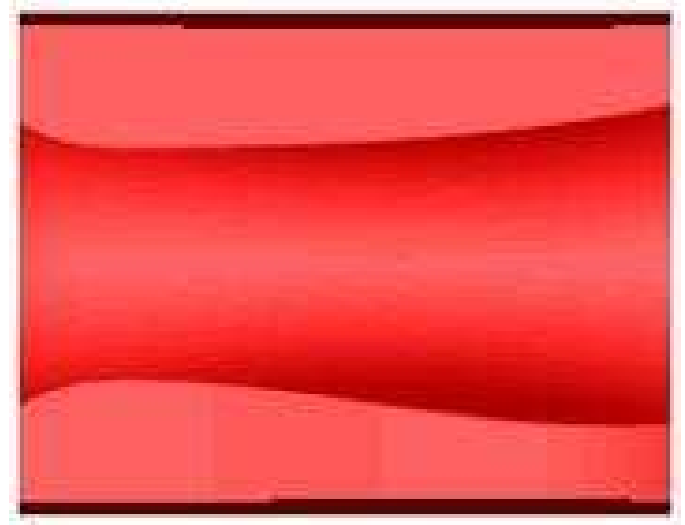

Fig. 10: Guiding tool used in the Finite Element model

\section{MODELLING DAMAGE AND CRACKS}

Two models were used to describe damage evolution during the process, a normalised Latham and Cockcroft and a modified Lemaitre model [2] which is updated incrementally (5): 


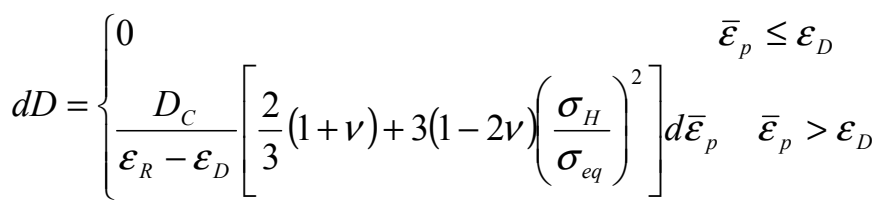

where $\mathrm{D}$ is the damage variable, $\mathrm{E}$ the Young's modulus, $v$ the Poisson's ratio, $\sigma_{H}$ the hydrostatic pressure, $\sigma_{e q}$ the von Mises equivalent stress, $\varepsilon_{D}$ the strain of damage onset, $\varepsilon_{R}$ the strain at fracture, $D_{C}$ the amount of damage at fracture.

This model is modified in order to take into account the loading in tensile on one hand, and in compressive modes on another hand [3]. This is necessary since a material volume of the billet experiences cyclic loading in the tube piercing process. Damage parameters are calibrated using tensile tests and micrographic analysis of the initial porosities in the material. As an example, a map of the damage intensity is shown in Figure 11.

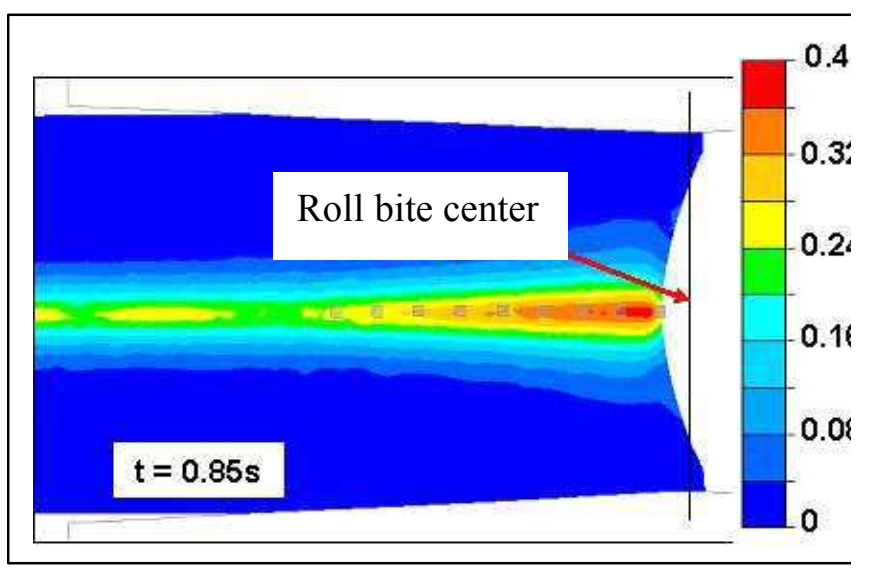

Fig.11: Damage values according to the modified Lemaitre model in a longitudinal cross section of the billet. The line shows the center of the roll bite i.e. the intersection between the central planes of the biconical rolls

The position of maximum damage is predicted along the central axis of the billet, and a critical damage value corresponding to the creation of a crack is found inside the billet, at about $14 \mathrm{~mm}$ within the billet. As observed in the industrial products, the crack is created along the central axis upstream from the roll bite center. A kill element technique is coupled in Forge2005 $\AA$ to show and propagate the crack (Figure 11).

\section{CONCLUSIONS AND PERSPECTIVES}

The tube piercing starting from solid billets has been investigated and modelled using a 3D finite element code. Specific features of the code were used to prevent artificial volume increase and to describe the stable motion of the billet. Rheological and damage models were identified and used to estimate where and when crack is created.

The next step has been to describe the material flow thereafter, once the plug is in place.

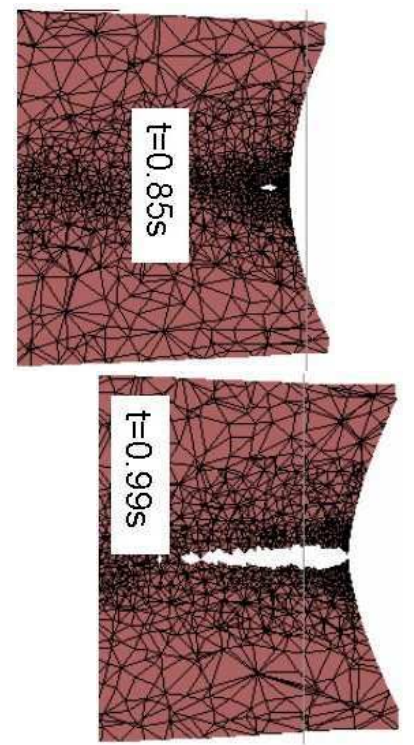

Fig. 12: Crack in the billet after 0.85 and 0.99 second.

\section{REFERENCES}

1. Yang J., Li G., Wu W., Sawamiphakdi K., and Jin D., Process modelling for rotary tube piercing application, Materials Science \& Technology, Vol 2 New Orleans LA (2004) 137-148

2. J. Lemaitre and R. Desmorat, Engineering damage mechanics: ductile, creep, fatigue and brittle failures, Springer-Verlag, Berlin (2005).

3. P.O. Bouchard, L. Bourgeon, Enriched Lemaitre damage approach for cold forging applications, International Symposium on Plasticity, Kona, Hawaii, USA, January 2-8 2008.

4. Fanini S., Ghiotti A., Bruschi S., Evaluation of Fracture Initiation in the Mannesmann Piercing Process, 10th ESAFORM Conference on Material Forming, edited by E. Cueto and F. Chinesta, (2007) American Institute of Physics 978-0-7354-0414-4/07, 709-714.

5. Ceretti E., Giardini C., Attanasio A., Brisotto F. and Capoferri G., Rotary tube piercing study by FEM analysis: 3D simulations and experimental results, Tube \& Pipe Technology (March/April, 2004) 155-159. 


\title{
Products quality improvement through numerical simulation in Steel Industry
}

\author{
J. Demurger ${ }^{1}$, R. Forestier ${ }^{1}$, B. Kieber ${ }^{2}$, G. Mathieu ${ }^{1}$ \\ ${ }^{1}$ ASCOMETAL CREAS, BP 70045, 57301 Hagondange, Cedex, France \\ URL: $\underline{\text { www.ascometal.com }}$ \\ e-mail:j.demurger@ascometal.lucchini.com; \\ r.forestier@ascometal.lucchini.com

\section{ASCOMETAL FOS SUR MER, BP 30, 13771 Fos sur Mer, Cedex, France \\ URL: $\underline{w w w . a s c o m e t a l . c o m} \quad$ e-mail: b.kieber@ascometal.lucchini.com;}

ABSTRACT: Increasing requirements concerning the product quality have led ASCOMETAL to build research projects where the relationship between surface quality, internal segregation or porosity, and product quality are studied using numerical simulation. These numerical tools, more and more powerful and accurate, are today a deciding and validating factor used to improve our products. ASCOMETAL is equipped with process simulation software: continuous casting and ingot casting simulation software, rolling and straightening simulation software that can cover the entire manufacturing process of steel bars. They are used to study the effect of process parameters on defect formation or evolution. Applications are the adjustment of continuous casting primary and secondary cooling and the adjustment of roll pass design to improve the billet quality, internal porosity as well as bars surface quality.

Key words: Process Modelling, Rolling, Casting, Damage criterion, Hot tearing

\section{INTRODUCTION}

Steelmakers are facing an ever increasing demand to improve product quality, not only to minimise scrapping and increase productivity but also to ensure customers satisfaction. Concerning the latter, measures can be taken to ensure final product quality. The most common procedure consists in ensuring absence of unwanted defects through a variety of non-destructive testing methods, repairing defects when possible and scrapping when not. While this allows for defects detection and guarantees the final product conformity, it does not affect defect occurrence and therefore does not help reduce scrapping. Defect formation may happen at different stages along the steel manufacture route (casting, cooling, rolling, etc). To reduce defect occurrence, it is therefore important to understand the mechanisms of formation of the different kinds of defects, and quantify the influence of the processing parameters. Numerical simulation softwares are today of considerable help in these tasks, as they allow for a reasonably accurate modelling of the temperature and stress conditions at any point of the processing route. With the help of a few carefully designed experiments, it is possible to correlate defect occurrence with calculated stress and temperature conditions. An optimised process route can therefore be proposed to reduce the likelihood of occurrence of a given kind of defect. In the following, we provide three such examples. In the first case, calculation of stresses during continuous casting were used together with a damage criterion to reduce hot tearing. In the second, the influence of the rolling schedule of square bars on porosity closure is modelled, and the results used to propose an alternative rolling schedule. In the last example, modelling of surface damage during rolling is used to redefine the geometry of the intermediate passes and minimise the risk of surface cracking, while leading to the same final geometry in the same number of passes.

\section{CRACKING DURING THE CONTINUOUS CASTING PROCESS}

In continuous casting, both solidification cracks (hot tears) and intergranular cracks can be caused by solid skin deformation. In the secondary cooling zone, these deformations are mainly caused by the bulging of the solid skin between the supporting rolls, by thermal stresses or by the contact with the supporting rolls themselves .

The software THERCAST ${ }^{\circledR}$ [1] is used for the simulation of casting processes. Thermal-mechanical modelling of continuous casting was not possible few years ago because of the high computational time it requires. Numerical and hardware developments allow us today to use 3D FEM modelling of continuous casting in the industrial 
framework. The continuous casting process is modelled here using a transient approach [2] (upgraded Lagrangian method). The heat equation, and the mechanical equilibrium equation are solved using 3D finite element methods. Hence, the Cauchy stress tensor, the strain and the temperature fields are outputs.

Due to spray cooling and roll contact (figures 1 and 2), series of compressive and tensile stress areas occur at the surface of the bloom.

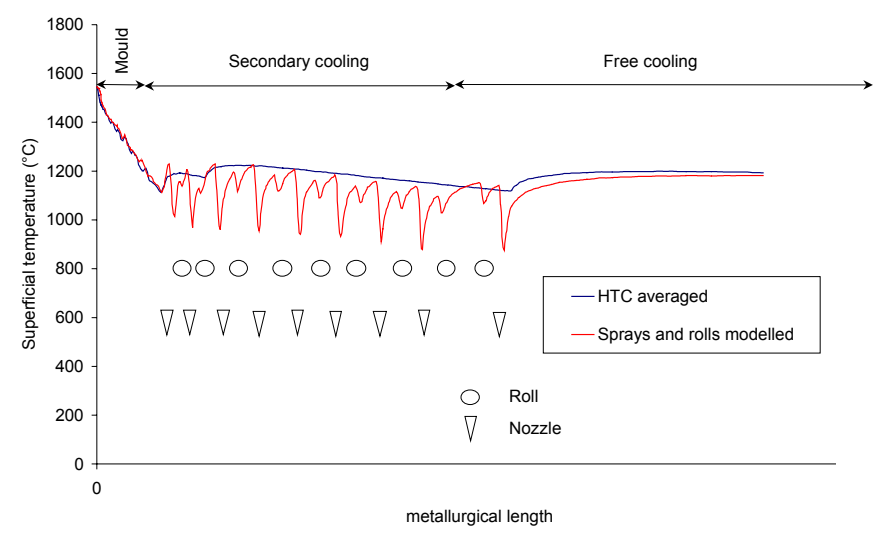

Fig. 1 : Temperature evolution : primary and secondary cooling zones

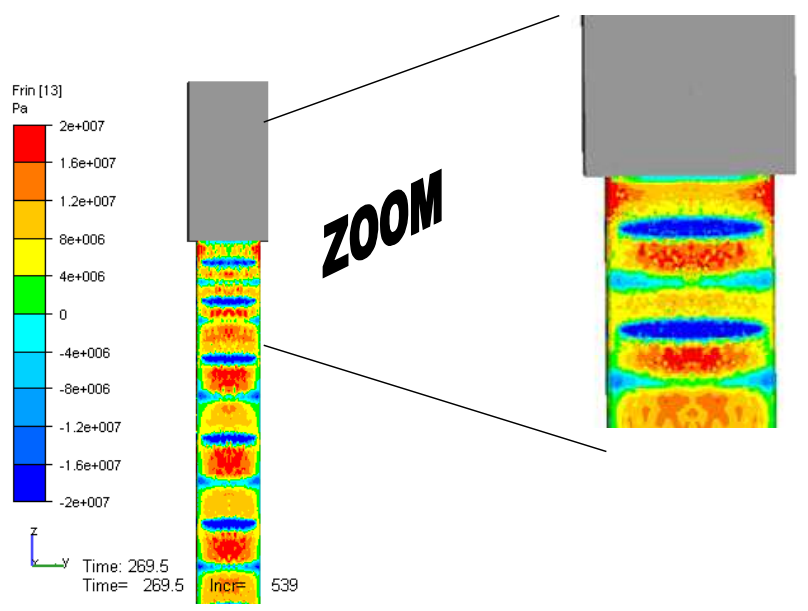

Fig. 2 : Pressure field in the secondary cooling zone

A hot tear criterion (Yamanaka criterion [4]) is used to determine the critical areas in the bloom during casting (figure 3 ). It is supposed that the material is brittle between 0,9 and 0,99 of solid fraction. Using this criterion, it is then possible to study the impact of process parameters - such as cooling spray patterns for example - on the occurrence of solidification cracks. Results are shown for two different kind of sprays (figure 4).

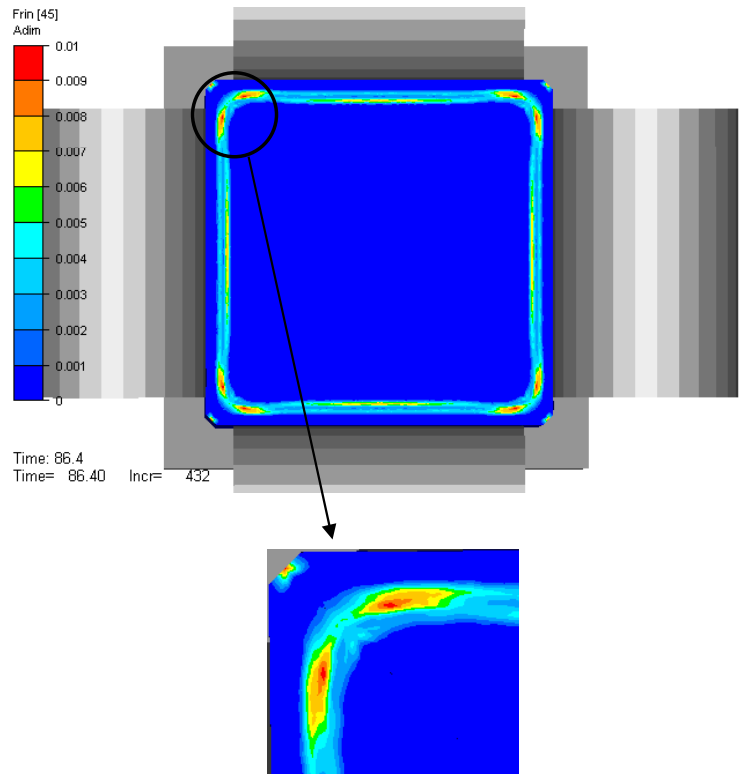

Fig. 3 : Yamanaka et al. [3] criterion at the corner

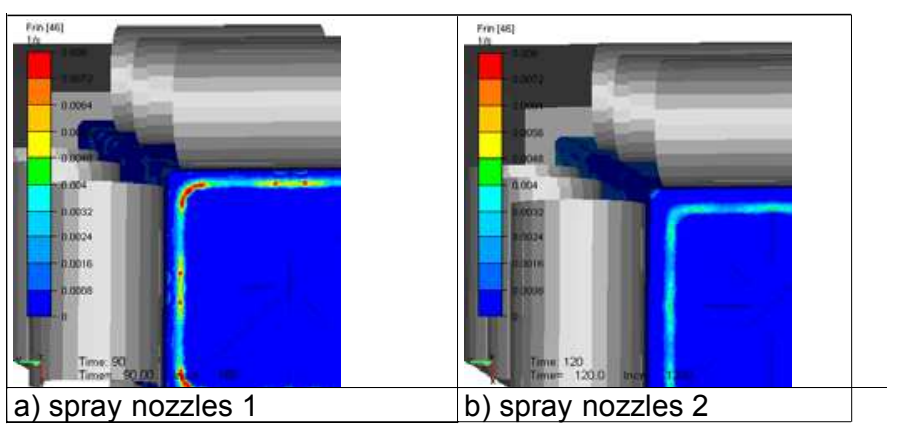

Fig. 4 : Yamanaka et al [3] criterion (cutting plane) for two different cooling patterns

Finally, we concluded that increasing the spray impact surface, decreasing the casting speed or the roll pitch induce significant reduction of the Yamanaka et al. [3] criterion. Thermal-mechanical modelling helps to determine the optimal casting parameters for grades sensitive to solidification cracks.

\section{POROSITY REDUCTION FOR LARGE DIAMETER PRODUCTS}

Solidification shrinkage leads to the creation of porosity into the cast product. Mostly, they are closed during rolling if the rolling reduction is large enough. For large diameter products, it is necessary to optimise the rolling parameters in order to obtain an internal soundness which satisfies the customer's quality requirements. Two different rolling schedules leading to the same final section were investigated. The question is: which one is the most efficient to close the porosity?

FE software LAM3® [4] and FORGE2005® [5] were used to simulate the rolling schedule. LAM $3 \AA$ is based on a steady state resolution and FORGE2005® is used for transient simulations. 


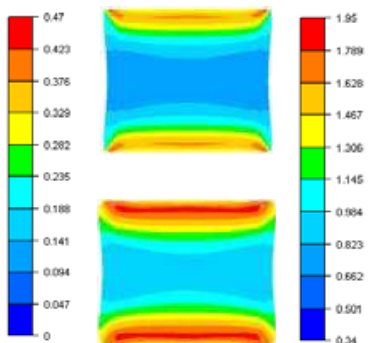

Pass 1

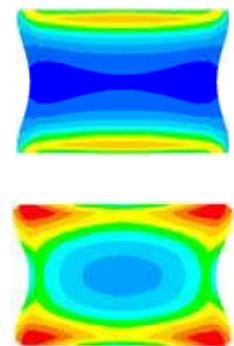

Pass 5

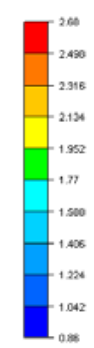

Last pass
Fig. 5 : Cumulated strain evolution during rolling for two roll pass design leading to the same final section (LAM3 $®$ )

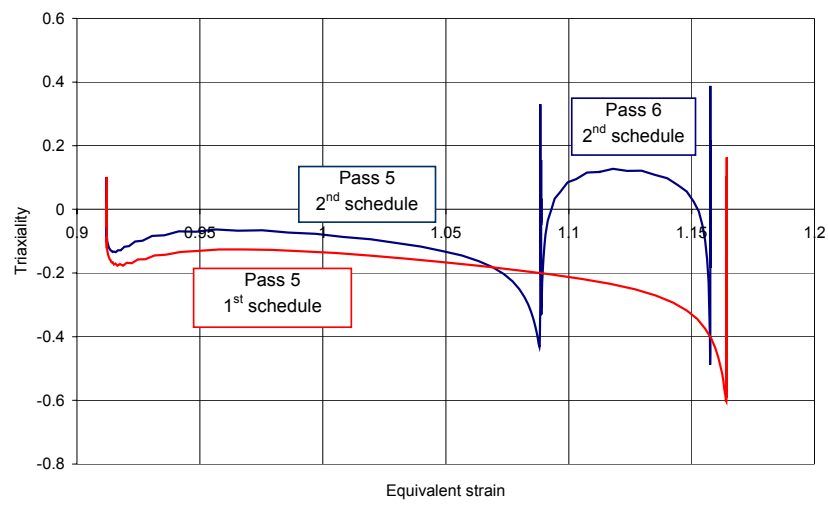

Fig. 6 : Triaxiality versus strain for both rolling schedules at the billet centre and during one (two) pass(es)

A simple analysis of the cumulated plastic strain at the bloom centre is not sufficient to select the best rolling schedule (Fig. 5). An explanation is given on figure 6: passes 5 and 6 of the second rolling schedule are equivalent in term of cumulated strain to the $5^{\text {th }}$ pass of the $1^{\text {st }}$ rolling schedule but, for the first one the stresses remain compressive, whereas the second one is submitted to a tensile stress. This tensile stress may reopen the porosity.

To simulate the porosity evolution, a $10 \mathrm{~mm}$ hole was introduced in the FE mesh at the billet centre (figure 7). The effect of different parameters such as the rolling schedule itself, the roll diameter or the thermal gradient on the pore volume evolution during rolling were analysed.

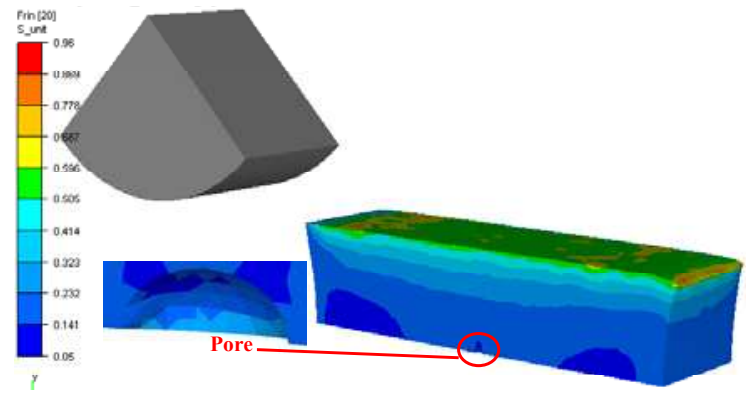

Fig. 7 : Forge $2005 \AA$ simulation of porosity evolution using an actual hole in the mesh (transient simulation)

The main results are given in table 1 . The efficiency is measured using the evolution of the cavity volume $\left(\mathrm{V} / \mathrm{V}_{0}\right)$.
Table1. Results on pore closing efficiency

\begin{tabular}{|l|c|}
\hline & $\mathrm{V} / \mathrm{V}_{0}$ \\
\hline RPD 1 (isothermal, mean roll radius) & $74 \%$ \\
\hline RPD 2 (at the same elongation) & $90 \%$ \\
\hline RPD 1 with thermal gradient (core hotter than skin) & $60 \%$ \\
\hline RPD 1 with thermal gradient (core colder than skin) & $83 \%$ \\
\hline RPD 1, roll diameter + 15\% & $72 \%$ \\
\hline RPD 1, roll diameter - 15\% & $80 \%$ \\
\hline
\end{tabular}

These results allow to classify the effect of parameters on pore closing. The roll pass design and the thermal gradient are of primary importance, the diameter roll evolution (successive remanufacturing) lead also to a loss of efficiency of the roll pass design on pore closing.

\section{PRODUCT SURFACE QUALITY}

Other unwanted defects are the skin defects that can have effects on cracking risks during forging or on fatigue life. Some of the defects are mechanical defects due to shocks, stripes or scale incrustation. In this study we focussed on intergranular cracking caused by the nucleation, growth and connection of voids. The FE software LAM $3 \AA$ and a damage criterion (Cocks model [6,7]) were used to simulate the rolling schedule in order to detect the critical areas for each stand of the wire rolling mill.

Curves of triaxiality rate versus strain were plotted at a point, along a streamline on the free surface, where the damage criterion is maximum. On figure 8 the triaxiality rate evolution on 4 stands of the wire rolling mill is plotted versus cumulated strain. It can be seen on this graph that, obviously, at stand 4 the product surface is submitted to a high triaxility rate.

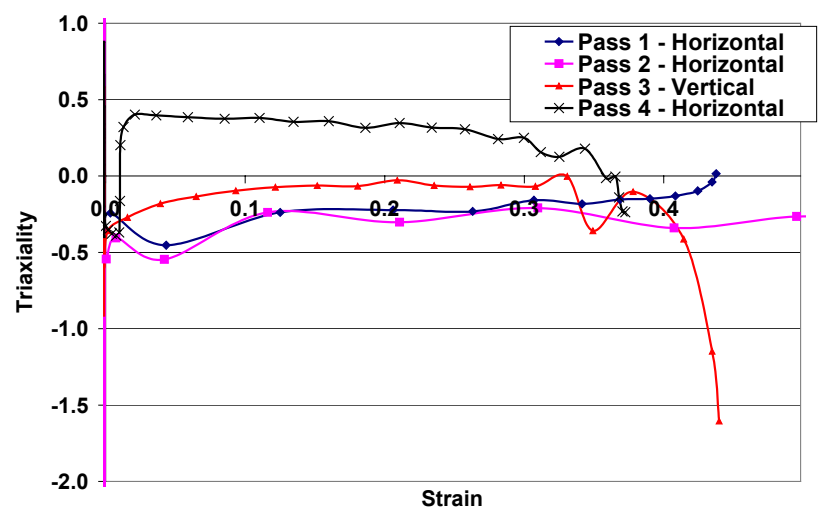

Fig. 8 : Triaxiality rate versus strain evolution during rolling on the free surface 

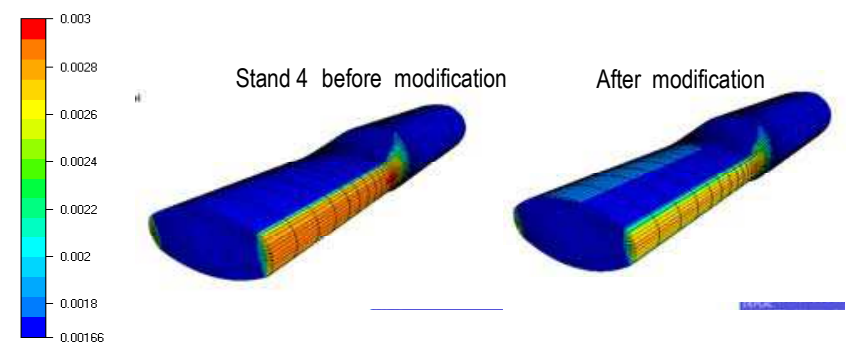

Fig. 9 : Damage contours on stand 4 before and after groove radius modification.

The groove radius of stand 4 was then modified to reduce the damage criterion value (figure 9). It can be seen on figure 10 that, at stand 6 , the shape of the product remain the same. It was not necessary to modify the following stands. The related changes on the rolling force are :

- stand $4:-0.6 \%$

- stand $5:-3 \%$

- stand $6:+3.8 \%$

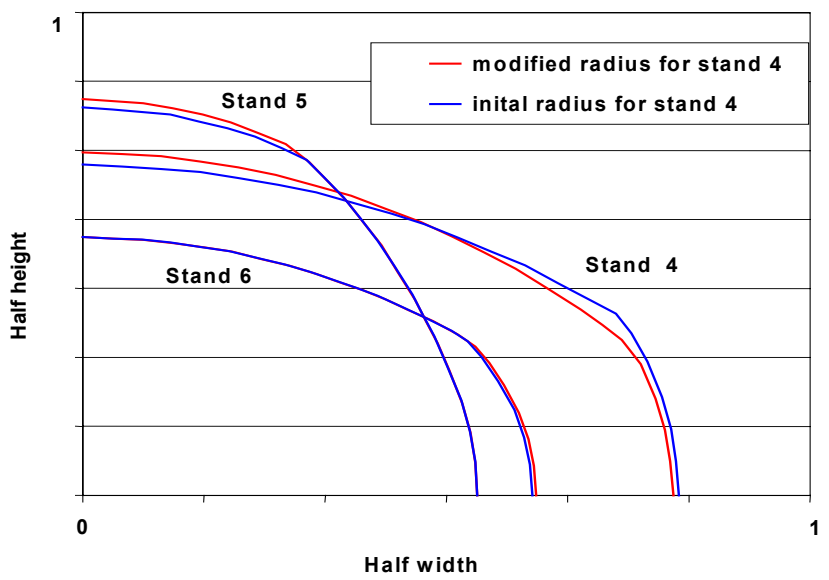

Fig. 10 : Groove radius modification for stand 4, effect on stands 5 and 6

This modification has been scheduled on ASCOMETAL plant. The actual impact of this modification is of course difficult to measure on the final product because the wire is the result of a wide number of operations. As the mechanical solicitation of the product surface during rolling is reduced on stand 4 (lower strain and lower triaxiality), the occurrence of defects is reduced.

\section{CONCLUSIONS}

This paper gives an overview of how numerical simulation is nowadays used in the industrial framework to study and optimise process parameters. Today, most of the industrial processes involved in steelmaking companies can be modelled. Using such models, expensive and time consuming industrial trials are avoided. They permit to understand how and when some defects may occur all along the process stages.

Thermal-mechanical modelling of continuous casting is applied to understand how defects such as hot tearing occur in the product. In order to avoid them, parametric analysis can then be applied to understand the impact of process parameters on the defect formation. The example of spray cooling pattern is given herein.

Rolling process is also widely studied using numerical models. Damage criteria are used to study surface defect formation. The study of the closure of internal porosity is also presented here. It is shown that the influence of process parameters such as the groove radius, the roll pass design or the reheating conditions on the internal and on the surface quality.

ASCOMETAL takes part in several French and Europeen research projects like Simulforge, Osc, Pacrolp, Improsound, Cracracks.

\section{REFERENCES}

1. Thercast $\AA$, TRANSVALOR, WWW.transvalor.com

2. Frédéric Costes. Modélisation thermomécanique tridimensionnelle par élément finis de la coulée continue d'aciers. Thèse de doctorat, Ecole des Mines de Paris 2004

3. A. Yamanaka, K. Nakajima, K. Yasumoto, H. Kawashima, K. Nakai, Measurement of critical strain for solidification cracking, Model. Cast. Weld. Adv. Solidification processes, V, ed. M. Rappaz, Min. Met. Mat Society, 1997, pp. 279

4. Lam3®, TRANSVALOR, WWW.transvalor.com

5. Forge2005®, TRANSVALOR, WWW.transvalor.com

6. Cocks A.C.F. j. Mech. Phys. Sol, Vol 37, pp 693-715 (1989)

7. P. Mazataud, E. Bourgain, and all, A mesoscopic approach of ductile damage during cold forming processes. Proceeding of the third international conference on material processing (1-3 July 1997) 


\title{
Investigations into Roll Thermal Fatigue in Hot Rolling
}

\author{
Dr. C. Fedorciuc - Onisa ${ }^{1}$, Dr. D.C.J. Farrugia ${ }^{1}$ \\ ${ }^{1}$ Corus RD\&T UK, Swinden Technology Centre \\ Moorgate Rd, Rotherham, South Yorkshire, S60 3AR, UK \\ URL: http://www.corusgroup.com \\ e-mail: Christian.Onisa@corusgroup.com \\ Didier.Farrugia@corusgroup.com
}

\begin{abstract}
In the current paper, a study into the mechanism of roll thermal fatigue crack propagation during hot rolling of long products is presented. A range of 2D implicit FEM models taking into account the complex thermal and mechanical interactions during rolling and cyclic cooling have been developed and used to predict how the stress state inside the roll contributes in a different manner to energy release at the crack tip, depending on the length of the initial crack. A stress intensity factor (SIF) approach has been used to derive the crack growth rate for a given roll material and roll cooling configuration. This work describes the methodology of predicting thermal fatigue crack growth using innovative modelling techniques and highlights the importance one needs to attach to operating conditions (roll cooling, roll coating, controlling oxide scale etc.) alongside the optimum selection of roll material for reduced surface degradation of current hot long product rolls.
\end{abstract}

Key words: hot rolling, thermal fatigue, roll cooling, crack propagation, J integral

\section{INTRODUCTION}

Rolls during hot rolling are subjected to cyclic thermal variations, which, depending on the mill operating conditions (position in the mill, rolling schedule) may induce severe thermal gradients. The developed thermal stresses add to already existing internal tensile residual stresses (from casting for a cast roll or shrink fit for sleeved roll). If undetected, the resulting fire cracking on the surface ("fire crazing") can lead ultimately to roll breakage, with costly consequences to mill production. In addition, any mill incidence, such as a stall ("cobble") can further contribute to a reduction in roll life. The current remedy practice of removing the outer surface layer (sometimes beyond the required dressing imposed by "normal" roll wear) amounts to production costs and may require an increase in roll stock.

Despite the considerable effort devoted, during the last decades, to study thermal fatigue phenomenon, it is recognised that in the case of hot rolling of long products there is a lack of understanding how, when and how fast thermal cracks advance with respect to rolling parameters. This is due to the complexity of processing factors (variations in roll heating/cooling regimes, complex contact areas, internal crack oxidation, lubrication-when used), as well as to the paucity of roll material data in the range of operating conditions. Most of the published results relate to steel rolls, such as high speed steel [1, 2, 3]. A general analytical approach to predict thermal crack growth for high/low thermal cycle was proposed by Malm and Nortrsom in 1979 [ $\square$.

In the current paper, an investigative work into the mechanism of thermal fatigue crack propagation during a rolling cycle is presented using a FE modelling approach. It is shown how the stress state inside the roll contributes in a different manner to energy release at the crack tip, depending on the length of the initial crack.

A stress intensity factor (SIF) approach has been used to derive the crack growth rate for a given roll material and roll cooling configuration.

This work describes the methodology of predicting thermal fatigue crack growth using innovative modelling techniques and highlights the importance one needs to attach to operating conditions (roll cooling, roll coating, controlling oxide scale etc.) alongside the optimum selection of roll material for a better usage of the current rolls for hot rolling. 


\section{THERMAL CRACK MODELLING}

\subsection{FE model}

A simplified 2D FE model of roll cooling (figure 1) has been used to simulate the effect of cyclic heating and cooling on four different predefined cracks. The hot feedstock was modelled as an equivalent heat source, which also exerts a mechanical pressure onto the roll. Heat transfer coefficient in the cooling area is calculated based on real cooling configuration (system geometry, nozzle type, water flow rate/pressure) using an in-house software package. The coupled thermo-mechanical FE analysis was carried out using the implicit Abaqus 6-6.1 version. A sufficient number of revolutions (depending on roll speed) are required to achieve a quasi steady state heat exchange regime, which can significantly increase the CPU time. This drawback can, however, be overcome by running a heat transfer analysis using a simpler 2D FE model (with no cracks) and importing the roll temperature gradient into the first model.

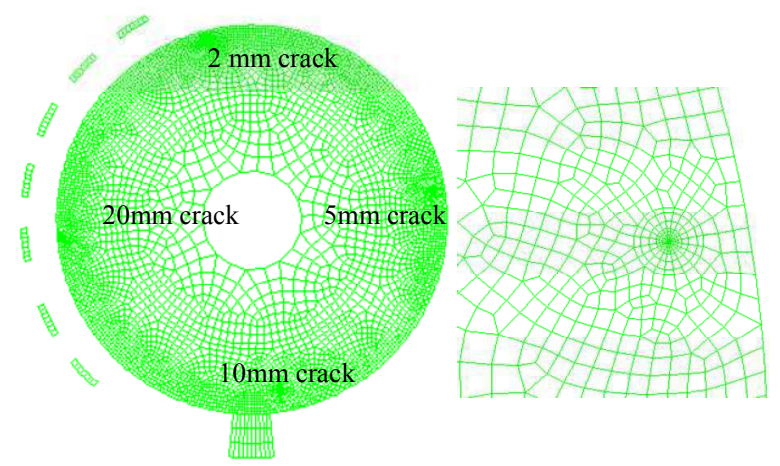

Fig. 1 The FE model with cracks used for analysis

A linear elastic roll material justified the application of LEFM concepts for extraction of $J$ integrals at crack tips (as a measure of energy release rate). Paris law is then employed to relate the crack length to number of cycles, provided that roll material parameters are known. Using this approach, the FE model can simulate quantitatively the effect of various roll cooling and heating scenarios on thermal crack growth.

\subsection{Effect of roll cooling intensity on energy release rate}

As roll cooling is an independent and significant rolling process parameter that can be controlled in a mill environment within boundaries imposed by mill logistics (such as nozzle type, water flow pressure at main pipes, efficiency of filtering system for coolant recirculation etc.), the effect of roll cooling on thermal crack growth has been studied. Three different cooling scenarios have been simulated: "normal" regime $\left(\mathrm{HTC}=0 \mathrm{~kW} / \mathrm{m}^{2} \mathrm{~K}\right)$, poor cooling $\left(\mathrm{HTC}=20 \mathrm{~kW} / \mathrm{m}^{2} \mathrm{~K}\right)$ and overcooling $\left(\mathrm{HTC}=100 \mathrm{~kW} / \mathrm{m}^{2} \mathrm{~K}\right)$. In the last case, a quasi steady state thermal regime, achieved under "normal" cooling is followed by a brusque increase in cooling intensity (due to, for instance, severe fluctuations in roll cooling intensity: sudden unblocking of some of the nozzles, mains pressure increase etc.). The effect of these cases on the amount of energy release rate is shown in figure 2 .

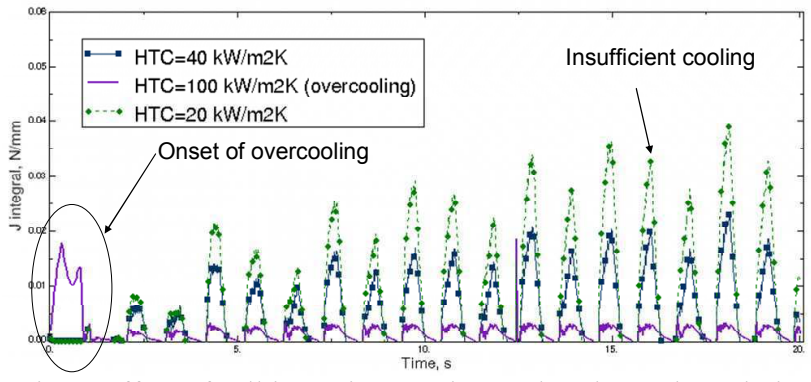

Fig. 2 Effect of roll intensity on J integral at thermal crack tip (initial roll temperature: $30^{\circ} \mathrm{C}$, roll speed: $6 \mathrm{rad} / \mathrm{s}$, feedstock temperature: $1100^{\circ} \mathrm{C}$, roll diameter: $360 \mathrm{~mm}$ )

It can be noticed that an "optimum" cooling regime assures a quasi constant variation of $\mathrm{J}$ integral, which results in a similar effect on the thermal crack growth rate. On contrary, as expected, an insufficient roll cooling results in continuously increasing rate of energy release at crack tip (resulting in an accelerated growth). As this phenomenon is proportional to the roll surface temperature variation (measurable), methods to control roll thermal fatigue can thus be developed and applied. A slightly more complicated case can occur in practice when excessive roll cooling is applied suddenly on a hot roll. The initial thermal shock results in a severe and- most importantly- over a long time interval of the energy release rate at the crack tip. It is interesting to know what the effect on the roll's microstructure this prolonged state of stress might have, so that superior materials could be developed.

\subsection{Analysis of thermal crack growth over one cycle}

Optimum roll cooling regime should ensure a constant thermal crown (roll heat affected zone, 
RHAZ), where the temperature fluctuates cyclically, the depth of which is dictated by the contact time with the hot feedstock via roll's thermal diffusivity. a. Shallow thermal cracks (sometimes left over after roll regrinding or initiated around hard carbides/inclusions) within this thermal band are subjected to cyclic heat variations, exacerbated by the unequal thermal stresses on each side of the crack due to the inherent nature of the phenomena (i.e., one side is always hotter/cooler then the other one) in a steady state rolling thermal regime. As the FE model shows (figure 3), the hoop stresses within the RHAZ, due to only heat exchange and mechanical rolling, are compressive (ignoring shrink-fit or manufacturing residual stresses). Instead, the axial stresses (figure $\square$ ), induced by the asymmetrical thermal gradient, seem to be the main parameter for roll thermal fatigue (steady state thermal conditions).

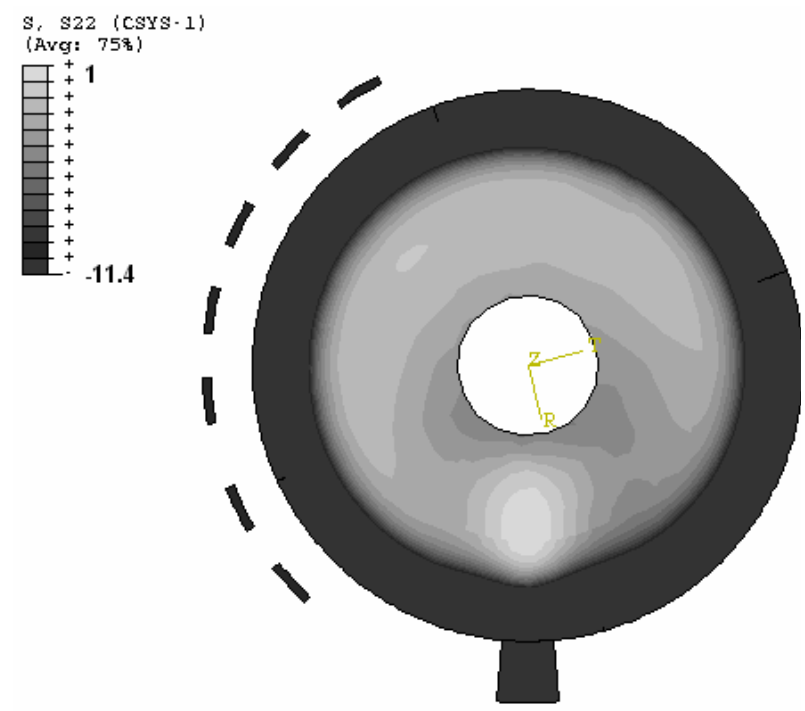

Fig. 3 Normalised hoop stress during thermal steady state hot rolling (residual stresses ignored)

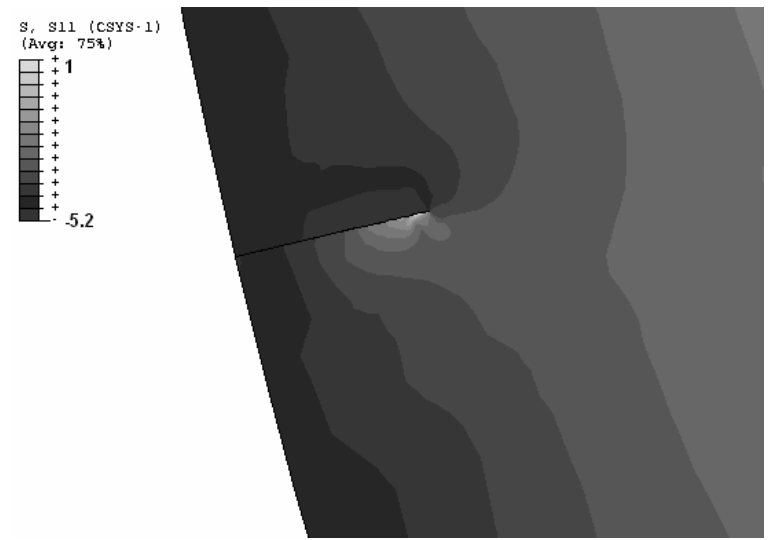

Fig. $\square$ Axial normalised stress (shallow crack in cooling area)
This corresponds to Mode II of crack surface displacement (sliding). Once the crack grows to a certain length, its tip can reach the high hoop tensile stress deeper below the surface (see figure 3) and Mode I (opening) complements Mode II. First mode can also occur in the case of insufficient cooling/mill incidence, high frictional force or high roll speed.

b. Deep thermal cracks, beyond the RHAZ, are mainly affected by the mechanical contact with the feedstock due to the contact pressure (Mode II). Their growth is therefore more influenced by pass reduction. The mixed thermal crack growth mechanism is sketched in figure 5.

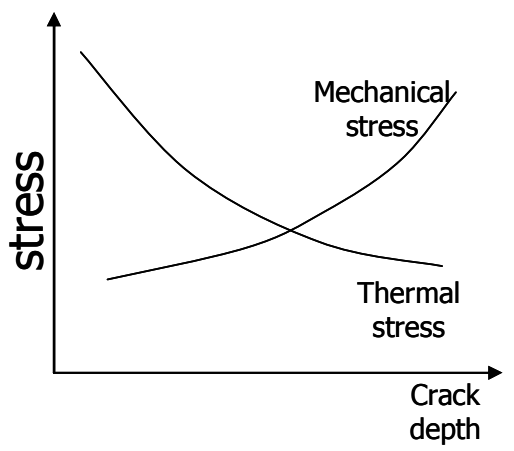

Fig. 5 Dual mechanism of thermal crack growth in hot rolling

Evolution of $\mathrm{J}$ integral for two thermal cracks over one cycle against roll surface temperature evolution near the crack is shown in figure 6. Maximum energy release rate for a "deep" crack takes place at entry to roll gap, whilst for a "shallow" crack, it is the cooling area, mainly beneath the first cooling nozzle, where energy release rate associated with crack growth take place. This observation can lead to optimisation of the roll cooling design, with the objective to reduce the severe thermal gradient between crack sides (i.e., ramping the heat extraction, whilst maintaining the RHAZ depth constant).

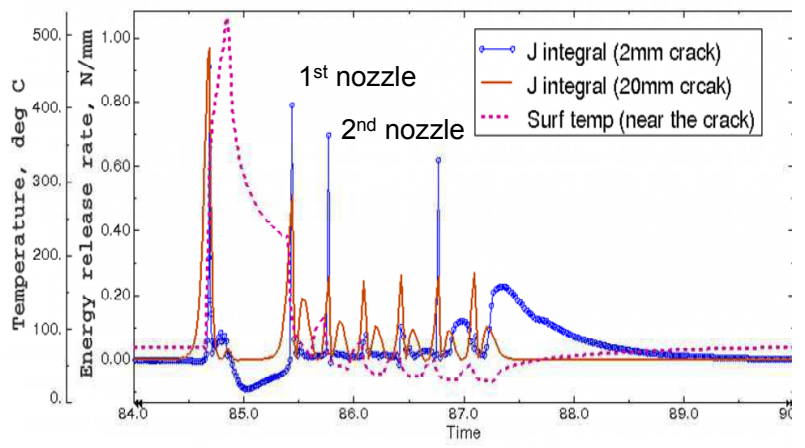

Fig. $6 \mathrm{~J}$ integral for a "shallow" $(2 \mathrm{~mm})$ and a "deep" $(20 \mathrm{~mm})$ thermal crack over one cycle vs. roll surface temperature near each of the cracks 


\subsection{Prediction of work roll thermal fatigue and roll life}

Using the $\mathrm{J}$ integral (hence SIF) calculated from the FE model and assuming known roll material parameters Paris law can be used to calculate the number of cycles (for a given set of rolling/cooling parameters, under the assumption of linear crack growth regime) until a certain length of thermal crack is reached and roll returned to roll shop for redressing. An example of the capability of the proposed approach is shown in figure 7, where a roll cooling situation was simulated using two different roll materials (material $1-$ high $\mathrm{Cr}$ and material 2 Superten) in two different cooling scenarios: poor cooling, $\mathrm{HTC}=20 \mathrm{~kW} / \mathrm{m}^{2} \mathrm{~K}$ and more intense cooling, $\mathrm{HTC}=5 \mathrm{~kW} / \mathrm{m}^{2} \mathrm{~K}$. In addition to optimising roll cooling based on required HTC and available mill capacity, one can also assess the suitability of other roll materials for a given rolling stand. (Here, the indications are that more performance can be obtained from the second roll material if the same improvement in roll cooling was made.)

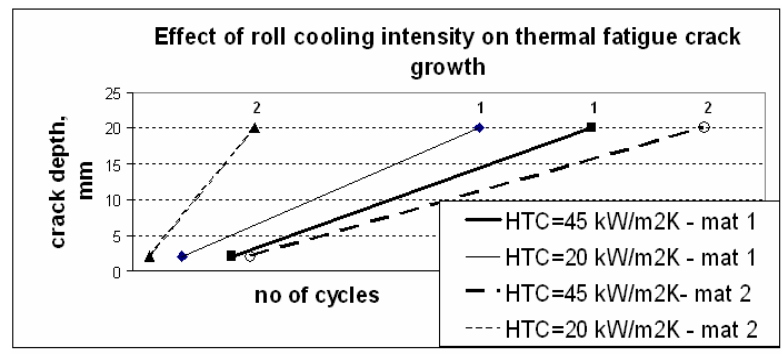

Fig. 7 Example of predicting thermal crack growth for two different roll materials under two different cooling regimes for the same rolling conditions

Controlling roll surface temperature by an optimum roll cooling is paramount in limiting the thermal crack growth. For instance, a numerical calculation shows that an increase of roll surface temperature of $16^{\circ} \mathrm{C}$ can increase the rate of crack growth by a factor of 2.58 .

\section{CONCLUSIONS}

An FE based method for investigating the mechanism of thermal crack growth has been proposed. Using the concepts of LEFM, estimations of roll life, from the perspective of thermal fatigue, can be developed. This can be further utilised to optimise roll cooling within the constraints of the mill, as well as the roll capability in service. More work is, however, needed to obtain material properties of current or prospective rolls at operational temperature.

\section{REFERENCES}

1. Molinari A, Tremea A, Peliizzari M, Biggi A and Corbo $\mathrm{G}$, High speed steels for hot rolls with improved impact and thermal fatigue resistance, Materials Science and Technology, 18, Dec (2002), pp 157 $\square-1581$.

2. Chang K K, Park J I, Ryu J H, Lee S, Correlation of microstructure and thermal-fatigue properties of centrifugally cast high-speed steel rolls, Met. and Mat. Trans. A, 35A, Feb (200ロ), pp 81- 92.

3. Person, A., Hogmark, S., Bergstrom, J., Simulation and evaluation of thermal fatigue cracking of hot work tool steel, International Journal of fatigue, 26 (200ロ), p 1095-1107

$\square \quad$ Malm, S., Norstrom, L.A, in Metals Sci. (1979) no 9, p. $5 \square-550$

5. Stevens, $\mathrm{P}$ G et al., Increasing Work-Roll Life by Improved Roll Cooling Practices, JISI, 1971, pp 1-11.

6. Ryu, Jae Hwa, Ryu, Han-Bin, Effect of thermal fatigue property of hot strip mill work roll materials on the rolled - in defects in the ultra-low carbon steel strips, ISIJ international, vol. $\$$ (2003), p. 1036-139

7. Brechet, Y., Magnin, T., Sornette, D., The CoffinManson law as a consequence of the statistical nature of the LCF surface damage, Acta Materialia, vol. $\square$, No. 9, p.2281-2287, 1992

8. Lieurade, H. P., Dias, A., Giusti, J., Wisniewski, A., Experimental simulation and theoretical modelling of crack initiation and propagation due to thermal cycling, High temperature technology, vol. 8, (1990), no. 2, p. $137-1 \square 5$

9. Lundberg, Sven-Erick, Evaluation of deterioration mechanisms and roll life different roll materials, Steel

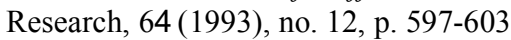

10. Pellizzari, M; Molinari, A.; Straffelini, G.: Tribological behaviour of hot rolling rolls, Lubrication and Wear 259 (2005) $7 / 12,1281-1289$

11. Perez, A et al.: Computer simulation of the thermal behaviour of a work roll during hot rolling of steel strip,

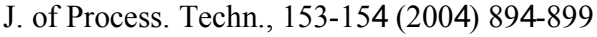




\title{
Forming residual stresses effects on the electron beam welding distortions of thick components
}

\author{
S. Gallée ${ }^{1}$, C. Bois ${ }^{2}$, P. Vadon ${ }^{3}$, D. Nelias ${ }^{4}$ \\ ${ }^{1}$ ESI-France - Le Récamier, 70 rue Robert, 69458 Lyon Cedex 06, France \\ URL: $\underline{w w w . e s i-g r o u p . c o m} \quad$ e-mail: sebastien.gallee@esi-group.com \\ ${ }^{2}$ AREVA NP SAS - 10-12 rue Juliette Récamier, 69456 Lyon Cedex 06, France \\ URL: $\underline{\text { www.areva.com }}$ \\ e-mail:claude.bois@areva.com \\ ${ }^{3}$ DCNS - INDRET, 44620 La Montagne \\ URL: $w w w . d c n . f r$ \\ e-mail:philippe.vadon@dcn.fr \\ ${ }^{4}$ LaMCoS - INSA-Lyon, CNRS UMR5259, F69621, France \\ URL: http://lamcos.insa-lyon.fr e-mail: daniel.nelias@insa-lyon.fr
}

ABSTRACT: The purpose of this study is to evaluate the effects of forming residual stresses on the electron beam welding distortions of thick components building up the ITER vacuum vessel. The deformed shape of a thick plate is obtained by a three point rolling process. The numerical simulation of this process is then performed to evaluate the induced residual stresses. Forming residual stresses are taken into account as initial conditions for the welding simulation of two deformed thick plates. A simulation is finally performed to evaluate the influence of the forming residual stresses on the welding distortions.

Key words: thick plates, rolling, electron beam welding, distortions.

\section{INTRODUCTION}

Numerical simulations of welding processes have been performed since many years now [1]. Thanks to these simulations, the welding distortions and their influence on the behaviour of the welded components can be investigated.

The manufacturing of the ITER vacuum vessel involves the welding of thick deformed plates $(60$ $\mathrm{mm}$ thickness). These $316 \mathrm{~L}(\mathrm{~N})$ austenitic stainless steel plates are curved using a three point rolling process which induced residual stresses. The deformed plates are then electron beam. The aim of this study is to investigate the influence of the residual stresses induced by the forming process on the welding distortions. For comparison, a simulation on two plates without residual stresses will also be performed.

In the first part, the experimental device and the numerical simulation of the forming process will be described. The simulation requires a mechanical behaviour law for the steel that is identified thanks to an experimental database. In the second part, the welding simulation is described and the influence of the forming residual stresses on the welding distortions is investigated.

\section{FORMING OF A THICK PLATE}

\subsection{Experimental device}

The dimensions of the plate are $1400 \times 1000 \times 60$ $\mathrm{mm}^{3}$. It includes over-lengths on both side of the plate for the rolling process. These over-lengths are water-jet cutting after the rolling to obtain the final dimensions and shape of the plate $(1000 \times 1000 \times 60$ $\mathrm{mm}^{3}$ ). The rolling process consists in the displacement of a plate between three cylinders to obtain a curved deformed shape of this plate (figure 1). The plate is deformed in several passes (displacement from one side to the other) between two fixed cylinders under the plate and the upper movable cylinder that gives the curvature by going down during the displacement of the plate. Furthermore, a load is applied on the upper cylinder by two jacks during the process.

After the rolling, the over-lengths are water-jet cut and four holes are drilled on the plate, also by water- 
jet cutting. These operations must be taken into account in the numerical simulation for a better description of the residual stresses distribution at the end of the overall process, i.e. from the forming to welding.

\subsection{Mechanical behaviour law}

Monotonous tensile tests and cyclic tensilecompression tests have been performed at different temperatures to characterize the behaviour of the 316L(N) austenitic stainless steel [2]. The behaviour of this steel is described by an elastic-plastic model [3] with a non-linear kinematic hardening. The numerical simulations have been carried out using SYSTUS $^{\circledR}$ software. This model is closed to the one proposed by Armstrong-Frederick [4]. The hardening is described by two variables. The first one (1) is a variable of Prager type that depends on the cumulated plastic strain. The second one (2) is a classic Armstrong-Frederick variable. The evolution laws of these variables are:

$\underline{\underline{\chi}}_{1}=\frac{2}{3} h_{1}\left(\varepsilon_{e q}^{p}\right) \underline{\underline{\dot{\varepsilon}}}^{p}$

$\underline{\underline{\chi}}_{2}=\frac{2}{3} h_{2} \underline{\underline{\varepsilon}}^{p}-k_{2} \underline{\underline{\chi}}_{2} \dot{\varepsilon}_{e q}^{p}$

With $h_{1}\left(\varepsilon_{e q}^{p}\right)=\frac{\partial \overline{\sigma_{1}}}{\partial \varepsilon_{e q}^{p}}$

And $\bar{\sigma}\left(\varepsilon_{e q}^{p}\right)=\overline{\sigma_{1}}\left(\varepsilon_{e q}^{p}\right)+\frac{h_{2}}{k_{2}}\left(1-e^{-k_{2} \varepsilon_{e q}^{p}}\right)$

Where $\bar{\sigma}\left(\varepsilon_{e q}^{p}\right)$ represents the stress for a monotonous tensile test minus the initial yield stress. This model allows a good description of the monotonous tensile test curve. However, only weak variations of the parameter $h_{1}$ with $\varepsilon_{e p}^{p}$ are allowed and the variation of $\overline{\sigma_{1}}\left(\varepsilon_{e q}^{p}\right)$ must be nearly linear.

The parameters of this model are identified thanks to SYSTUS $^{\circledR}$ software by an inverse approach based on the least square method. The response of the model is compared to experimental data and the parameters are identified in order to minimize the gap between the numerical results and experiments.

\subsection{Numerical Simulation of the process before welding}

The forming process is divided into different steps, from the rolling to the drilling of the holes. The methodology used for the simulation is the following: a 2D simulation using plane strain assumption of the rolling process is first performed, the 2D results are then transferred on a 3D mesh of the plate including the holes and the over-lengths. Finally the machining of the over-lengths and the drilling of the holes by water-jet cutting are simulated by decreasing the machined elements stiffness down to zero. This approximation can be used due to the fact that the water-jet cutting process induces no significant thermal effects near the hole. The 2D simulation of the rolling is performed in plane strain conditions and finite displacements with sliding contacts between the plate and the cylinder. The mesh of the plate is composed of four-node quadrilateral linear elements with 4 integration points (12 elements through the thickness). To take into account the contact with the cylinders, the plate skin is meshed by 1D linear elements with 2 integrations points.

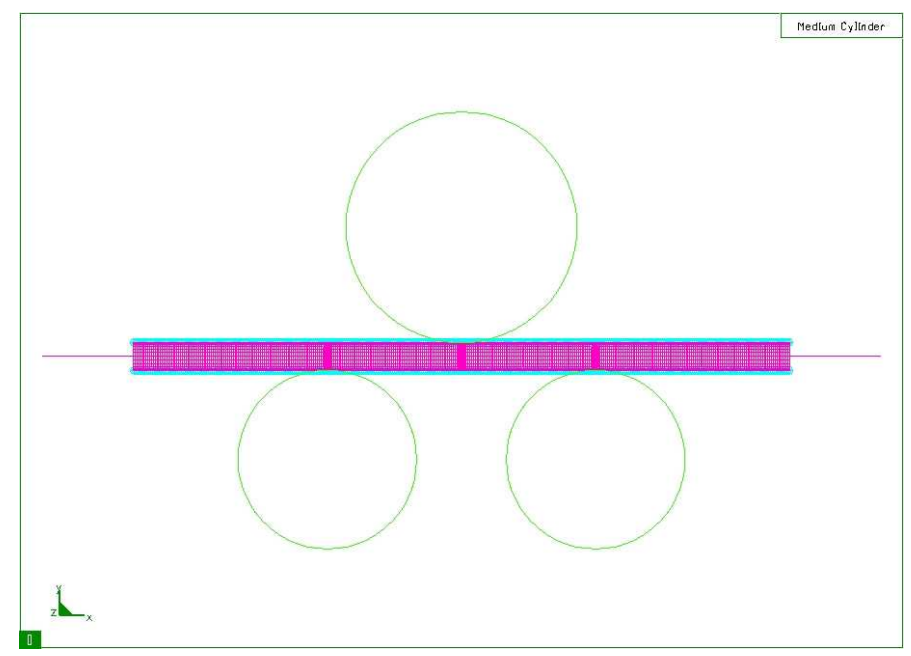

Fig. 1. Mesh of the plate and solid rigid cylinders.

To validate the use of linear elements, the numerical simulation of a three point bending test on this geometry has been performed with linear and quadratic elements (same size of elements for the two simulations). The two simulations highlight the same results. Consequently, linear elements have been used for the simulation in order to decrease the calculation time. Concerning the boundary conditions, the two lower cylinders are constrained in the $\mathrm{X}$ and $\mathrm{Y}$ directions and the upper cylinder can only move in the $\mathrm{Y}$ direction. The displacement of the plate is performed thanks to a spring type 1D element at each extremity of the plate.

The results of the rolling simulation show that the stresses are low in the over-lengths and that they are 
concentrated on the central part of the plate (between the two lower cylinders). The results also give information about the deformation mode of the plate. In the final state, a bending profile can be observed with the apparition of the neutral fibber. This fibber is the separation between two domains within the plate: compression in the upper part and tension in the lower part.

The next step of the simulation is the transfer of the $2 \mathrm{D}$ results on a $3 \mathrm{D}$ model for the simulation of the machining and drilling, which are $3 \mathrm{D}$ processes. The 3D model includes the mesh of the holes and of the over-lengths. After this operation, a balance of the plate is performed to consider the edge effects.

The influence of the machining and drilling can be estimated in term of stress distribution and changes of the deformed shape of the plate. The results show that the machining has negligible effects on the residual stresses but, even if the variations of displacement are weak, this operation gives a saddle shape of the deformed shape of the plate. Regarding the drilling of the four holes, this step only has a little effect on the stress distribution near the holes (relaxation of $20 \mathrm{MPa}$ for the $\sigma_{11}$ stress). Figure 2 gives the distribution of the $\sigma_{11}$ stress at the end of the forming process.

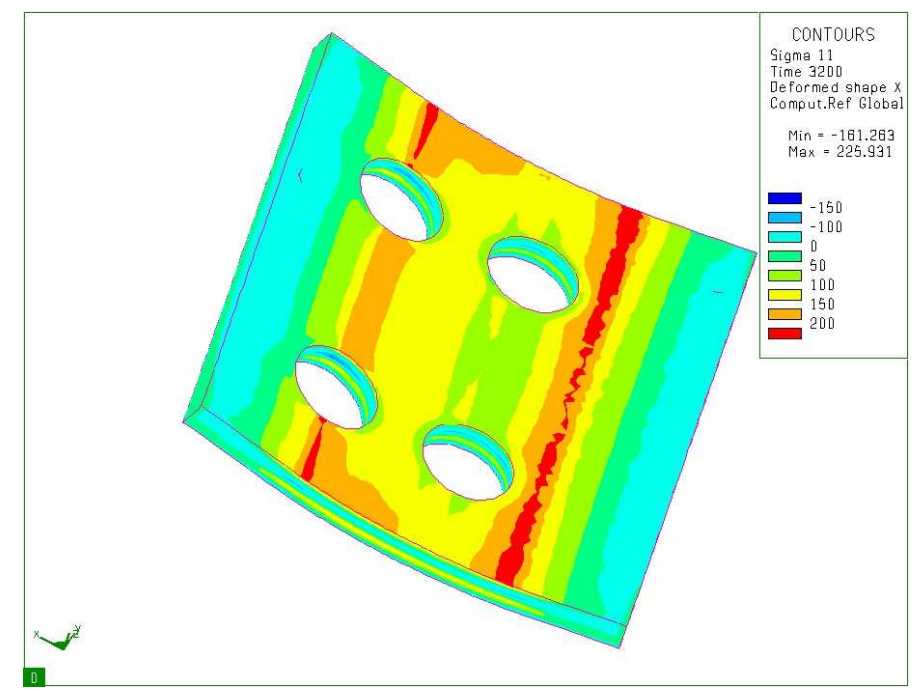

Fig. 2. Sigma 11 distribution at the end of the forming process.

\section{INFLUENCE OF RESIDUAL STRESSES ON THE WELDING DISTORTIONS}

Forming residual stresses are taken into account as initial conditions for the welding simulation of two deformed thick plates. Welding process which involves complex physical phenomena [5] leads to residual stresses in the welded region and global distortions along the components that may have negative effects on the welded structure behaviour in term of strength and displacement margin. Numerical simulations of residual stresses and distortions due to a welding operation need to accurately take into account the interactions between heat transfer, metallurgical transformations and subsequent mechanics loading. In the present investigation, the $316 \mathrm{~L}(\mathrm{~N})$ austenitic stainless steel does not exhibit any phase transformation so the simulation is simplified. The welding simulation could be performed to evaluate the influence of the forming residual stresses on the welding distortions using a local/global approach similar to the one commonly employed to access welding distortions of large assembly [6] but due to the size of the model and its geometry, a classical approach is used [7]. In order to study the influence of forming residual stresses, two simulations are performed: the first on a plate without residual stresses and the second one on a deformed shape with residual stresses. The welding simulations are performed using SYSWELD ${ }^{\circledR}$ software.

The 3D forming simulation has shown little effects of the drilling of the holes on the deformed shape of the plate. As a consequence, only the 2D forming results taking into account the influence of the machining of the over-lengths will be taken as initial conditions for the welding. A first approach is to use a 2D model for the welding simulation and to consider generalized plane strain assumption. This approach has already been validated for tubular structure [8]. Furthermore, the welding simulation is performed on the middle of the plate where the stresses are maximal and only a half of plate is meshed for symmetry reasons $\left(500 \times 60 \mathrm{~mm}^{2}\right)$. Twodimensional linear elements are used and the mesh is refined under the heat source (middle of the plate). Regarding the boundary conditions, the nodes along the weld line are constrained in the Ux direction (symmetrical conditions) and a node at the extremity of the plate is constrained in the Uy direction to stabilize the structure.

The simulation is performed using an electron beam welding process. The first step of the process is the heat input-fitting source. The fitting is validated thanks to a comparison between numerical results on a plane plate $60 \mathrm{~mm}$ thick with experimental results (molten zone size, temperature distribution). The welding simulation can then be performed using this heat source. Figure 3 shows the thermal state at the 
end of the heating. The molten zone is well defined and a difference of width of the molten zone between the upper and lower skins of the plate is also found numerically.

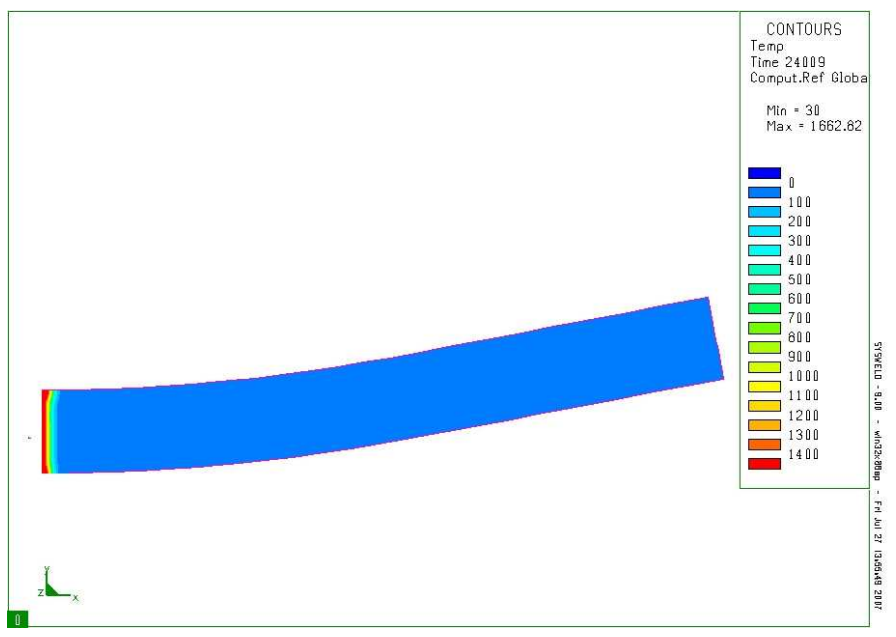

Fig. 3. Thermal state at the end of the heating.

The results of the two simulations (with and without residual stresses) are compared in term of displacements. During the welding, for the two simulations, the plate tends to move towards the convex side. It means that the plate is on flexion.

In term of displacements, the distribution of the Ux and Uy components are identical between the two simulations. The maximum difference of $\mathrm{Ux}$ displacement is of the order of $0.02 \mathrm{~mm}$ at the extremity of the plate and also in the molten zone. The maximum difference of the Uy displacement is of the order of $0.16 \mathrm{~mm}$ and is located in the molten zone (figure 4). There is no variation of the $\mathrm{Uy}$ displacement at the extremity of the plate.

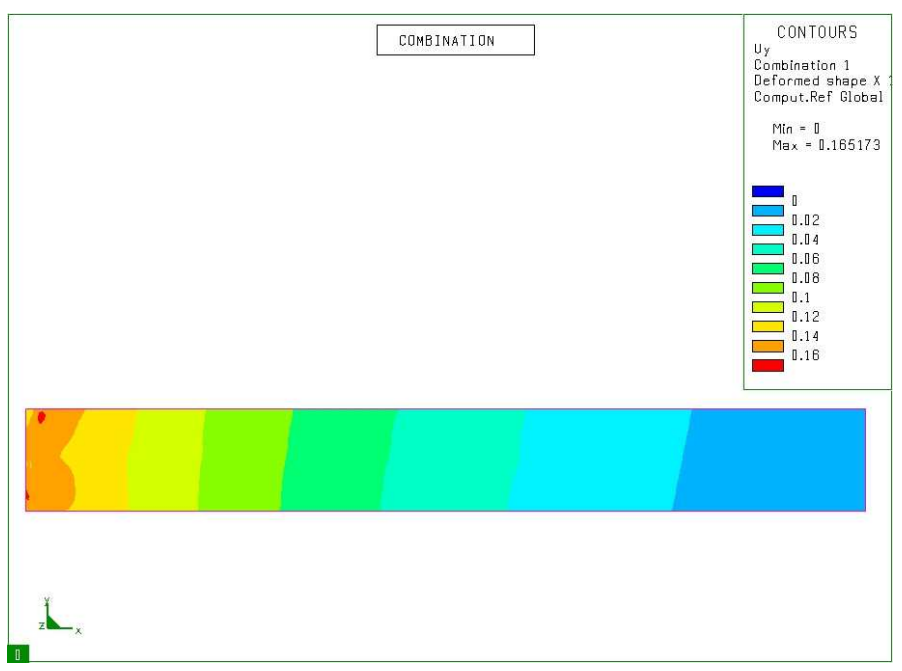

Fig. 4. Difference of UY displacements between the two welding simulation.
To conclude this part, the results show that forming residual stresses have a negligible effect on the distortions induced by the welding process.

\section{CONCLUSION}

Forming residual stresses effects on the welding distortions have been investigated on this paper. The first step was the simulation of the forming process of a thick plate to estimate the residual stresses induced by the forming. Then, the second step was the electron beam welding simulation of two thick plates taking into account the forming residual stresses. The results show a little influence of the residual stresses due to the forming on the welding distortions.

\section{REFERENCES}

1. F. Boitout and J.M. Bergheau, 'The numerical simulation of welding in Europe: present capabilities and future trends', Trans JWRI, 32, No 1, (2003), 197-206.

2. S. Gallée, P.Y. Manach and S. Thuillier, 'Mechanical behaviour of a metastable austenitic stainless steel under simple and complex loading path', Materials Science and Engineering A, 466, Issue 1-2, (2007) 47-55.

3. J.B. Leblond, 'New model with two kinematic variables for steels behaviour during phase transformation', ESI Internal Report, Ref. F/LE/04.5859/A (2004).

4. P.J. Armstrong and C.O. Frederick, Cgeb report $\mathrm{rd} / \mathrm{b} / \mathrm{n}$, 731 (1966).

5. J.B. Leblond, D. Pont, J. Devaux, D. Bru and J.M. Bergheau, 'Metallurgical and mechanical consequences of phase transformations in numerical simulations of welding processes', Modelling in welding, Hot Powder Forming and Casting, chapter 4, edited by Pr Lennart Karlsson, ASM International, (1997) 61-89.

6. B. Souloumiac, F. Boitout and J.M. Bergheau, 'A new local/global approach for the modelling of welded steel component distortions', Graz-Seggau, Austria, October 2001, In: Mathematical Modelling of Weld Phenomena 6, eds H. Cerjak, The institute of Materials, London, (2002) 573-590.

7. V. Robin, J. Devaux, S. Bhandari and J.M. Bergheau, 'Modelling of bimetallic welds', Graz-Seggau, Austria, October 2001, In: Mathematical Modelling of Weld Phenomena 6, eds H. Cerjak, The institute of Materials, London, (2002) 769-791.

8. J. Devaux, G. Mottet, J.M. Bergheau, S. Bandhari, C. Faidy, 'Evaluation of the integrity of PWR bi-metallic welds', ASME J. Pressure Vessel Tech., 122, (2000), 368373. 


\title{
A Simulation of Hollow and Solid Products in Multi-Pass Hot Radial Forging Using 3D-FEM Method
}

\author{
S. Khayatzadeh ${ }^{1}$, M.Poursina ${ }^{2}$, H.Golestanian ${ }^{3}$ \\ 1 Master of Science Student, Khomeinishahr Azad University, 84175-119, Iran. \\ URL: www.iaukhsh.ac.ir e-mail:Saber_Khayatzadeh@yahoo.com; \\ ${ }^{2}$ Assistant Prof., Faculty of Engineering, Shahrekord University, 88186-34141, Iran. \\ URL: www.sku.ac.ir \\ e-mail: Poursina@eng.sku.ac.ir; \\ ${ }^{3}$ Assistant Prof., Faculty of Engineering, Shahrekord University, 88186-34141, Iran. \\ URL: www.sku.ac.ir \\ e-mail: Golestanian@eng.sku.ac.ir;
}

\begin{abstract}
Radial forging is an incremental forming process, where the total deformation is achieved by successive individual forming steps. Most researchers investigating radial forging processes have used axisymmetric models. In this research, multi-pass hot radial forging of short hollow and solid products are investigated using a 3-D finite element simulation. The workpiece is modeled as an elastic-viscoplastic material. Three-pass radial forging of solid cylinders and tube products are simulated. Temperature, stress, strain, and metal flow distributions are obtained in each pass through a 3D thermo-mechanical simulation. Finally, the results of 3D FEM models are compared with results obtained by axisymmetric FEM models from previous work and with available experimental data.
\end{abstract}

Key words: Radial forging, solid forging, mandrel forging, 3-D FEM.

\section{INTRODUCTION}

Radial forging is a hot or cold forging process utilizing two or more radially moving anvils, or hammer dies, to produce solid or tubular components with varying cross section along their length [1]. Radial forging is a cost-effective and material-saving forming process for reducing the round, square and rectangle cross-sections of rods, tubes, and shafts. This process may be performed cold or hot on metals such as steel alloys, titanium alloys, beryllium, tungsten, and high-temperature super-alloys. The properties of products of radial forging include tight tolerances, smooth surface finish, preferred fiber structure, minimum notch effect, and homogenous grains due to full penetration of deformation to the core of the workpiece [2]. The process properties include low energy consumption, considerable material savings, avoiding surface cracks, center bursts, and suck-in at the ends of work piece, and short process cycle times [3]. Radial forging was first developed in Austria in 1946. It was initially used for hot forging of small parts and cold forging of tubes over mandrels [4]. Radial forging is now widely used for reducing the diameter of ingots and bars, forging of stepped shafts and axles, and for producing tubular components with and without internal profiles. The process possesses the capability for virtually chipless manufacturing of rods and tubes to provide precision-finished products. Figure 1 shows the principle of radial forging of rods with a fourhammer radial forging machine. Lahoti et al. [5-6] analyzed the mechanics of radial forging process, RFP, for single and compound angle dies using the slab method. Tzaeng and Kobayashi were the first to model tube forging using finite element method [7]. However their work was based on an isothermal analysis and they assumed that the bore diameter of preform was equal to the mandrel diameter. The visco-plastic finite element model, which accounts for the effect of rate-dependent materials, was found suitable for modeling hot metal-forming processes like hot radial forging. In this study the workpiece is modeled as an elastic-viscoplastic material. A mixture of coulomb law and constant limit shear is applied to simulate the workpiece-mandrel and workpiece-die contact. Three-pass hot radial forging of solid cylinders and tube products are simulated. 
Temperature, stress, strain, and metal flow distributions are obtained in each pass through a 3D thermo-mechanical simulation. Finally, the results of 3D FEM models are compared with results obtained by axisymmetric FEM model of previous work and with available experimental data.

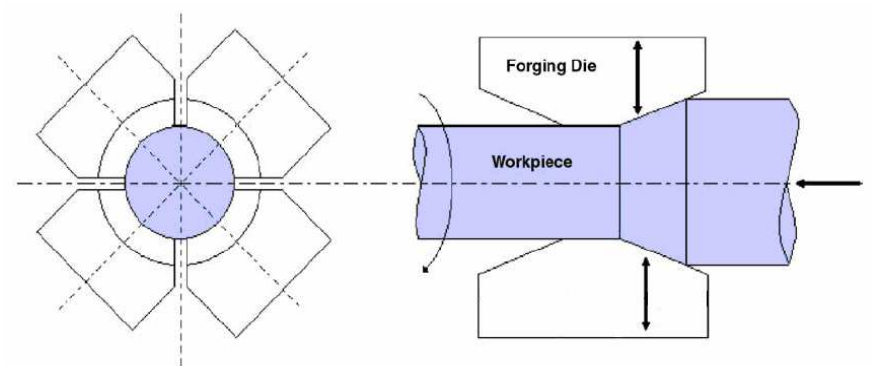

Fig1. The principle of radial forging machines [4].

\section{FEM MODELING}

The radial forging process is characterized by complex cyclic and transient loading conditions. Thus, the FEM model should have the capability to analyze complex deformation and heat transfer for the determination of material flow and deformations. In this study some process parameters such as rotational feed, axial feed, length of stroke and die geometry are considered. The commercial finite element software ABAQUS is used to model the RFP and to determine the thermal effects on deformation of the products. Finite element model for the tube product is shown in figure 2 .

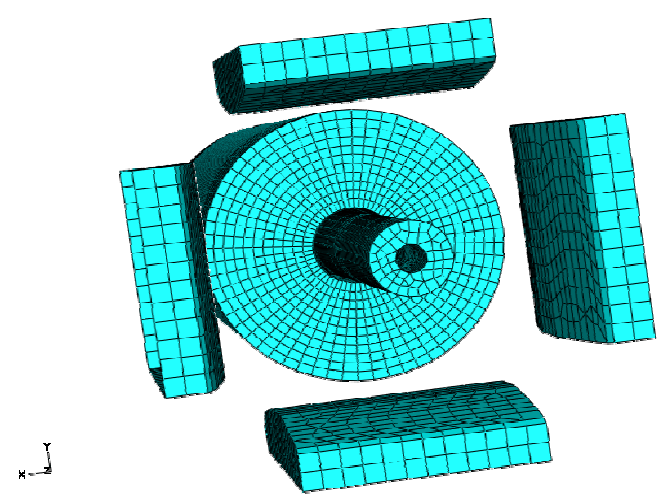

Fig2. FEM Model, hollow Cylinder Forging.

To model the friction in the contact surfaces, a mixing of coulomb law and constant limit shear in which the limiting shear stress is obtained by $m \bar{\sigma} / \sqrt{3}$ was used. In this model $\bar{\sigma}$ is the flow stress and $\mathrm{m}$ is the friction coefficient. Analysis of deformation process depends on many factors such as initial shape of material and dies, rate of deformation, temperature, constitutive equation, friction and so on. In this study to obtain accurate flow stress data for FEM simulations the behaviour of material was determined using the dilatometery test which is one type of hot compression test [8]. The dilatometery tests were performed according to AISI 4337 at four different temperatures of 850, $950,1050,1100^{\circ} \mathrm{C}$. The least square curve fitting on the dilatometery experimental data for material was performed using table-curve-3D software that shows the results were best fitted under Inouye equation of the form:

$$
\sigma=A \varepsilon^{\mathrm{n}} \dot{\varepsilon}^{\mathrm{m}}
$$

The magnitude of the constants $\mathrm{A}, \mathrm{m}$ and $\mathrm{n}$ are given in table 1 .

Table1. Elastic-viscoplastic properties of material.

\begin{tabular}{|c|c|c|c|c|}
\hline Temperature & 850 & 950 & 1050 & 1100 \\
\hline $\mathrm{A}(\mathrm{Pa})$ & $2.63 \mathrm{e} 8$ & $1.54 \mathrm{e} 8$ & $1.36 \mathrm{e} 8$ & $1.095 \mathrm{e} 8$ \\
\hline $\mathrm{n}$ & 0.102 & 0.115 & 0.116 & 0.079 \\
\hline $\mathrm{m}$ & 0.071 & 0.134 & 0.108 & 0.131 \\
\hline
\end{tabular}

Transient heat transfer occurs by radiation, free convection and conduction during deformation in each pass. Also, in hollow forging there is conduction between mandrel and workpiece since mandrel is colder than the workpiece. Two sets of springs in chuck heads, which allow limited movement of workpiece in the axial direction during forging, are considered. Radial velocity of each die was considered to follow that of harmonic or sinusoidal function like a slider crank mechanism. In simulations thermal and mechanical properties of a low alloy steel are used. This process has three passes with each pass having 50 strokes. The dimensions of the workpiece, hammer and mandrel which are used in modeling are given in Table 2.

Table 2. Geometry of workpiece, hammer and mandrel.

\begin{tabular}{|c|c|}
\hline $\begin{array}{c}\text { Length of workpiece } \\
\text { Outer diameter of perform for solid } \\
\text { and hollow }\end{array}$ & $1.6 \mathrm{~m}$ \\
\hline Inner diameter of perform for hollow & $0.54 \mathrm{~m}$ \\
\hline $\begin{array}{c}\text { Outer diameter of product for solid } \\
\text { and hollow }\end{array}$ & $0.15 \mathrm{~m}$ \\
\hline Inner diameter of product for hollow & $0.39 \mathrm{~m}$ \\
\hline Outer diameter of mandrel & $0.13 \mathrm{~m}$ \\
\hline Die land length & $0.13 \mathrm{~m}$ \\
\hline 1st die inlet angle & $6^{\circ}$ \\
\hline 2nd die inlet angle & $8^{\circ}$ \\
\hline Total length of die & $0.68 \mathrm{~m}$ \\
\hline Maximum velocity for die per stroke & $400 \mathrm{~mm} / \mathrm{s}$ \\
\hline Axial feed per stroke & $0.02 \mathrm{~m}$ \\
\hline Rotational feed per stroke & $12^{\circ}$ \\
\hline
\end{tabular}




\section{RESULTS}

In this section the results of this investigation will be presented. It should be noted that only the important results will be discussed due to space limitation. The maximum effective plastic strain of hallow and solid forged products at the end of each pass are shown in figure 3.

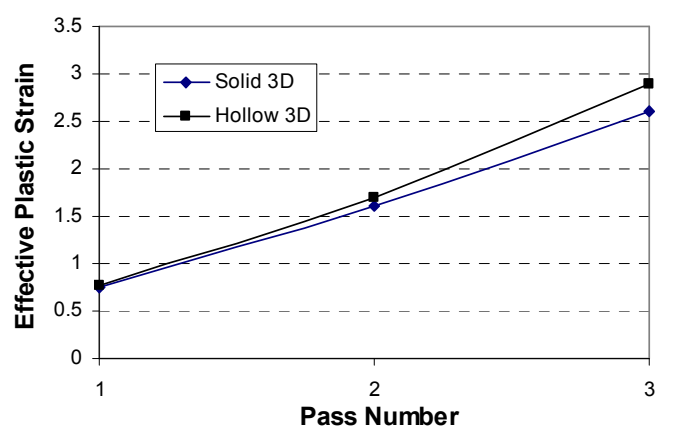

Fig3. Maximum effective plastic strain of products at the end of each pass

As can be seen in this figure the maximum effective plastic strain increases by increasing the number of passes. Figure 4 shows the effective plastic strain distribution after the third pass. According to this figure the tube product has a more uniform strain distribution compared to the solid cylinder. These results can be verified experimentally by cutting some samples along the workpiece and macro etching them. Figure 5 shows the results of such experimental observations. Flow pattern in the hollow and the solid cylinder products after macro etching can be seen in this figure [3]. The compacted flow pattern in figure $5 \mathrm{~b}$ indicates the penetration of material deformation through out the tube product thickness.

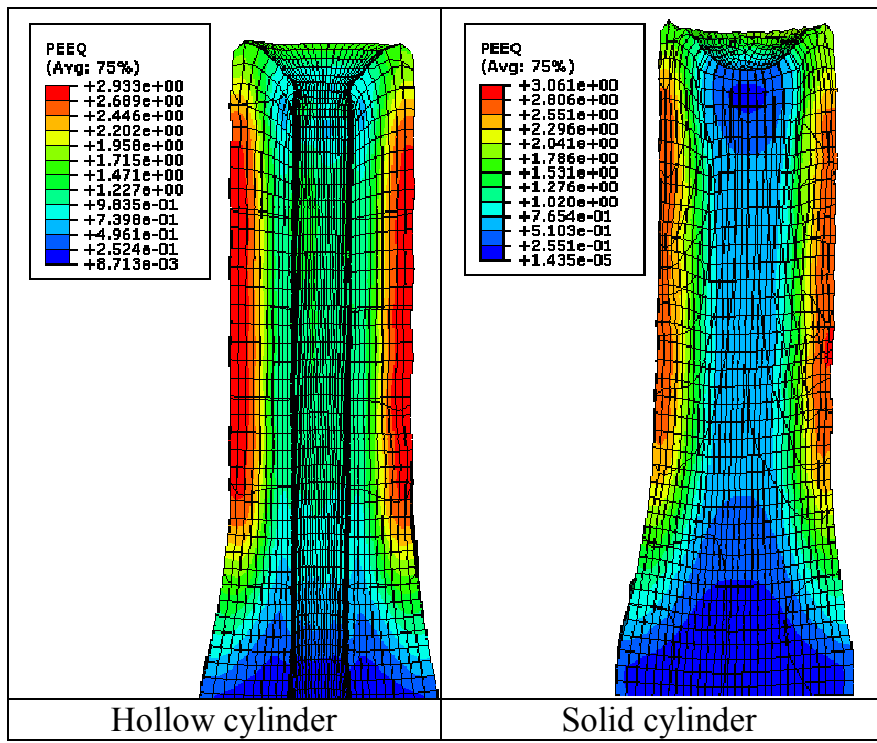

Fig4. Effective plastic strain distribution of products after third Pass.

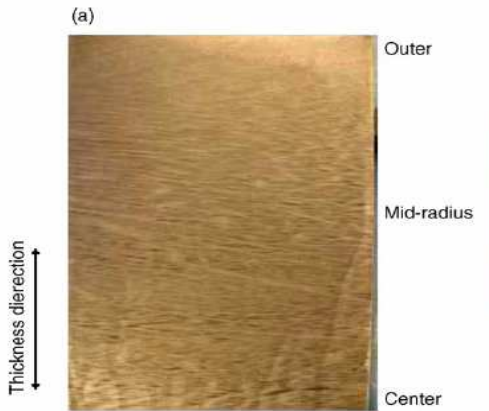

Fig5. The flow pattern of tube and cylinder forged product.

a) Solid Cylinder, b) Hollow Cylinder.

Figures 4 and 5 show that the maximum deformation of the tube occurs at the inner and outer surfaces. Figure 6 shows the comparison between the results obtained from axisymmetric and 3D FEM simulations. As can be observed in this figure the trend of both results is similar and indicates an increase in the maximum equivalent plastic strain by increasing the number of passes.

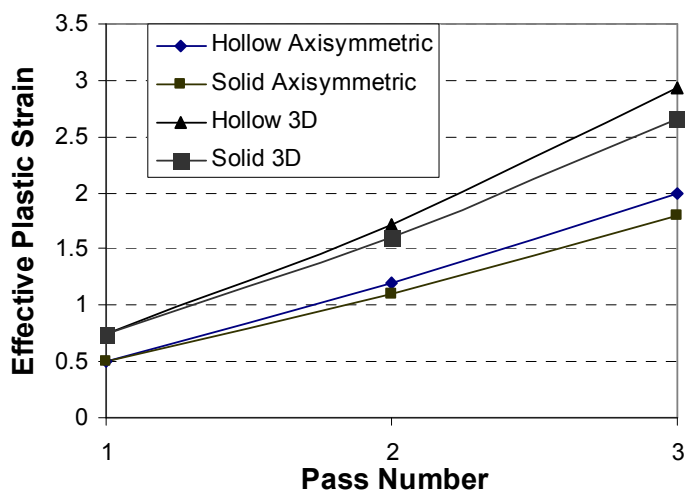

Fig6. Comparison of the maximum equivalent plastic strain through axisymmetric and 3D FEM simulations.

Temperature distribution is as important as strain distribution in the final product properties. Temperature distributions in the solid and tube products after each pass are shown in figure 7.

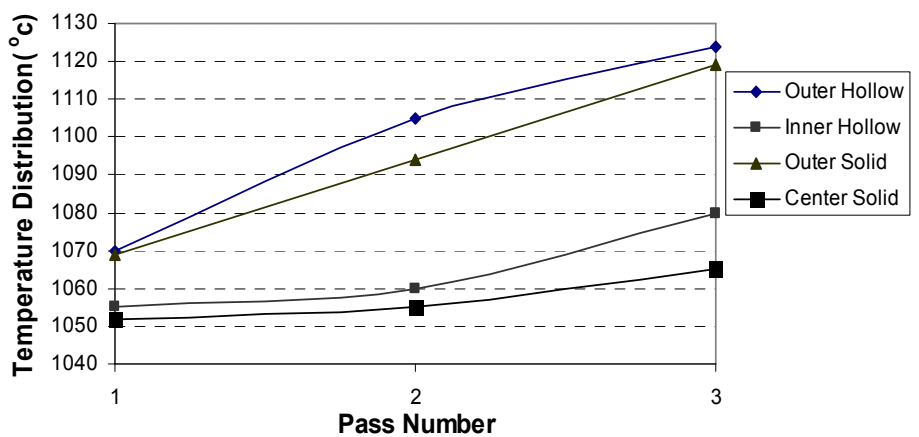

Fig7. Temperature distribution of products after each pass.

In order to manufacture products with improved properties, the temperature gradient should be as low as possible. As shown in this figure temperature gradient in the cylinder is higher than in the tube due 
to lower heat transfer in the solid cylinder. This temperature gradient leads to a non-uniform microstructure.

Figure 8 shows the temperature distributions in the products from the axisymmetric models. Through thickness temperature gradients can be observed in the products at higher number of passes.

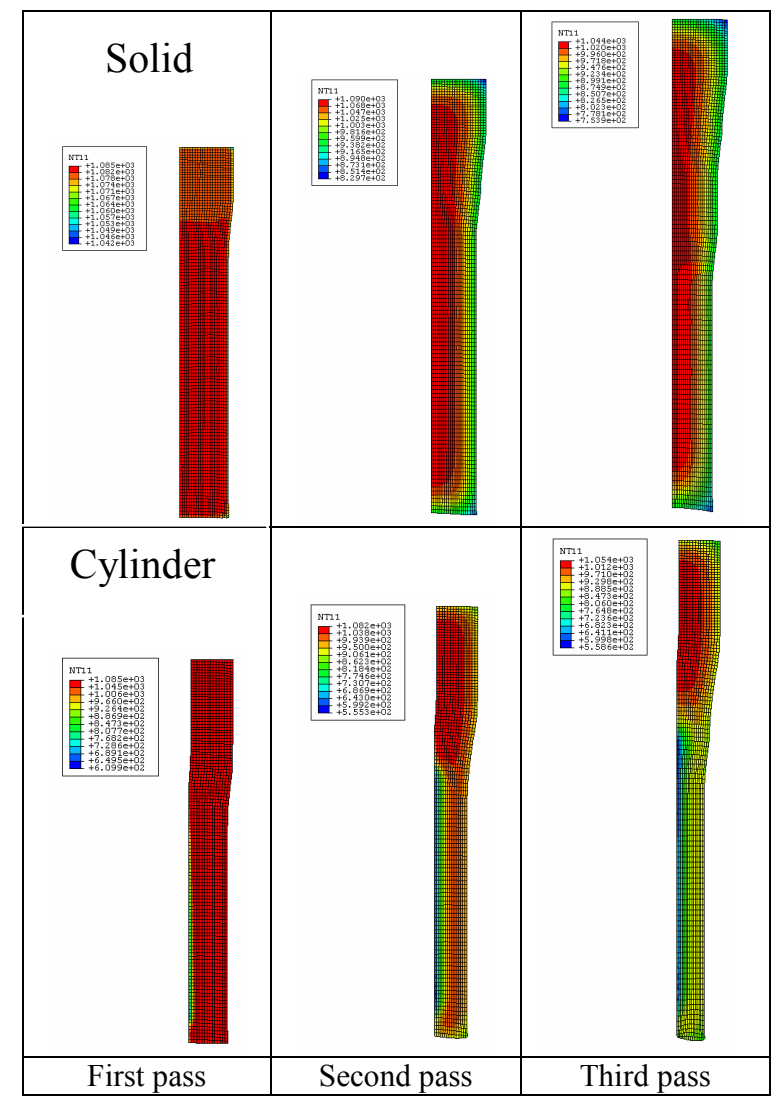

Fig8. Temperature distributions of products after each pass through axisymmetric simulation.

\section{CONCLUSIONS}

In this paper, the feasibility of using ABAQUS/explicit FEM package to model the radial forging of tubes and cylinders was investigated. Models were developed to determine material flow and temperature fields in RFP. The following conclusions were made based on the current investigation.

1. Deformations in the final tube product are larger and are more uniform than in the solid cylinder.
2. By increasing the number of passes, more uniform products can be produced.

3. Deformations at the outer and inner surfaces of the tube are larger than within the wall thickness.

4. There is a deformation gradient through the thickness of solid cylinder. The outer surface of the solid cylinder is more deformed than center.

5. Material properties are the same along the axial direction in both the tube and the solid cylinder.

6. The temperature gradient in the solid cylinder is higher than in the tube product. This results in more uniform material properties in tube products.

7. The highest components of stress and strain occur along the axial direction which causes improved properties along this direction.

\section{REFERENCES}

1. Ghaei and M.R. Movahhedy, die design for the radial forging process using 3D FEM, journal of material processing technology 187(2007) 534-539.

2. G.D.Lahoti, and T. Altan, Analysis and optimization of the radial forging process for gun barrels, U.S. Army Report, September 1974,p.12

3. Abedian A., Poursina M. and Golestanian H, "A Comparison between the Properties of Solid Cylinders and Tube Products in Multi-Pass Hot Radial Forging Using Finite Element Method", NUMIFORM 2007, Porto, Portugal, June 17- 21, pp.963-968.

4. Metals handbook, ninth edition, volume 14, forming and forging

5. G.D. Lahoti, P.V. Dembowski, T. Altan, Radial forging of tubes and rods with compound-angle dies, in: Proceeding of NAMRC-IV, May 17-19, Columbus, OH, 1976, pp. 87-98.

6. G.D. Lahoti, T. Altan, Analysis of the radial forging process for manufacturing of rods and tubes, ASME J. Eng. Ind. 98 (1976) 265-271.

7. T.C.Tszeng and S.Kobayashi, Determination of residual stresses in radial forging, Manufacturing Processes Simulation, PED-20, (1986) 31-45.

8. M. Poursina, H. Ebrahimi, J. Parvizian, Flow stress behavior of two stainless steels: An experimentalnumerical investigation. Journal of Material Processing Technology 199 (2008) 287-294.

9. A. Ghaei, A.K. Taheri, M.R. Movahhedy, A new upper bound solution for analysis of the radial forging process, Int. J. Mech. Sci. 48 (2006) 1264-1272. 


\title{
A Virtual Inspection Technique for Assessing the Dimensional Accuracy of Forged Compressor Blades Using FE Modeling and CMM Inspection
}

\author{
J. Makem ${ }^{1}$, H. Ou ${ }^{1}$, C.G. Armstrong ${ }^{1}$, A. Rennie ${ }^{2}$, S. Nikov². \\ ${ }^{1}$ School of Mechanical \& Aerospace Engineering, Queen's University, Belfast, Ashby Building, Stranmillis \\ Road, Belfast, UK. BT95AH. \\ URL: $\underline{w w w . m e . q u b . a c . u k}$ \\ e-mail:jmakem01@qub.ac.uk;.h.ou@qub.ac.uk
}

${ }^{2}$ Rolls-Royce plc, $U K$.

URL: $\underline{w w w . r o l l s-r o y c e . c o m}$

ABSTRACT: This paper presents research for developing a virtual inspection system that evaluates the dimensional tolerance of forged aerofoil blades formed using the finite element (FE) method. Conventional algorithms adopted by modern coordinate measurement processes have been incorporated with the latest freeform surface evaluation techniques to provide a robust framework for the dimensional inspection of FE aerofoil models. The accuracy of the approach had been verified with a strong correlation obtained between the virtual inspection data and coordinate measurement data from corresponding aerofoil components.

Key words: Forging, Finite Element, Coordinate Measurement, Dimensional Inspection.

\section{INTRODUCTION}

The high demand for manufacturing quality and optimum performance of components within the aerospace industry requires parts to adhere to the relevant geometrical and dimensional specifications. Consequently, components are inspected to evaluate their dimensional tolerance. In particular, the dimensional inspection of complex parts comprising free-form geometry, such as aero-engine blades, is becoming increasingly important due to the requirement for higher precision and efficiency. Generally, the objective behind the majority of inspection techniques is to determine if the part meets a set of specific design criteria by assessing the deviation between the manufactured part and the nominal model.

For quality assurance purposes, high precision dimensional measurement techniques are employed to evaluate the dimensional tolerance of compressor blades. The contact inspection process of coordinate measurement is one of the most effective measurement techniques, providing both high accuracy and repeatability. The process employs a computer controlled coordinate measurement machine $(\mathrm{CMM})$ to inspect the part automatically by moving a tactile probe along the work-piece surface, to measure the coordinates of individual contact points.

Compressor blades are manufactured using the closed die hot forging process. The major contributors to dimensional and shape errors in forged aerofoil components are press and die elasticity during forging, material spring back and thermal distortion at the cooling stage [1]. Due to the complexity of the hot forging process, forging design practice is largely based on the trial and error approach [2]. These forging trials employ a direct compensation approach which involves modifying the die shape by a fraction of the measured forging tolerance until the blade dimensions are within the allow limits.

The finite element (FE) method has been used successfully to simulate the forging of compressor blades [3]. By accurately predicting material deformation, stress/strain rate distribution and temperature change in hot forging, the FE method may be used to quantify the forging tolerances and optimise the die shape, removing the need for experimental testing and thereby reduce the 
overall development timescales and costs. Consequently, as the FE error governs die shape modification, it's necessary to assess the dimensional accuracy of the forged components produced in simulation by comparison with coordinate measurement data from actual aerofoil sections. Thus, to gain an accurate comparison between the FE generated error and that quantified using the CMM, the FE error must be evaluated using a similar approach to that employed by the coordinate measurement process.

This paper presents a virtual inspection approach used for the validation of an FE blade forming simulation. The developed system provides a fully automated tool for dimensional inspection in a virtual environment. A robust framework has been developed incorporating various iterative algorithms to register the FE model in relation to a CAD nominal and generate inspection data for comparison with CMM measurements on a real part. It will be shown that a strong correlation exists between simulated and real parts, verifying the validity of the approach.

\section{BLADE INSPECTION}

The process of aerofoil inspection via CMM comprises three main stages, including; part localisation, blade section inspection and finally blade parameters analysis [4]. A unique coordinate system can be established by defining six datum points on the blade. The blade sections are then measured using a two stage process involving an initial rough measurement of each section followed by a more accurate assessment of the profile in fine measurement mode. Finally, after the measurement data for each blade section has been correctly aligned with the respective nominal profile, blade parameters and profile tolerances may be evaluated.

\subsection{Part localisation}

The process of localisation, also known as registration, mathematically locates the part prior to inspection by determining a rigid body $3 \mathrm{D}$ coordinate transformation between the design coordinate system (DCS) and the measurement coordinate system (MCS). For aerofoil inspection, the 3-2-1 method or six point principle is commonly used to determine the MCS [5]. Firstly, the primary datum plane is determined by three points on the free-form concave surface of the blade, including $K_{1}$ and $K_{5}$ on the root section and $K_{3}$ on the tip section. The secondary datum plane is constructed using the central axis of cylindrical features at each end of the blade, defined by $P_{1}$ and $P_{2}$. Finally, the tertiary datum plane, orthogonal to both datum planes is determined using the last datum point, $K_{P}$, located on the root block. Finally, both coordinate systems are then aligned via rigid body transformation. The position of the datum points on a nominal blade model is shown in figure 1 .

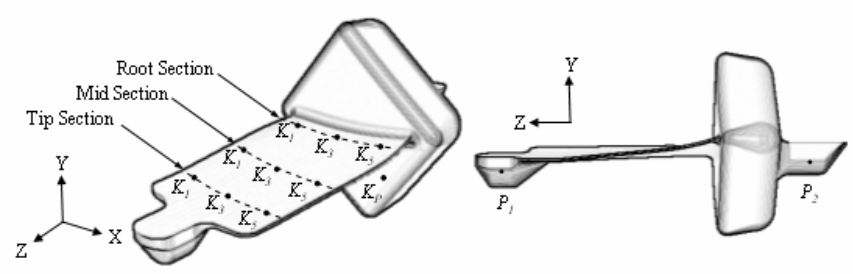

Fig. 1 Datum point locations on nominal blade model.

\subsection{Blade measurement}

The coordinate measurement process employs a contour measurement mode, where each blade profile was measured at a constant height ( $\mathrm{z}$ coordinate). CMM data is recorded at three sections along the blade for both concave and convex surfaces. Each section is defined by six datum points ( $K$ points) around the profile of the component. A two stage process involving a rough and fine measurement mode is used to evaluate each section.

\subsection{Blade parameters analysis}

Once the profiles of each section have been obtained, a tolerance evaluation algorithm is implemented whereby the convex and concave profiles for each section are positioned with respect to the corresponding nominal profile. The shape tolerance is then represented in the form of a plot comparing the nominal and measured profiles. Also, the thickness, $\delta_{1}$, bow, $\delta_{2}$ and twist, $\delta_{3}$ deviation are evaluated at the relevant $K$ point stations, as shown in figure 2 .

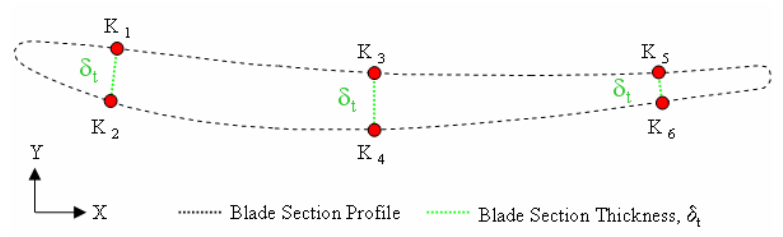

(a)

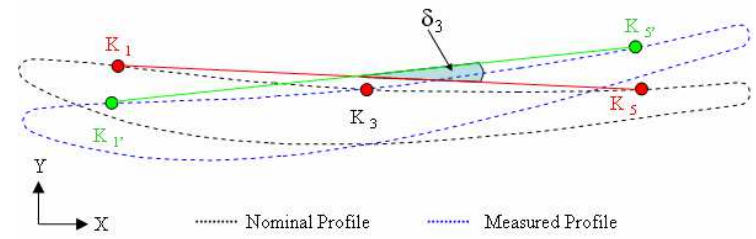

(b)

Fig 2.Defintion of (a) section thickness \& (b) twist deviation. 
$\delta_{1}$ and $\delta_{2}$ are calculated using equations 2 and 3 .

$$
\begin{aligned}
& \delta_{t}=\sqrt{\left(x_{K_{C C}}-x_{K_{C V}}\right)^{2}+\left(y_{K_{C C}}-y_{K_{C V}}\right)^{2}} \\
& \delta_{1}=\delta_{t}{ }^{\prime}-\delta_{t} \\
& \delta_{2}=y_{K 3^{\prime}}-y_{K 3}
\end{aligned}
$$

where $\delta_{t}{ }^{\prime}=$ measured thickness and $\delta_{t}=$ nominal thickness.

\section{VIRTUAL INSPECTION SYSTEM}

The main programming languages employed in the development of this software were Python and MATLAB. Figure 3 shows the basic structure of the virtual inspection framework.

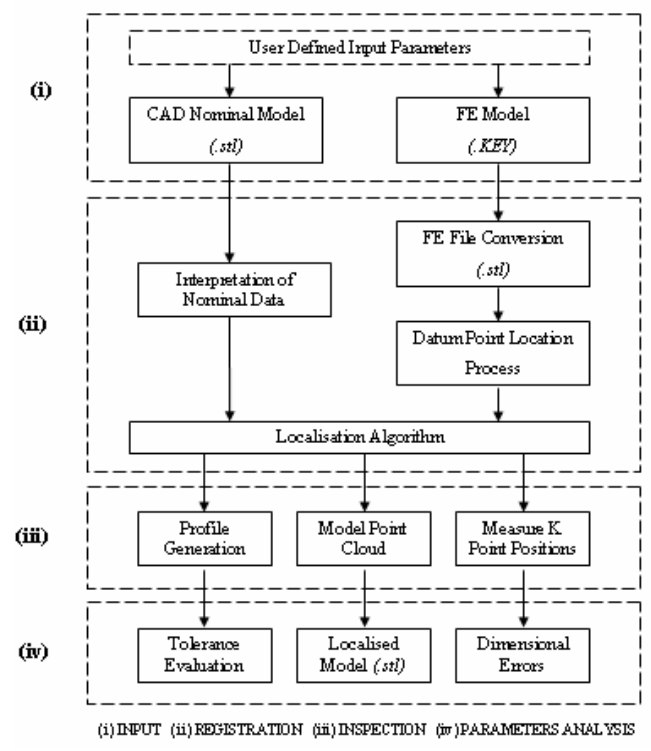

Fig 3. Structure of virtual inspection system.

\subsection{Component registration}

To initiate localisation, datum points were firstly identified on the blade formed from the FE forging simulation. As the initial position of the blade was in roughly close proximity to the nominal coordinate system due to constraints applied in the FE simulation, no preliminary transformation process was required. An initial estimate of the position of datum points $K_{1}, K_{3} \& K_{5}$ shown in figure 1 were found via interpolation from profiles generated by intersecting the FE mesh at the tip and root sections. Subsequently, using the rules of orthogonality and sequence for datum frame construction [6], the secondary datum was established by estimating the location of $P_{1}$ and $P_{2}$. This was achieved by fitting the nodal coordinates situated on each cylindrical surface according to the least squares principal. Thus, after identifying the respective point clouds using a shape recognition algorithm, each dataset was submitted to the least squares calculation which yielded the coordinates of the datum points on the respective cylinder axes.

After locating the position of five datum points, the normal vectors, $\vec{p}, \vec{s}^{\prime}$ and $\vec{t}^{\prime}$ of the respective datum planes in the MCS were determined using equations $4-6$.

$$
\begin{aligned}
& \vec{p}^{\prime}=\left(K_{5}-K_{1}\right) \times\left(K_{3}-K_{1}\right) /\left|\left(K_{5}-K_{1}\right) \times\left(K_{3}-K_{1}\right)\right| \\
& \vec{s}^{\prime}=\left(P_{2}-P_{1}\right) \times \vec{p}^{\prime} /\left|\left(P_{2}-P_{1}\right) \times \vec{p}^{\prime}\right| \\
& \vec{t}^{\prime}=\left(\vec{p}^{\prime} \times \vec{s}^{\prime}\right) /\left|\vec{p}^{\prime} \times \vec{s}^{\prime}\right|
\end{aligned}
$$

According to the sequence rule in datum setting, the first stage of the localisation involves aligning the components primary datum plane with that of the nominal. This was achieved by aligning $\vec{p}$ with $\vec{p}$, the direction cosine of the primary datum in the DCS. This first transformation was decided by a translation and two rotations in sequence. The second phase involved alignment of the secondary datum planes by rotation about $\vec{p}$. Finally, to align the tertiary datum planes, a single translation, $T$, between the two coordinate frames was applied. The entire transformation is represented by:

$$
X_{1}=R(\beta) R(\theta, \alpha) X_{m}+T
$$

where $R(\theta, \alpha)=$ rotational matrix for angles $\theta$ and $\alpha$ to align $\vec{p}^{\prime}, R(\beta)=$ rotational matrix for angle $\beta$ to align $\vec{s}^{\prime}$ and $X_{m}=$ point on unregistered part.

This localisation process was repeated iteratively until the discrepancy between the datum points on the blade and the corresponding points on the nominal were within a desired tolerance.

\subsection{Comparative analysis and part validation}

The measurement data was generated by intersecting the aerofoil surface at the respective $K$ point sections using the method described. The section thickness was measured at the $K$ point locations. Also, the bow deviation was recorded at the mid section, as well as the twist deviation at the mid and tip sections. To evaluate the profile tolerance, an additional alignment procedure based on an iterative closest point algorithm was required to fit the relative profile data to the respective nominal curve. The approach uses a least squares minimisation technique that iteratively estimates the transformation parameters between the respective data sets [7]. 


\section{RESULTS and DISCUSSION}

A contour plot displaying the results of the localisation process is shown in figure 4 .

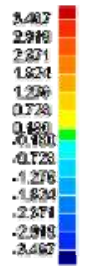

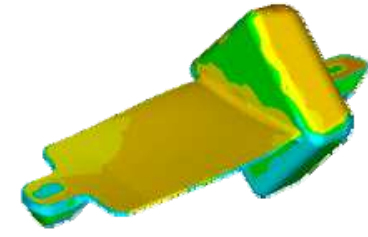

(a) Before Localisation

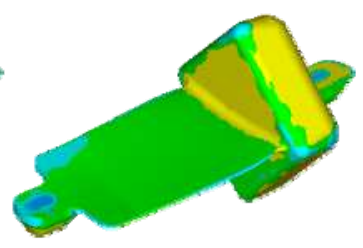

(b) After Localisation
Fig. 4 Deviation between Nominal \& Forged Component

The registration algorithm effectively locates the blade using the iterative six point approach. The deviation between the nominal and the FE model has been dramatically reduced in this area.

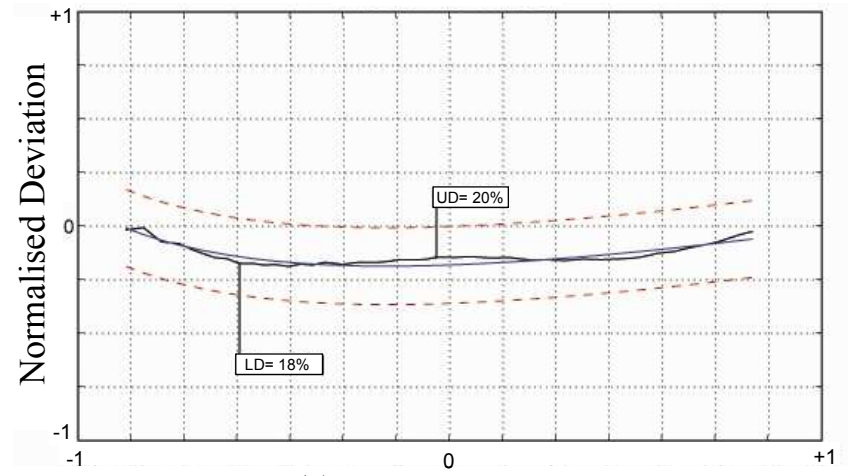

(a) Horizontal Axis

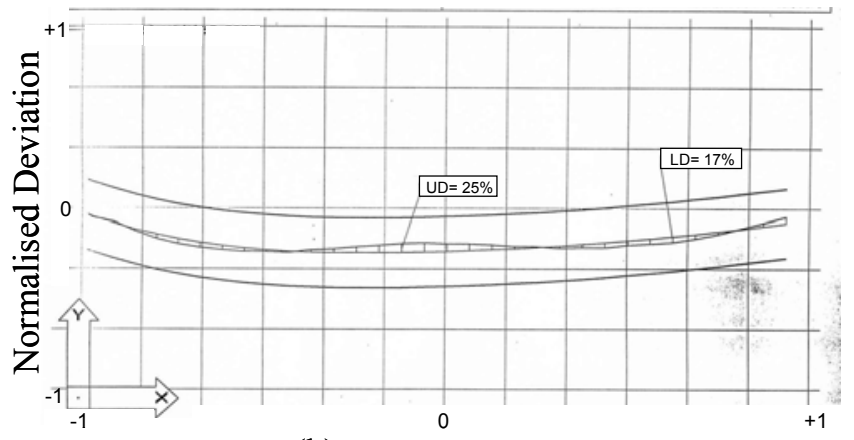

(b) Horizontal Axis

Fig. 5 Comparison between Normalised

(a) FE and (b) CMM Mid Convex Profile Deviation

A strong correlation exists between the FE results measured using the virtual system and the actual form measurements. In particular, the data recorded at the mid convex section displays the strongest correlation with a discrepancy of less than $18 \%$ between the maximum profile deviations, as shown in figure 5. Generally, only small discrepancies between the virtual and actual CMM results for both twist and bow deviation were apparent. The virtual measurement of bow deviation differed by approximately $0.01 \mathrm{~mm}$ in comparison the CMM result, whereas a maximum difference of $0.2^{\circ}$ in twist deviation was recorded at the tip section.

In terms of the thickness deviation measurements, values recorded at the root and mid sections are reasonably consistent with CMM values. However, slightly larger discrepancies are apparent at the tip which may be attributed to the inability of the FE method to accurately simulate the deformation in this region.

\section{CONCLUSIONS}

The virtual inspection system provides a complete, robust procedure for the dimensional inspection of forged aerofoil blade models formed using the finite element method. The localisation process used by the system accurately registers the component with the nominal model. The inspection and parameters analysis modules incorporate various iterative algorithms and the latest evaluation techniques to successfully quantify the forging tolerance to within a high degree of accuracy. The strong correlation between measurements generated from this system and actual CMM measurement data, validates the approach as an effective means to quantify the forging tolerance using the coordinate measurement process in a virtual environment.

\section{ACKNOWLODGENTS}

The authors wish to thank the Engineering and Physical Sciences Research Council ESPRC and Rolls-Royce plc for funding and support of the present research (EP/C004140/1).

\section{REFERENCES}

1. Ou H., Lan J., Armstrong C.G., Price M.A., Walloe S.J., Ward M.J., 'Reduction in post forging errors for aerofoil forging using finite element simulation and optimisation'. Modelling Simul.Mater.Sci.Eng, 14, (2006) 179-193

2. Ou H., Armstrong C.G., Price M.A., 'Die shape optimisation in forging of aerofoil sections'. Journal of Materials Processing Technology, 132, (2003) 21-27

3. Hartley P., Pillinger I., 'Numerical simulation of the forging process'. Comput Methods APPL Mech Eng, 195, (2006) 6676-6690

4. Hsu T., Lai J., Ueng W.E., 'On the development of airfoil section inspection and analysis technique'. Int. Journal of Adv Manuf Technol, 30, (2006) 129-140

5. Hsu T., Lai J., Ueng W.E., Hwang J., 'An iterative coordinate setup algorithm for airfoil blades inspection'. Int J Adv Manuf Technol, 26, (2005) 797-807

6. Huang X., Gu P., 'CAD-model based inspection of sculptured surfaces with datums'. Int Journal of Production Research, 36, (1998) 1351-1367

7. $\mathrm{Li}$ Y., Gu P., 'Free-form surface inspection techniques state of the art review'. Journal of Computer-Aided Design, 36, (2004) 1395-1417 


\title{
Multiaxial fatigue criterion accounting for anisotropy in forged components
}

\author{
M. Milesi ${ }^{1}$, Y. Chastel ${ }^{1}$, M. Bernacki ${ }^{1}$, R.E. Logé ${ }^{1}$, P.O. Bouchard ${ }^{1}$
}

\author{
${ }^{1}$ CEMEF - Centre de Mise en Forme des Matériaux, Ecole Nationale Supérieure \\ des Mines de Paris B.P. 20706904 Sophia-Antipolis Cedex \\ URL: www-cemef.cma.fr \\ e-mail: marc.milesi@ensmp.fr; marc.bernacki@ensmp.fr; roland.loge@ensmp.fr; \\ pierre-olivier.bouchard@ensmp.fr
}

\begin{abstract}
Numerical modelling of fatigue behavior for anisotropic structures has become critical for design applications. This is particularly true for forged components due to the intrinsic anisotropy of the material resulting from the process. The aim of this study is to relate the microstructure scale to the process scale, i.e. the engineer scale. Anisotropy induced by the forming process and the most relevant feature which results from forging, is the preferential orientation of structural defects and grains in the direction of the deformation. Grain flow is modelled using a fiber vector at the level of the representative elementary volume. It can then be used to improve and refine the Papadopoulos fatigue criterion by taking into account fatigue limits for each direction of anisotropy. In practice, it is very tedious to determine precisely these fatigue limits and impossible to obtain experimentally all of them for each direction of uniaxial loading. To circumvent this difficulty, we simulate the problem at the microstructure scale by considering fiber vector as the result of the inclusion and grain orientation. Microstructures are then precisely modelled using DIGIMICRO software. A representative elementary volume including inclusions is meshed and high cycle fatigue simulation is performed. The results can be used in order to optimize the preform of the component before simulation.
\end{abstract}

KEYWORDS: High Cycle Fatigue Multiaxial Criterion - Fiber Vector - Digital Material - Multiscale approach

\section{INTRODUCTION}

Among all forming processes, forging gives raise to the most resistant components withstanding a large number of loading modes. However, forging induces a strongly heterogeneous microstructure in the material. High mechanical properties of such material are directly related to this heterogeneity or anisotropy. The problem is the numerical representation of this anisotropy. In practice, high cycle fatigue simulations are performed without accounting for the past of the component and even less anisotropy. In most cases, only geometric form and residual stresses stemming from the process are used. Therefore, it is necessary to adapt traditional high cycle fatigue criteria which were developed assuming isotropy to anisotropic material behavior configurations. Thus, the ANR (French National Research Agency) Optiforge project was launched. Its goal is to account for the forming process and its effect on the microstructure to perform high-cycle fatigue studies. A virtual simulation chain is created between the forming process and the microstructure history. The Papadopoulos criterion [5] was finally chosen to develop a microstructure scale approach based on forging characteristics. A representative elementary volume is meant to describe explicitly the shape and orientation of both inclusions and grains. This microstructure study is performed using the DIGIMICRO software [1]. Figure (1) sums up the objectives of this project.

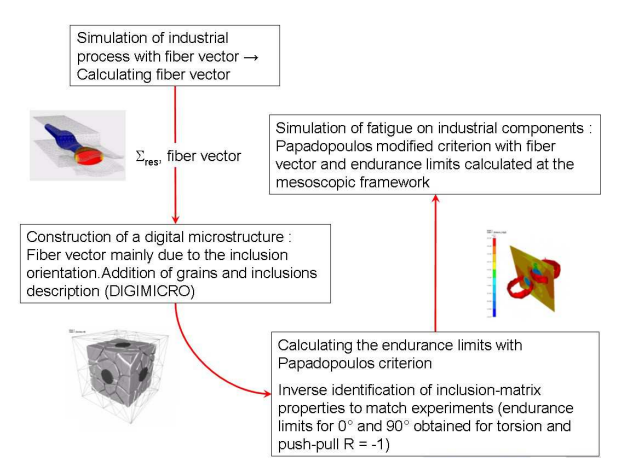

Figure 1: Objectives of the project 


\section{CHARACTERISTICS OF A FORGING PRO- CESS}

Forging processes induce, inevitably, high level of deformation giving raise to anisotropy of the components. Indeed, due to the reduction of the section, the matter follows the deformation. This phenomenon is also called grain flow orientation. The extension and the orientation of the matter is directly related to the kneading rate undergone by the matter. The kneading $K_{n}$ is defined by the ratio of the initial section $S_{0}$ over the final section S: $K_{n}=S_{0} / S$.

The fiber vector is given by the definition of the gradient tensor $\underline{\underline{F}}$ given by (1):

$$
\underline{\underline{F}}=\underline{\underline{I}}+\underline{\underline{G r a d}} \underline{X}=\underline{\underline{R}} \underline{\underline{U}}=\underline{\underline{V}} \underline{\underline{R}},
$$

where $\mathrm{I}$ is the unit tensor, $\mathrm{X}$ is the displacement vector, $\underline{\mathrm{R}}$ is an orthogonal orientation tensor, $\underline{\mathrm{V}}$ and $\underline{\mathrm{U}}$ are symmetric positive tensor named respectively left distortion and right distortion. This is the polar decomposition of $\mathrm{F}$.

The vector is given by:

$$
d \underline{X}=\underline{\underline{F}} d \underline{X_{0}},
$$

where $d \underline{X}$ is the current position and $d \underline{X_{0}}$ is the initial position. For instance, figure (2) shows a cambering process with an initial grain flow orientation along the rod.

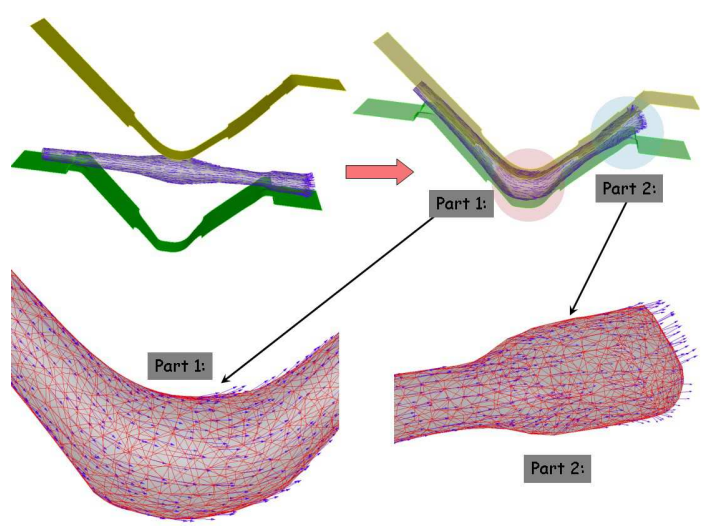

Figure 2: Flow orientation for a cambering process

\section{THE CRITICAL PLANE APPROACH FOR FA- TIGUE CRITERIA}

Standard high cycle fatigue criteria are determinist criteria, which means that for a calculated stress field and intrinsic parameters of the material, they provide a unique domain of validity. For most criteria, this domain is defined using a critical line in a specific space. This is the case of the Papadopoulos criterion [5]. The main idea consists in splitting a given structure into many sub-volumes which could be considered as representative elementary volumes (figure 3 ). Then, the maximum stress over a complete loading cycle is computed to determine when the structure breaks up.

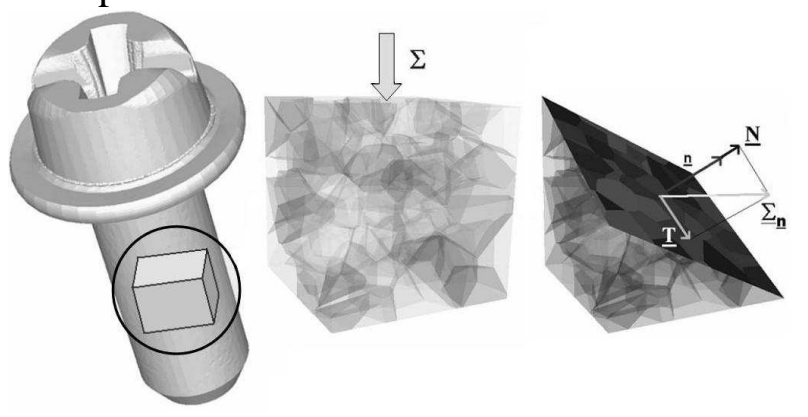

Figure 3: Schematics of a Representative Elementary Volume (R.E.V.)

To calculate this critical stress level for each R.E.V., it is assumed that an adapted state (or shakedown state) with a purely elastic behavior at the grain level, has been reached. Indeed, at the macroscopic level, the structure might be seen as undergoing an elastic loading but, locally, at the microscopic level, it may be possible that one or several grains are unfavorably oriented, thus leading to a local plastic behavior. This adapted state is reached after a few cycles (typically about 1000 cycles). Figure (4) shows the progressive stabilization at the microstructure level; $\Sigma$ is the macroscopic stress, $\sigma$ is the microscopic stress (for each grain), E is the macroscopic and $\epsilon$ the microscopic strain obtained from the Lin-Taylor approach. If no shakedown state can be reached, a crack is initiated at the microscopic level; it will lead to a macroscopic crack after some cycles. If $\Sigma_{n}$ is the stress applied onto a cross section (plane of normal $\underline{n}$ ) of the representative elementary volume (figure 3 ), its projection onto the plane is the shear stress $\mathrm{T}$. The goal of these criteria is to investigate iteratively many different plane orientations in order to find the maximum value of the shear stress. Moreover, the effect of the hydrostatic stress $\left(\sigma_{i i} / 3\right)$ has to be added [8]. The secure domain is defined by:

$$
T_{\Sigma}+\alpha \Sigma_{H, \max } \leq \beta,
$$

which defines a linear domain as seen in figure (5). If the curve described by the shear stress projected onto the critical plane is below a line so-called threshold, there is no initiation of macroscopic crack (figure 5). Generally, $T_{\Sigma}$ is the $\max _{\underline{n}} \max _{t \in[0, P]} \underline{\mathrm{T}}$ value on 
the critical plane where $\mathrm{P}$ is the loading period and $\Sigma_{H, \max }$ is the maximum hydrostatic stress over the loading cycle [4]. Coefficients $\alpha$ and $\beta$ are deduced from two reference fatigue limits (with a stress load ratio $R=\sigma_{\min } / \sigma_{\max }=-1$ ) from tension $\boldsymbol{s}$ and torsion $t$ data:

$$
\alpha=\frac{\boldsymbol{t}-\frac{s}{2}}{\frac{s}{3}}, \beta=\boldsymbol{t}
$$

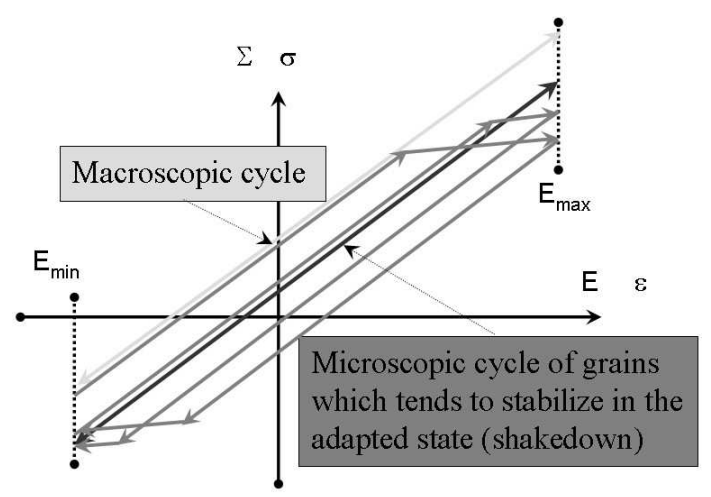

Figure 4: Macroscopic behavior of the structure and microscopic behavior of a grain misoriented which undergoes a plastic deformation

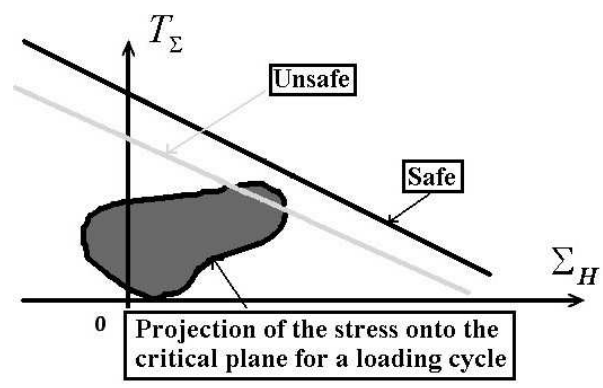

Figure 5: Threshold domain for a determinist fatigue criterion

Standard high cycle fatigue criteria predict efficiently the failure of an isotropic component (like casting component) but they are not reliable for forged components due to anisotropy.

\section{THE NEED FOR A MESOSCOPIC APPROACH}

The only means to perform a more trustworthy simulation is to take into account the microstructure. Indeed, most of fatigue cracks appear in the vicinity of an inclusion, especially for hard materials. In fact, the resistance to a high cycle fatigue uniaxial loading is very different for two materials composed with approximately the same constituents but with a different number of inclusions [7]. Generally, the resistance is lower for the material containing more inclusions. Moreover, the endurance limit is higher in the direc- tion of the grain flow compared to the transverse direction. These differences are directly related to the microstructure. To bring out this results, we have been working on a bainitic steel METASCOß MC. Several analysis show that the probability of crack initiation is high near MnSs inclusions (manganese sulphide), very common in modern steels due to their benefic role during machining (figure 6) [7]. For that reason, a new pre-processor, DIGIMICRO, is used to create realistic digital microstructures.

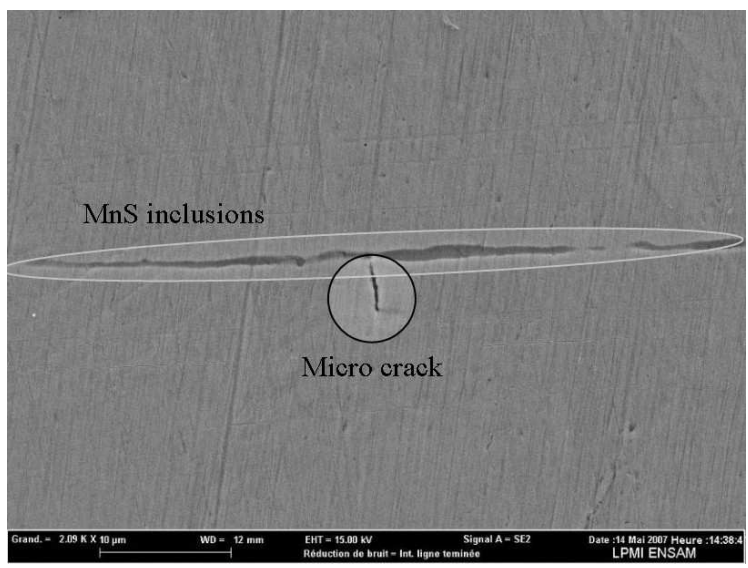

Figure 6: Several cracks are initiated near MnS inclusion interface

A realistic adaptated meshing can be performed by considering different options of generation. For instance, security distance can be given between each inclusions or orientation and position can be controlled directly. The goal is to create geometric entities in order to perform an adaptative mesh refinement near the interface in order to improve the calculus of gradients with any initial form of the R.E.V. (figure 7).

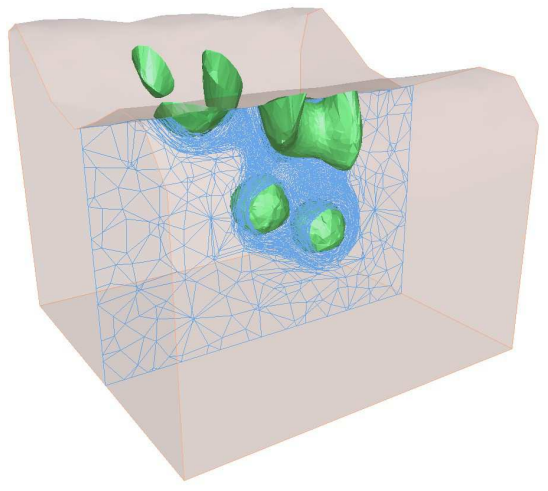

Figure 7: Geometry of a surface with a cluster of inclusions

Both inclusions and grains (defined by Voronoï tessellation) can be generated by considering an adaptated metric given to the MTC mesher developed by T. Coupez [2]. Finally, the R.E.V. is coated by a surrounding domain (figure 8 ). This do- 
main is meshed and its role is to transmit boundary conditions to the R.E.V. and avoid edge effects for the microstructure computation. This structure can be tested numerically for a fatigue loading simulation in order to calculate the endurance function. However, the most difficult part is to determine the rheology of different entities to fit the microstructure behavior compared to the macroscopic behavior.

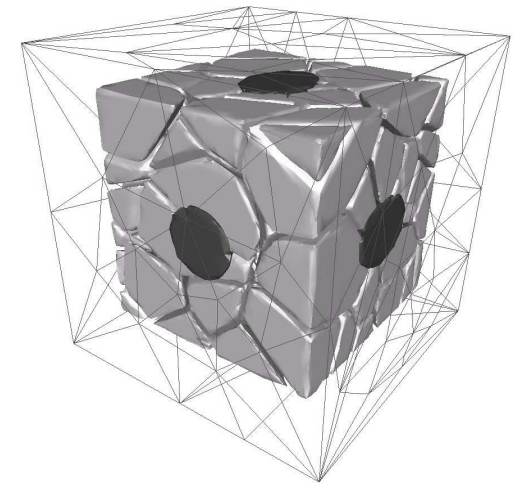

Figure 8: Mesh of a microstructure composed of 100 grains and 6 inclusions

In our study, only MnSs are studied and their behavior is approximately known [3]. Only the behavior of the matrix within inclusions are embedded must be determined (figure 9). Its rheological law is directly fitted with experimental data (for instance, data stemming from tension tests).

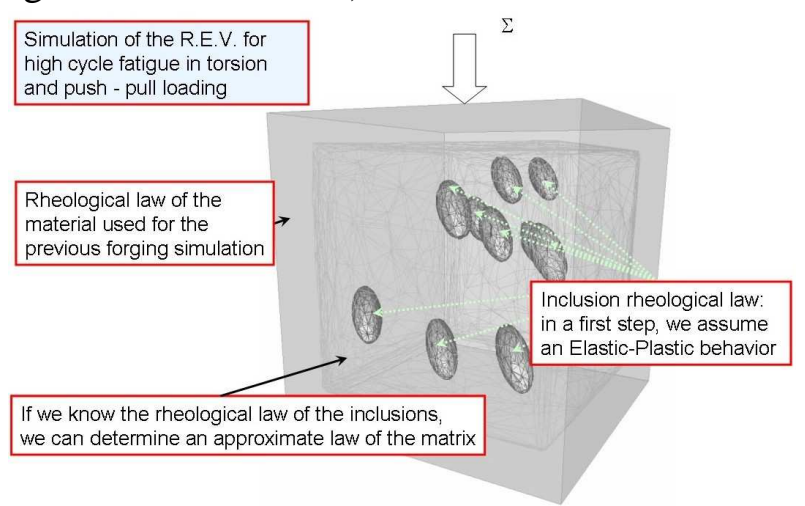

Figure 9: Simulation of a microstructure R.E.V.

By considering anisotropy is directly related to the orientation of inclusions, fiber vector can be associated to the direction of the first axle (the higher) of the inclusions. So, high cycle fatigue simulations are performed by changing the orientation of inclusions compared to the direction of the stress. Simple traction-compression or torsion tests are then simulated and the influence of the shape, the number and the orientation of the inclusions can be studied. Output parameters of such simulation give the endurance limits for the chosen direction which is directly associated to the macroscopic simulation by the means of fiber vector. Thus, we can predict the resistance of the forging component by knowing the endurance limits needed.

\section{CONCLUSIONS}

This work presents a new approach of fatigue analysis by considering directly the anisotropy in the $\mathrm{Pa}$ padopoulos criterion. A representative microstructure is coupled with a standard fatigue simulation. This link between forming simulation and fatigue analysis at the microstructure scale is promising to improve fatigue computation predictions.

\section{ACKNOWLEDGEMENT}

This work is being performed within the ANR (French National Research Agency) Optiforge project, in a partnership including several industrial partners (Ascoforge, Ascometal, Cetim, PSA, Setforge, Transvalor) and academic institutions (ENSAM d'Angers, INSA Lyon, ENSMP - CEMEF).

\section{REFERENCES}

[1] M. Bernacki, Y. Chastel, H. Digonnet, H. Resk, T. Coupez, and R.E. Logé. Development of numerical tools for the multiscale modelling of recrystallization in metals, based on a digital material framework. Computer Methods in Materials Science, 7:142-149, 2007.

[2] T. Coupez. Grandes transformations et remaillage automatique. PhD thesis, Ecole Nationale supérieure des mines de Paris, 1991.

[3] P. Meynaud. Prévision de durée de vie en fatigue de roulement d'un acier à partir de ses caractéristiques élastoplastiques et de celles de ses inclusions. $\mathrm{PhD}$ thesis, Institut National des Sciences Appliquées, 1995.

[4] F. Morel and L. Flaceliere. Data scatter in multiaxial fatigue: from the infinite to the finite fatigue life regime. Int. J. Fatigue 27, 2005.

[5] I.V. Papadopoulos. Fatigue limit of metals under multiaxial stress conditions: the microscopic approach. technical note no. NI.93.101, Commission of the European Communities, Joint Research Centre, 1993.

[6] J.A. Sethian. Level Set Methods and Fast Marching Methods. Cambridge University Press, Cambridge, 1996.

[7] C. Temmel, B. Karlsson, and N.G. Ingesten. Fatigue anisotropy in cross-rolled, hardened medium carbon steel resulting from mns inclusions. Metallurgical and Materials Transactions A, 37A:2995-3007, 2006.

[8] K. Dang Van, B. Griveau, and O. Message. On a new multiaxial high cycle fatigue limit criterion: Theory and application, biaxial and multiaxial fatigue. Mech. Engng Pub. EGF 3, 479-496, 1989. 


\title{
Kinematic and sensitivity analysis of rotary forging process by means of a simulation model
}

\author{
I. Montoya ${ }^{1}$, M.T. Santos ${ }^{1}$, I. Pérez ${ }^{1}$, B. González ${ }^{1}$, J.F. Puigjaner ${ }^{2}$ \\ ${ }^{1}$ LABEIN Tecnalia - C/Geldo Edificio 700 \\ Parque Tecnológico de Bizkaia \\ 48160-Derio (Bizkaia), Spain. \\ URL: www.labein.es \\ e-mail:imontoya@labein.es; santos@labein.es; \\ iperez@labein.es; bgonzalez@labein.es
}

\section{${ }^{2}$ Industrias Puigjaner S.A., DENN - Pintor Vila Cinca, 30} 08213 Polinyà (Barcelona), Spain.

URL: $\underline{w w w . d e n n . e s}$

e-mail:jpuigjaner@denn.es

ABSTRACT: Nowadays, due to the environmental regulations, the automotive market is demanding more complex components and the utilization of new materials. In this context, and due to its wide range of advantages, rotary forging technology is a very promising metal forming alternative to the conventional forming techniques. In this paper, an analysis of the material, the stress and strain has been realized, in order to show a comparison between conventional and rotary forging and to understand the mechanisms of rotary forming.

Key words: Rotary forging, automotive, simulation, incremental forming, bulk metal forming, FORGEC.

\section{INTRODUCTION}

We know as rotary forging an incremental manufacturing process that, based on the principle of continuous uniaxial pressure and using rotational movements in the dies, obtains net-shape revolution geometries from a "billet" as raw material. The most competitive advantages compared to the conventional forming techniques are the reduction of the forging force, the strong effect on the mechanical properties, the increment of the tensile and yield strengths and the accuracy of the obtained sections.

Prior to apply the incremental bulk metal forming to automotive industrial parts, a preliminary study has been done in order to understand the mechanisms of rotary forming and to show the main advantages versus the conventional forming. The study has been done using the commercial code FORGEC, a software dedicated to simulation of hot, warm and cold forging of both 3D parts and 2D geometry parts.

\section{SIMULATION MODELS}

Taking into account the kinematic, the following cases (Fig. 1) have been selected to achieve a simulation model computationally efficient, using relative movements in the dies to replace the turn of the material, which increases too much the CPUtime.

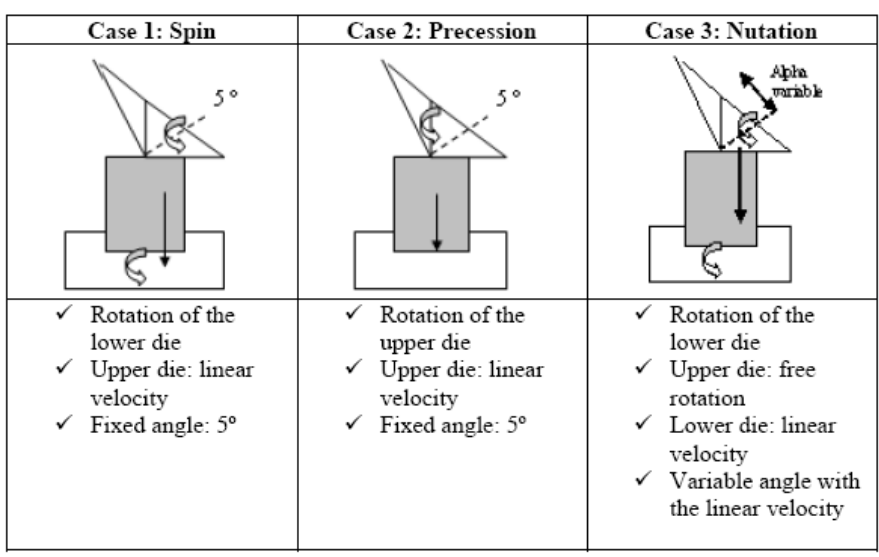

Fig. 1. Kinematic cases

Furthermore, the case 1 (spin) has been modelled turning the main and the nutation shafts both in the same as in the opposite sense.

As a first approach, the study began analyzing the five following models: 
1. Case: Conventional forge direction

2. Spin case, with turns in the opposite

3. Spin case, with turns in the same direction

4. Precession case

5. Nutation case: variable angle

To develop the analysis, an upsetting process with a plain lower die and a plain conical upper die with a slope angle of $5^{\circ}$ has been chosen.

Concerning the geometry of the model, the dimensions were a billet of $\varnothing 30 \mathrm{~mm} \times 56 \mathrm{~mm}$, which represents a ratio of 1'86. Having a $56 \mathrm{~mm}$ height, $10 \mathrm{~mm}$ of them are destined to fix the billet in the lower die.

The material selected is AA6061 aluminium at $480^{\circ} \mathrm{C}$, the model is isothermal and Coulomb's law has been used as friction law.

Thus, using these simulation models the following variables have been analyzed:

- Material fibers

- Plastic strains

- Von Mises stresses

- Forging loads

The following sections show, at first, an analysis of process in the case of fixed angle. Then, the differences with the variable angle have been studied.

\section{PROCESS ANALYSIS}

The results for each of the mentioned above variables are shown.

\subsection{Fixed angle}

\section{1.a Material fibers}

In each case, the fibers rotate due to the nature of the process itself (figure 2). However, the case of "spin" showed very good results. In this case, the lower die and the material rotate in one sense and the upper die turns in the opposite sense, obtaining a fiber without cuts and folds and getting a further upsetting compared to the same process conditions using conventional forge.

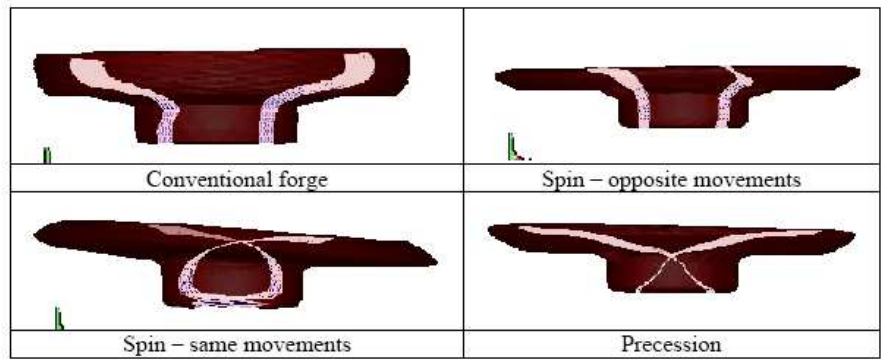

Fig. 2. Material fibbers

\section{1.b Strains}

As shown in Figures 3 and 4, the strain obtained in the spin case is higher than that for the conventional forge. As Fig. 3 shows, in traditional forge it would not be possible to obtain a similar strain, because in the outer zone an accumulated damage that would cause external cracks occurs. It is important to emphasize that the strain obtained is different in the four cases, being the most uniform the one corresponding to the "spin - opposite direction" case.

In the case where the rotational movements have the same sense the piece separates from the lower die, while in the precession case localized excessivestrain zones are generated, which predicts damage of the material. These processes will be more exhaustively studied in the future, in order to get a better understanding of the deformation mechanisms.

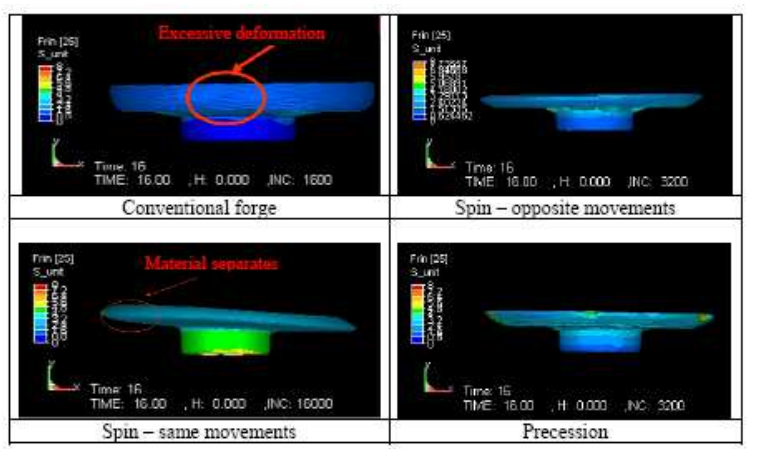

Fig. 3. Equivalent strains. Side view

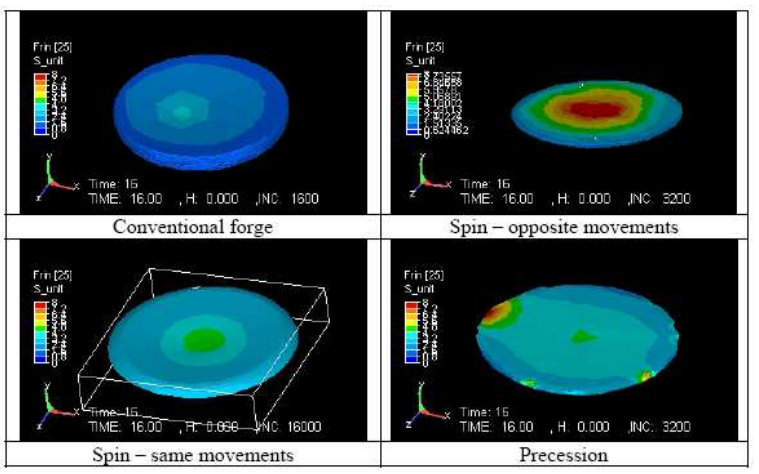

Fig. 4. Equivalent strains 


\section{1.c Stresses}

Regarding the stress distribution (Fig.5), there is a clear dependence on the angle in the plastification area. Besides, the higher values occur in the spin and precession cases, which provide more hardness to the material.

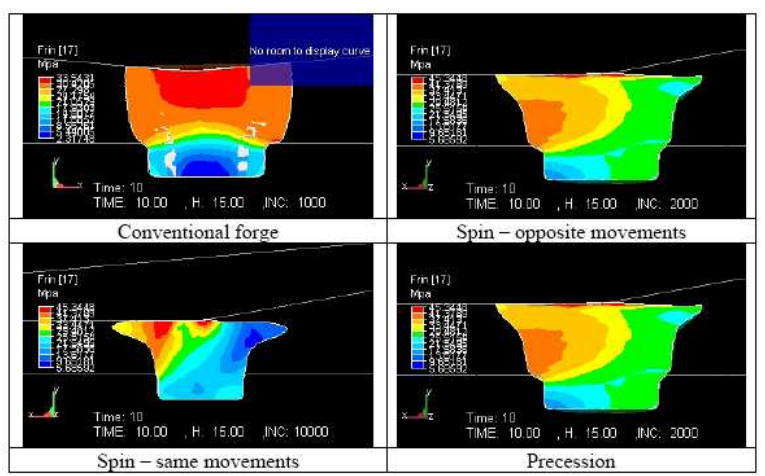

Fig. 5. Von Mises Stresses (MPa) in $\mathrm{t}=10 \mathrm{seg}$

\section{1.d Forming loads}

The most important advantage of the rotary forging is the reduction in the forging load (Fig. 6). This reduction is due to the contact area between the dies and the material, which is less than that in the conventional forging. Besides, in this new technology the nutation angle has a high influence in the forging load.

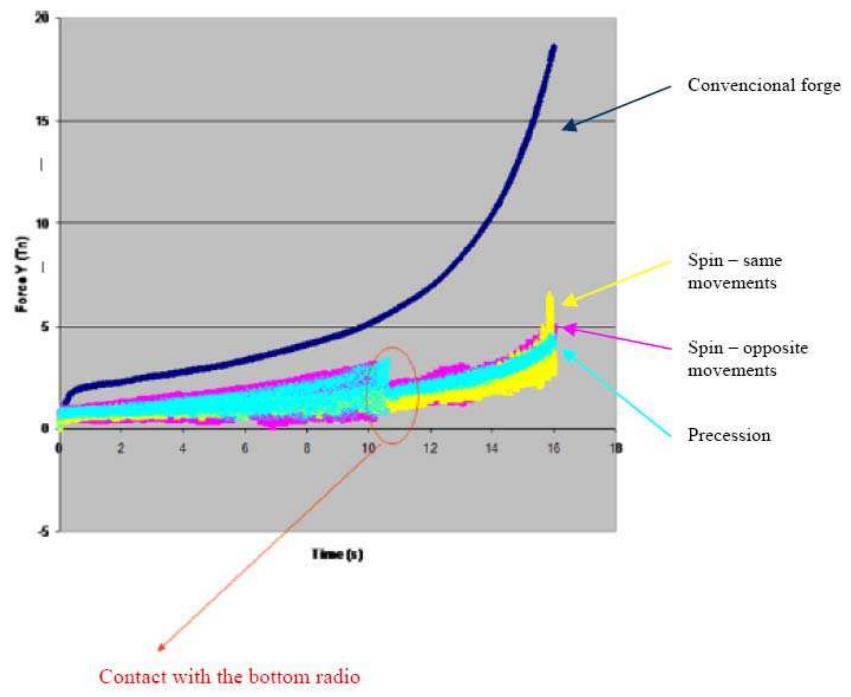

Fig. 6. Forces in upper die (Tn) comparison

As Fig. 6 shows, the loading force obtained in all processes is the third of that in the conventional forging, allowing the utilization of smaller and cheaper equipments.

\subsection{VARIABLE ANGLE}

The change in the angle during the process allows manufacturing more complex parts. Taking into account the best results obtained in the study above with the spin case, it was made a comparison with the variable-angle case.

First of all, the plastification area that appears in one step is larger in the variable-angle process, especially in terms of height. This fact is due to the high influence of the angle during the deformation process. Figure 7 shows the contact in the piece and the stresses generated, in a cutting plane, in both cases.

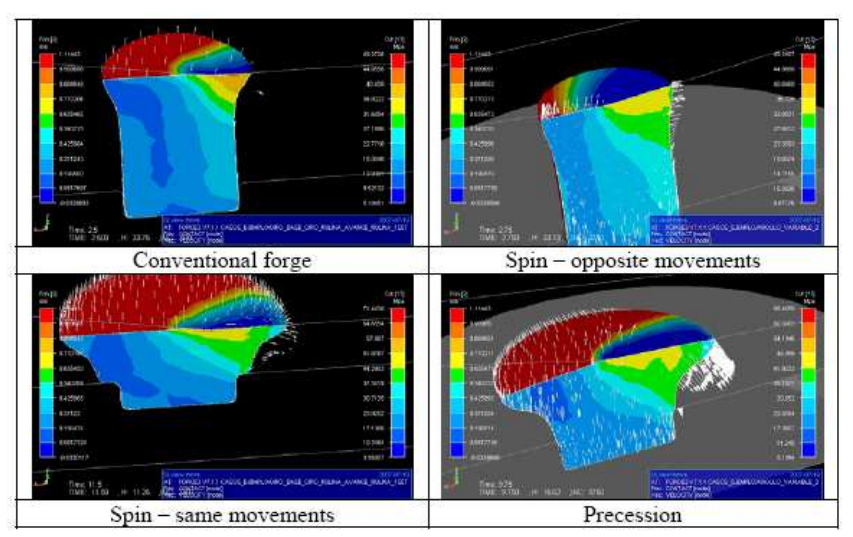

Fig. 7. Contact in the piece and Von Mises stresses (MPa) in a cutting plane

Besides, in order to understand better the mechanisms of deformation of the material, an analysis of the material speeds during both processes has been performed.

In the spin process and for an instant of time, the higher speeds are reached in the middle of the contact area, showing a triangular distribution. However, in the variable-angle case this triangular shape appears in a contact zone which is two times the previous one (Fig. 8).

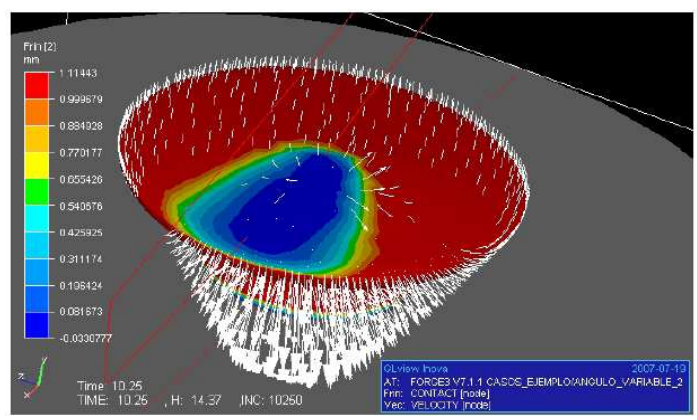

Fig. 8. Variable angle process. Contact area (in blue) and velocity distribution 
By the other hand, due to the rotary process whirlwinds in certain areas of the material arise, being bigger effect in the case with fixed angle (Figure 9). In the variable-angle case more zerospeed zones arise.

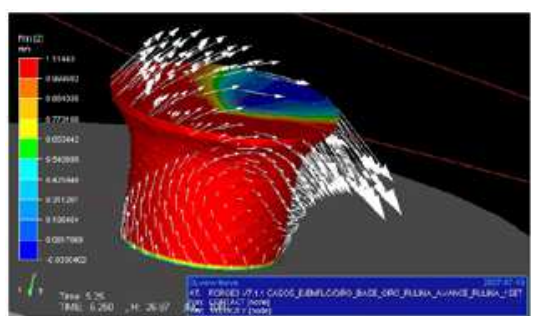

Fig. 9. Velocity evolution. Case: Spin - opposite movements

\section{SENSITIVITY ANALYSIS OF PROCESS WITH FIXED ANGLE}

Taking into account the above analysis, we can consider spin process the optimum one. After this case, an analysis of the influence of different process variables was performed, in order to eliminate defects and/or reduce forming loads.

In this context, the following variables are considered as the most influentials:

- Rotation speed

- Linear velocity

- $\mathrm{h} / \varnothing$ ratio of the initial billet

- Nutation angle

The following graphic shows that an increase in the angle is the change that involves a higher reduction in the load:

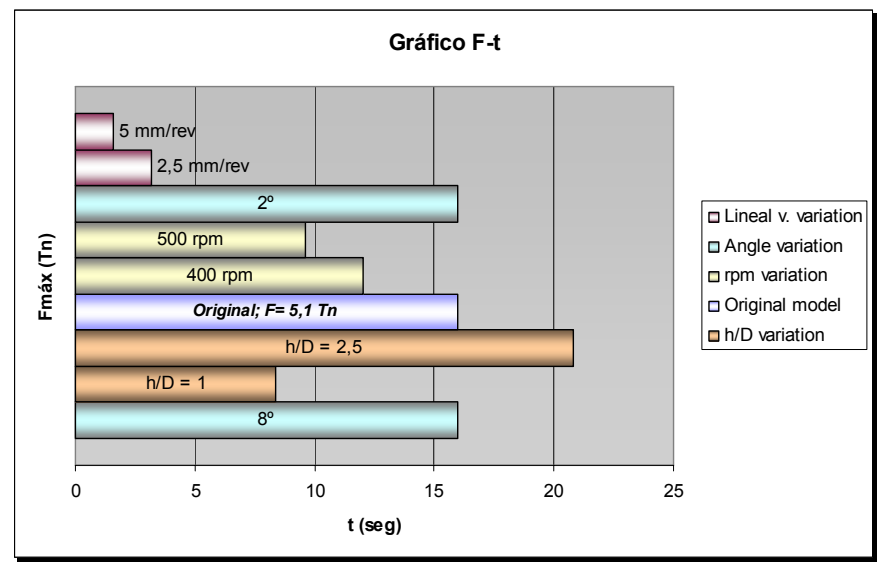

Fig. 10. Sensitivity analysis. Case: Spin - fixed angle.

\section{CONCLUSIONS}

After this study, it can be concluded that, generally, the spin process (fixed angle) with opposite rotational movement is the one that gives better results considering material fibbers, stresses, and strains. Nevertheless, there are not significant differences between the rotary cases in terms of forming loads.

Concerning to the sensitivity of process variables in the maximum load in this process, it has been found that the greatest influence is determined by the nutation angle or by the linear velocity, while the ratio $\mathrm{h} / \varnothing$ (height/diameter) or rotational speed do not affect significantly.

Furthermore, the rotation processes have less probability of failure (cracks) because the compression state is reached with an incremental process, allowing greater upsettings. However, it is important to consider the buckling in case of using high $\mathrm{h} / \varnothing$ ratios, which can cause wrinkles in the final piece.

\section{ACKNOWLEDGEMENTS}

This work has been possible thanks to support from the Basque Government within the framework of "SAIOTEK 2006-2007" (Project: "Desarrollo Del Proceso De Forja Rotativa Para Componentes De Automoción - FOROT").

\section{REFERENCES}

1. GROCHE P., FRITSCHE D., TEKKAYA E.A., ALLWOOD J.M., HIRT G., NEUGEBAUER R. "Incremental Bulk Metal Forming" 57th CIRP General Assembly, Dresden(Germany), 19/08/2007-25/08/2007.

2. STANDRING P.M. "The significance of nutation angle in rotary forging" Advance Technology of Plasticity, Vol III. Proceedings of the 6th ICTP, Sept. 19-24, 1999. 


\title{
Recent development in orbital forging technology
}

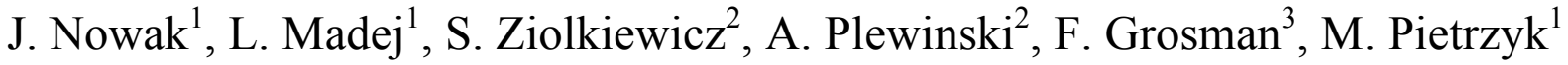 \\ ${ }^{1}$ Akademia Gromniczo-Hutnicza, al. Mickiewicza 30, 30-0159 Krakow, Poland. \\ URL: www.isim.agh.edu.pl \\ e-mail: nowak,lmadej, pietrzyk@metal.agh.edu.pl;
}

${ }^{2}$ Instytut Obrobki Plastycznej, ul. Jana Pawła II 14, 61-139 Poznan, Poland.

$U R L:$ www.inop.poznan.pl

e-mail: ziolkiewicz,plewinski@inop.poznan.pl;

${ }^{3}$ Politechnika Slaska, ul. Krasinskiego 8, 40-019 Katowice, Poland.

URL: $\underline{\text { www.rm.polsl.pl/ }}$

e-mail:franciszek.grosman@polsl.pl;

\begin{abstract}
The main subject of the present work is investigation of possibility of extension of classical orbital forging technology to obtain more cost effective forging process. Orbital forging is the process used for forging of shaped parts by applying the incremental forging method. Results of simulation of orbital forging are compared in the present work with the result obtained from a conventional forging process. 3D finite element (FE) simulations are used in the present project to evaluate the capabilities of the orbital forging process and proper die design, and to predict the forging loads the. Selected results of simulations are presented in the paper. These results are the basis for the further comparison and discussion about possible modifications of conventional orbital forging approach.
\end{abstract}

Key words: incremental forming, orbital forging, orbital press

\section{INTRODUCTION}

Advantages of incremental bulk forming are well known in the literature [1-5]. This technology is commonly applied in industrial conditions, to reduce loads and to increase workability during forging in comparison with the conventional monotonic process. Another advantage is the possibility to forge hardly formable materials and to obtain high deformation degrees. On the other hand, many steps are necessary in this process to obtain final shape of the product, what extends the manufacturing time. Typical examples of processes of incremental forming are cross and profile rolling, open die forging, rotary swaging or orbital forging (Figure 1) [6]. Analysis of advantages and limitations of orbital forging and investigation of possible improvement in this technology are the subject of this work.

Orbital forging, presented in Figure 2, is used for forging of shaped parts by applying the incremental method. In this technology a sample is placed between an orbiting upper die, that moves towards the sample, and a non-rotating lower die. The lower die is properly shaped and is used to transfer the shape of the final part. The first modification of this technology is to move the lower die axially toward the upper die, that in this case is fixed axially but still its axis makes orbital motions.

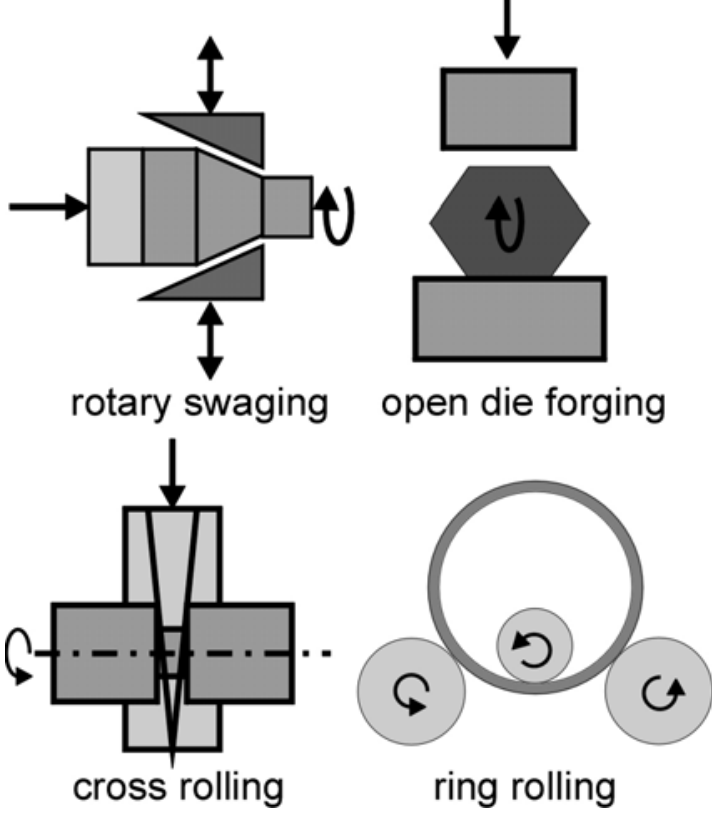

Figure 1. Examples of incremental forging processes.

These two technologies have similar advantages in comparison to conventional forging. The main advantage is load reduction and possibility to obtain very large deformations without the danger of material failure. 


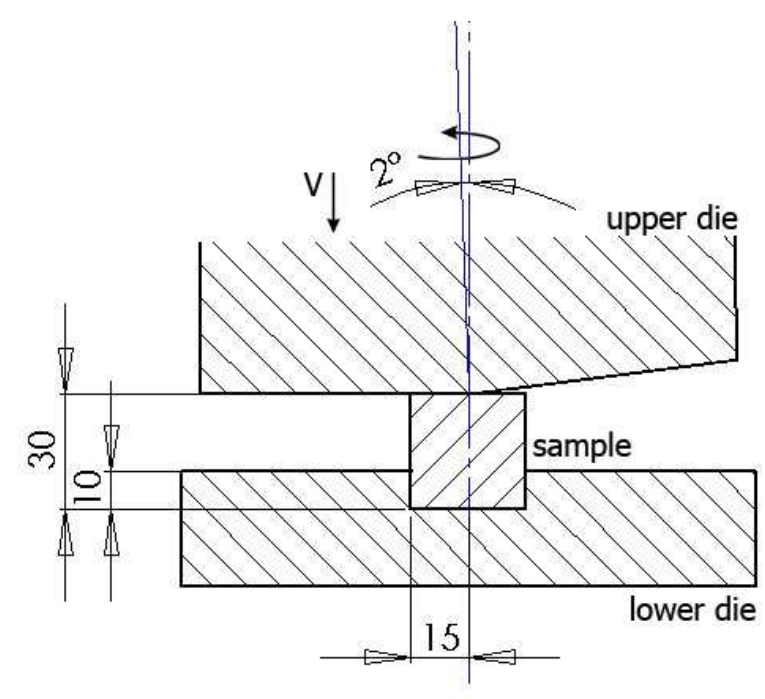

Figure 2. Schematic illustration of the orbital press. Main dimensions used during numerical simulation are given in $\mathrm{mm}$.

High smoothness of forging surface, material economy, simple design and easily exchangeable tools are also advantages of this technology. Forging of wheel disks with hubs, gears, bearing rings, rings of various contours, bearing-end covers etc., are typical applications of the orbital process [2,7]. However, due to the nature of this process, some surface deformation may occur in front of the moving upper die. That in some cases leads to micro crack initiation. Due to orbital movement, failure can also initiate at the circumference of the sample.

A variety of orbital forging processes are introduced in the industry in the word. The approach proposed by Marciniak [8], where orbiting upper die moves towards the sample, is considered below. Possibility of changing an inclination of the die is the main feature of this process. The objective of the work is to investigate potentials and limitations of this technology and to recommend modifications.

\section{SIMULATION OF THE ORBITAL FORGING}

Main process parameters used in simulation of deformation in the orbital press are gathered in Table 1. Numerical simulations were performed with the commercial Forge2005 software. Results obtained for this process are compared with those obtained for a conventional monotonic forging process. Strain distribution and final shape obtained after the end of the orbital process are shown in Figure 3. Comparison made at the cross section of the strain values obtained using two forging approaches are presented in Figure 4.

It is seen in Figure $4 \mathrm{~b}$ that due to orbital movement of the upper die strains in the upper part of the sample are lower than in the conventional method. Similar values are observed only in the region currently loaded by the rotating tool. Limited region of deformation in the orbital press reflects also in the distribution of the strain rates (Figure 5). Presented above differences in metal flow during deformation, may also be related to the differences in temperature distribution (Figure 6). In the orbital press high temperatures appear at the circumference. Temperature distribution in the sample is more uniform in the conventional process.

Table1. Process parameters

\begin{tabular}{|l|c|}
\hline \multicolumn{1}{|c|}{ Parameter } & Value \\
\hline Material & steel $40 \mathrm{H}$ \\
\hline Initial dimensions of the sample & $\phi 30 \times 30$ \\
\hline Press velocity & $2 \mathrm{~mm} / \mathrm{s}$ \\
\hline Angular velocity of the die & $400 \mathrm{rpm}$ \\
\hline Initial temperature & $650^{\circ} \mathrm{C}$ \\
\hline
\end{tabular}

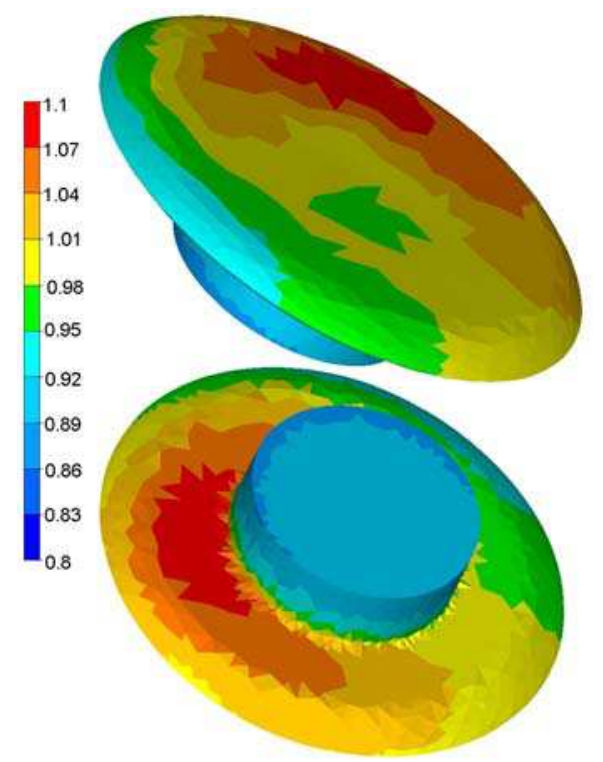

Figure 3. Strain distribution in 3D obtained at the end of deformation in the orbital press.

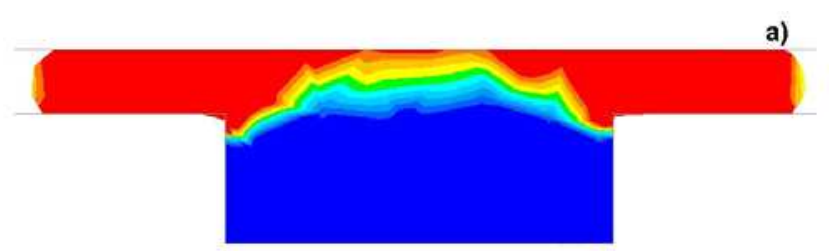

b)

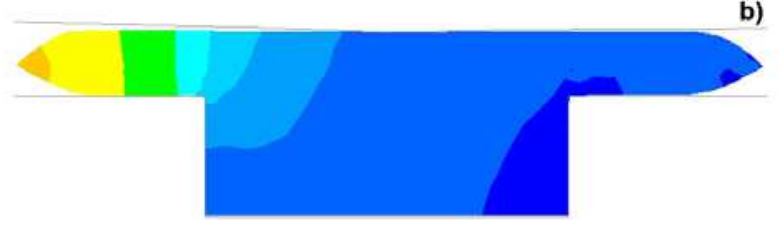

Figure 4. Strain distribution at the end of deformation in the conventional forging (a) and in the orbital press (b), scale as in Figure 3.

Tendency to crack initiation in the two considered processes was investigated next. Calculated distributions of the Latham-Cockcroft failure coefficient [9] are presented in Figure 7. The $3 \mathrm{D}$ distribution of the failure coefficient is presented in Figure 8. 


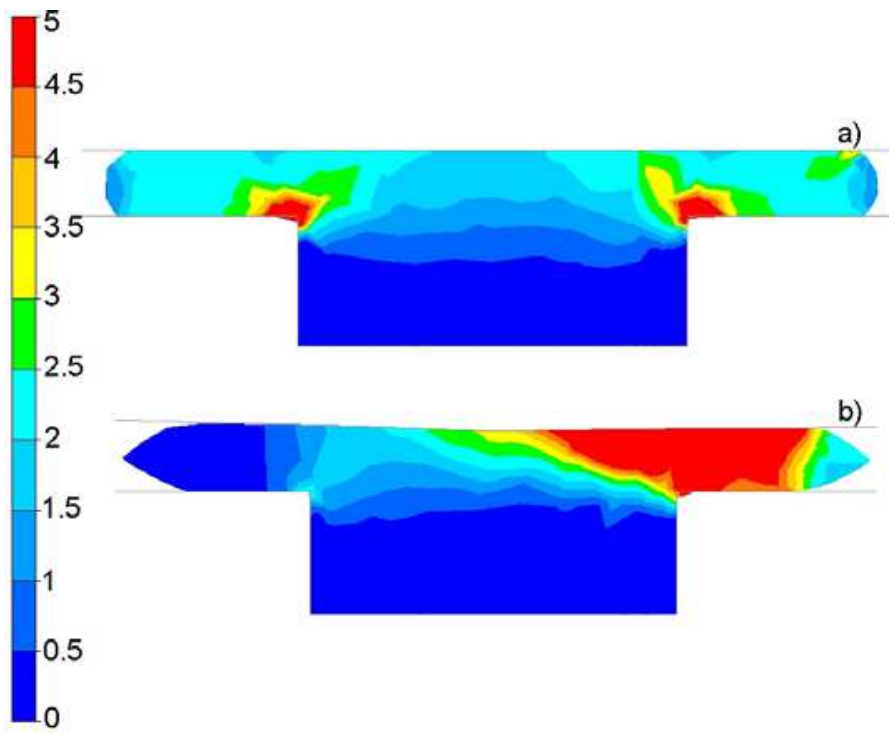

Figure 5. Strain rate distribution before the end of deformation in the conventional forging (a) and in the orbital press (b).

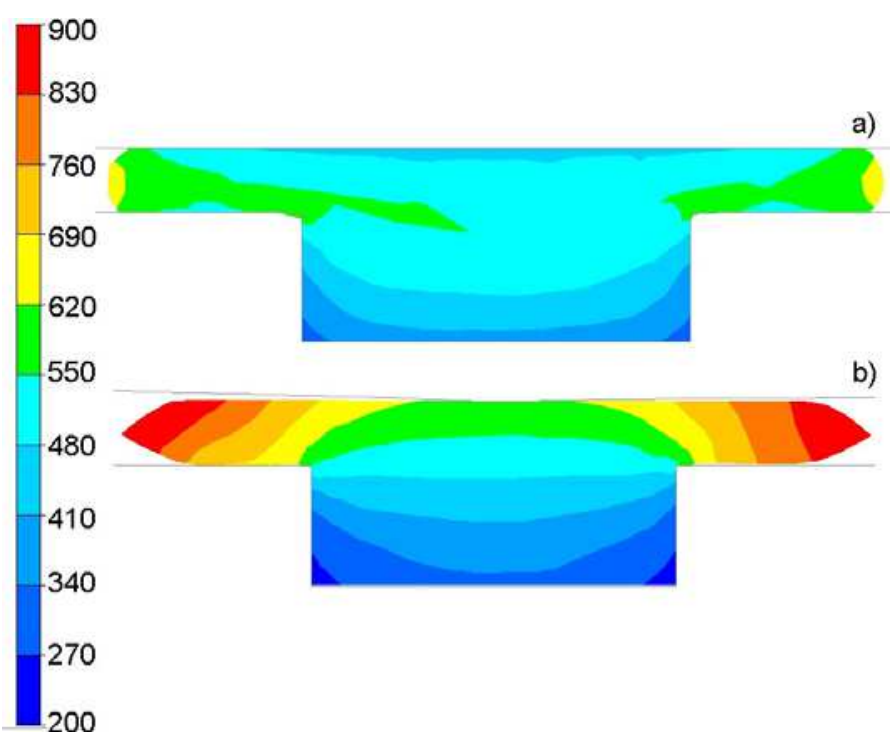

Figure 6. Temperature field obtained at the end of deformation in the conventional forging (a) and in the orbital press (b).

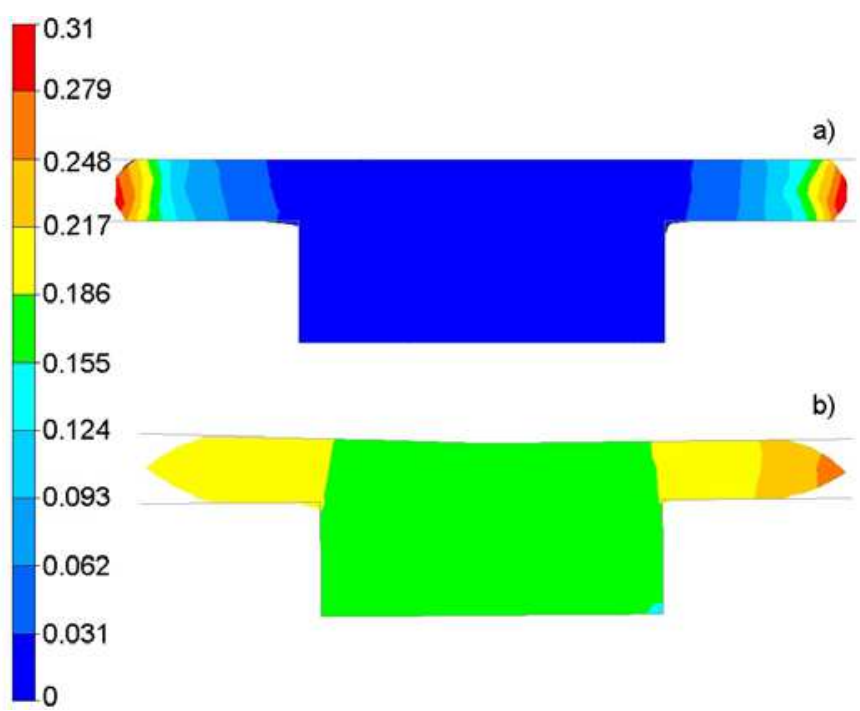

Figure 7. Latham-Cockcroft failure coefficient just before the end of deformation in the conventional forging (a) and in the orbital press (b).
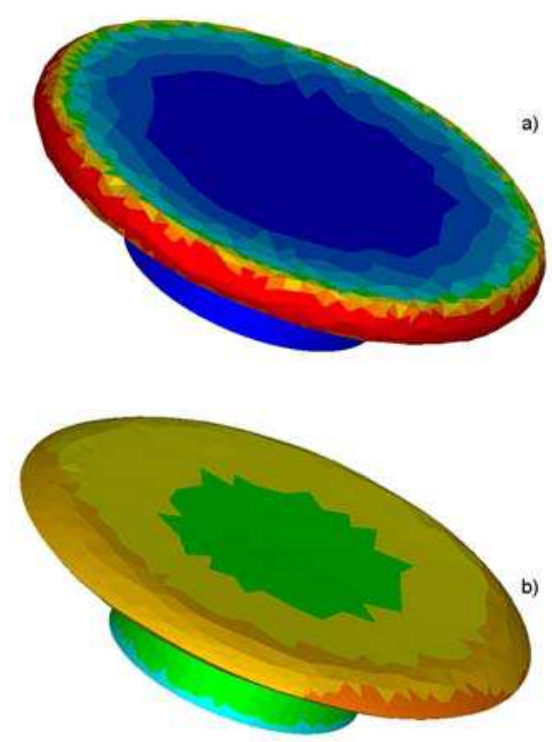

Figure 8. 3D view of the Latham Cockcroft failure coefficient just before the end of deformation in the conventional forging (a) and in the orbital press (b), scale as in Figure 7.

It is seen in Figure 8a that large values of failure coefficient are observed at the circumference in the conventional forging. That indicates high probability of failure in this region in this method. This is a limiting factor to obtain large deformations. The Marciniak method, as seen in Figure $8 b$, is free of such behaviour. Failure coefficients are lower that is one of the advantages of this incremental forging technology. Reduction of loads needed to obtain the same level of deformation, what is seen in Figure 9, is another advantage.

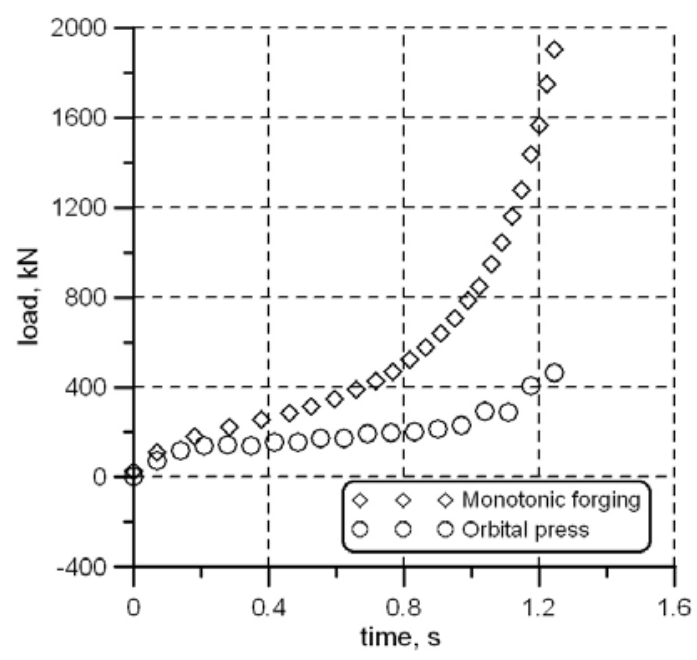

Figure 9. Comparison of the loads obtained from the conventional forging and the orbital press.

The orbital process was designed in the Institute for Metal Forming (INOP) in Poznan and the tests were performed, see macrographs in Figure 10. Experimental analysis confirmed results presented in Figure 9. This process is successfully introduced in the industrial practice now. 
However, despite important advantages of the orbital press in comparison with the conventional forging, the probability of failure initiation at the sample circumference at certain conditions still exists. It is due mainly to friction between rotating die and the workpiece. Thus, researchers have recently focused on further minimisation of this probability. That should results in a possibility to obtain larger deformation of the sample.

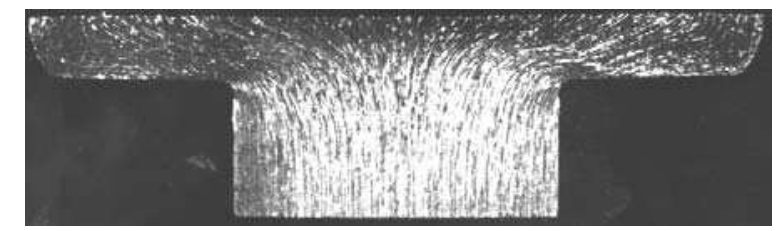

Figure 10. Macrograph of the cross section of the sample forged at the Marciniak press.

\section{POSSIBLE MODIFICATIONS}

Possibilities of modification of the classical Marciniak orbital forging technology to obtain more effective process are investigated to solve the problem with crack initiation. The idea of the modification of the orbital press is towards creation of the process that is strictly based on small incremental deformations. To reach this goal the shaped lower die is replaced by the flat one that pushes the sample up towards a series of small anvils. The motion of these anvils is constrained by an orbital movement of the upper die. Schematic idea of this process is presented in Figure 11.

The preliminary tests have shown that loads necessary to forge the material are smaller in comparison with the traditional orbital forging. Beyond this, the workpiece do not contact with the orbital die, therefore, it is expected that tendency to crack initiation should decrease. This process will be a subject of further experimental investigation and numerical modelling.

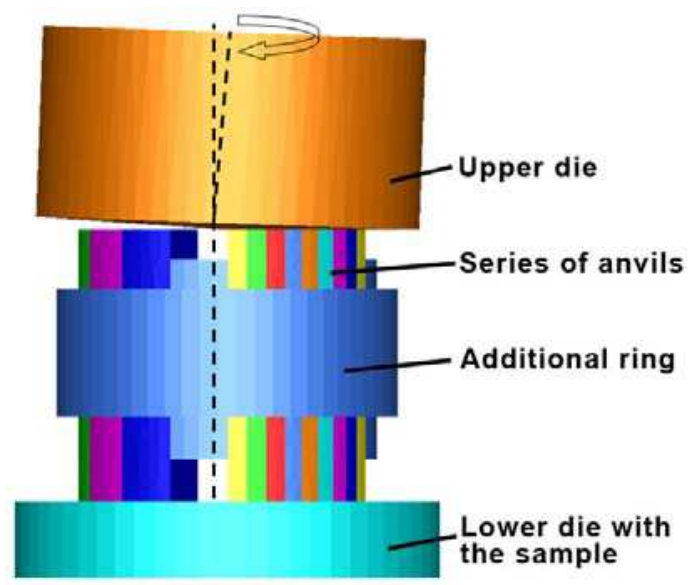

Figure 11. Schematic idea of the modification of the classical orbital forging technology.

\section{CONCLUSION}

This work is part of the larger project leading to create orbital forging technology that is capable to obtain large deformations without danger of material failure. Firstly, the classical Marciniak orbital forging process was compared with the monotonic forging. This comparison provided information regarding advantages and limitations of the orbital forging. Despite minimisation of the probability of failure in comparison with the monotonic forging, the danger still exists. Thus a possible modification to the Marciniak press was proposed. Elimination of the sliding of the die with respect to the deformed material is the main advantage of this process. Investigation of the material flow during deformation in the modified method will be a subject of further research.

\section{ACKNOWLEDGEMENTS}

Assistance of MNiSW, project R07 026 01, is acknowledged.

\section{REFERENCES}

1. GROCHE P., FRITSCHE D., TEKKAYA E.A., ALLWOOD J.M., HIRT G., NEUGEBAUER R., Incremental bulk metal forming, Annals of the CIRP, 56, 2007, 635-656.

2. LI G., JINN J.T., WU W.T., OH S.I., Recent development and applications of three-dimensional finite element modelling in bulk forming process, J. Mat Proc. Tech., 113, 2001, 40-45.

3. LIU G., YUAN S.J., WANG Z.R., ZHOU D.C., Explanation of the mushroom effect in the rotary forging of the cylinder, J. Mat Proc. Tech., 151, 2004, 178-182.

4. HIRT G., KOPP R., HOFMANN O., FRANZKE M. BARTON G., Implementing a high accuracy multi-mesh method for incremental bulk metal forming, Annals of the CIRP, 56, 2007, 313-316.

5. BRUSCHI S., CASOTTO S., DAL NEGRO T., ICARELLI R., Modelling material behaviour in incremental bulk forming processes, Proc. ICTP 2005, Verona, CD ROM.

6. GROCHE P., FRITSCHE D., Efficient algorithms for the simulation of incremental bulk metal forming, Proc. ICTP 2005, Verona, CD ROM.

7. MUNSHI M., SHAH K., CHO H., ALTAN T., Finite element analysis of orbital forming used in spindle/inner ring assembly, Proc. ICTP 2005, Verona, CD ROM.

8. MARCINIAK Z., A Rocking-Die technique for coldforming operations, Mech. Prod. Eng., 117, 792-797, 1970.

9. COCKCROFT M.G., LATHAM D.J., Ductility and the workability of metals, J. Inst. Metals, 96, 33-39, 1968. 


\title{
Production of blanks with thickness transitions in longitudinal and lateral direction through 3D-Strip Profile Rolling
}

\author{
N. Ryabkov ${ }^{1}$, F. Jackel ${ }^{1}$, K. van Putten ${ }^{1}$, G. Hirt ${ }^{1}$ \\ ${ }^{I}$ Institute of Metal Forming (IBF)-RWTH Aachen University, Intzestraße. 10, 52056 Aachen, Germany \\ URL: www.ibf.rwth-aachen.de \\ e-mail: ryabkov@ibf.rwth-aachen.de
}

\begin{abstract}
D-Strip Profile Rolling should enable the production of blanks with a defined thickness profile in latitudinal and longitudinal direction. The production chain of 3D-Strip Profile Rolling will combine Flexible Rolling in a first production step with Strip Profile Rolling in a second step. The control system to adjust the roll gap during 3D-Strip Profile Rolling is currently under development. Nevertheless, some first experiments have shown the general feasibility to produce 3D-profiled blanks. In 3D-Strip Profile Rolling the material will strain harden differently on different locations. This results in a variation of the material properties of the strip. Lateral spread, elastic roll stand deformation and local deformation will be influenced by this variation. To investigate these influences on the complete production process, the complete production chain needs to be modelled in the future with aid of finite element simulations. In this publication a first simulation model is used to study the influence of different grades of strain hardening in a Taylor Rolled Blank on the bulge formation that occurs during the rolling of a rill in this Tailor Rolled Blank.
\end{abstract}

Key words: Flexible Rolling, Strip Profile Rolling, 3D-Strip Profile Rolling, 3D-profiled blanks

\section{INTRODUCTION}

The combination of Flexible Rolling and Strip Profile Rolling should enable the production of strips with a thickness profile in latitudinal and longitudinal direction. This paper focuses on a concept to manufacture 3D-profiled blanks. First investigations on 3D-Strip Profile Rolling aim to show the feasibility of a coupling between Flexible and Strip Profile Rolling in one production chain. This paper presents the first results obtained by basic experiments, numerical analysis and their comparison.

\section{STATE OF THE ART}

\subsection{Flexible Rolling (FR)}

Flexible Rolling (Fig. 1) is based on the variation of the roll gap in a defined pattern during flat rolling [1]. It is applied to produce blanks with longitudinal transitions only, so called Tailor Rolled Blanks (TRB). During the rolling of the blanks, the thickness of the blank coming out of the roll gap is measured directly. An integrated algorithm conducts the variance comparison of the demanded profile online. With the ascertained failure the automatic gauge control is modified by changing the distance between the rolls.

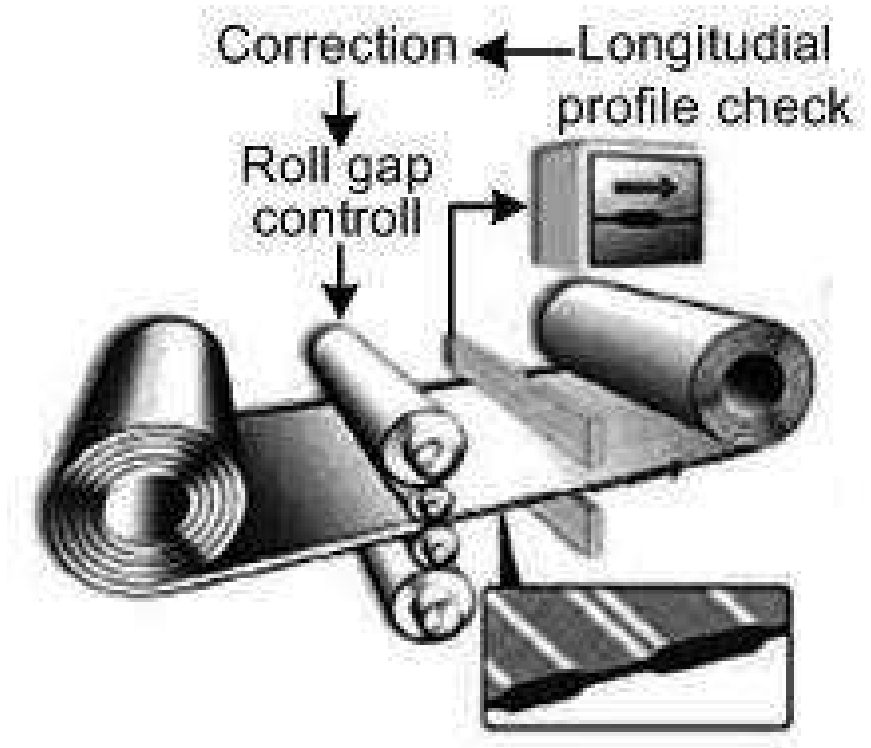

Fig. 1. Control system for the production of blanks with longitudinal thickness transition [2]

\subsection{Strip Profile Rolling (SPR)}

Strip Profile Rolling is applied to produce strips with defined thickness profile in latitudinal direction. 
This continuous production process (Fig. 2) is based upon the utilisation of a roll system that causes a material flow in latitudinal direction [3]. The geometry of the forming rolls and the contact area are the two variables that mainly influence the latitudinal material flow. The ratio of contact width $\left(b_{d}\right)$ to contact length $\left(l_{d}\right)$ in SPR (Fig. 3$)$ has to be significantly smaller than in common flat rolling, to obtain any material flow in latitudinal direction at all. In SPR an eventual material flow in longitudinal direction would cause flatness defects or even cracks. The high local thickness reduction causes to bulge formation near the rill [4].

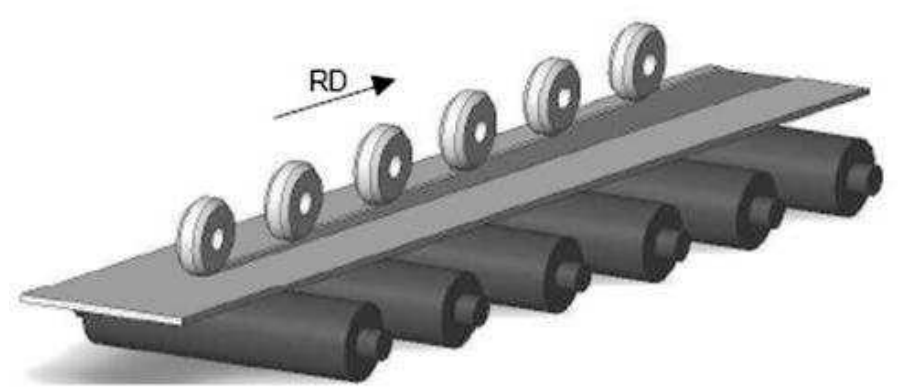

Fig. 2. Principle of production of blanks with latitudinal thickness transition [3]

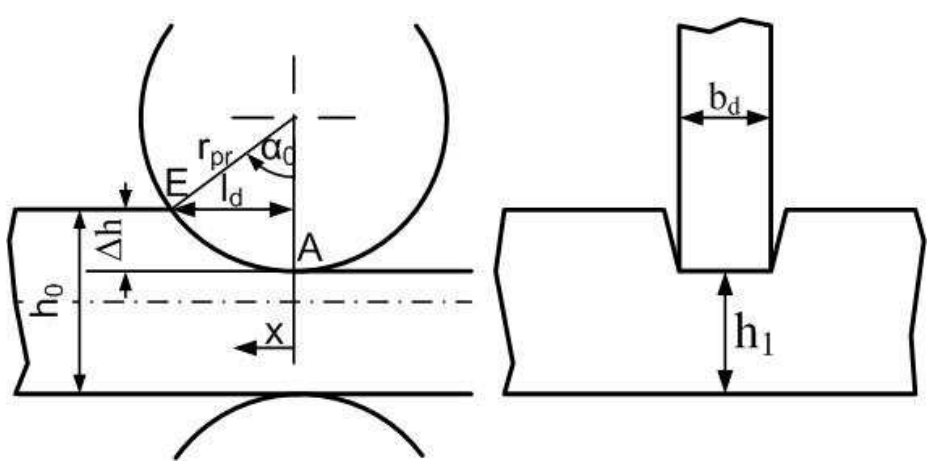

Fig. 3. Roll gap geometry in Strip Profile Rolling (SPR) left: longitudinal section, right: cross section [4]

\section{CONCEPT OF 3D-STRIP PROFILE ROLLING AND THE REQUIRED CONTROL SYSTEM}

\subsection{Concept}

By combining FR and SPR into one production chain it would be possible to produce blanks with both, longitudinal as well as latitudinal transitions. The process chain should exist of two sequent steps (Fig. 5). In the first step a longitudinal thickness profile is created by FR. Then, in the subsequent second step, a defined cross section is rolled in the strip by SPR.
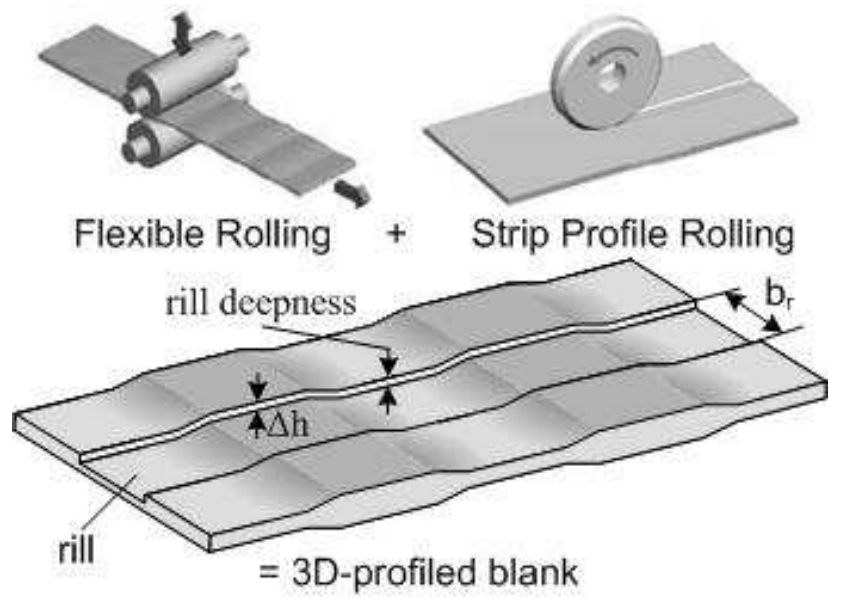

Fig. 5. Combination of Flexible Rolling and Strip Profile Rolling, product: 3D-Profiled Blank

Combining FR and SPR in one production chain brings several difficulties with it. On one hand the FR changes the material behaviour of the strip in a discontinuous way. TRB regions that have been reduced maximally in thickness (the thin regions) will have a higher yield stress as the regions which have been minimally reduced (thick regions) due to the strain hardening. This discontinuous material behaviour will effect the deformation, the lateral spread and the elastic roll stand deformation in the second SPR step. On the other hand, the thickness differences in rolling direction after FR bring the necessity to adjust the roll gap during SPR in order to enable the rolling of a rill with constant depth (or with a predefined varying depth).

\subsection{Control system for the manufacturing process}

To enable the production of 3D-profiled blanks a new control system has to be developed. The functional principle of the required control system is shown in Fig. 6.

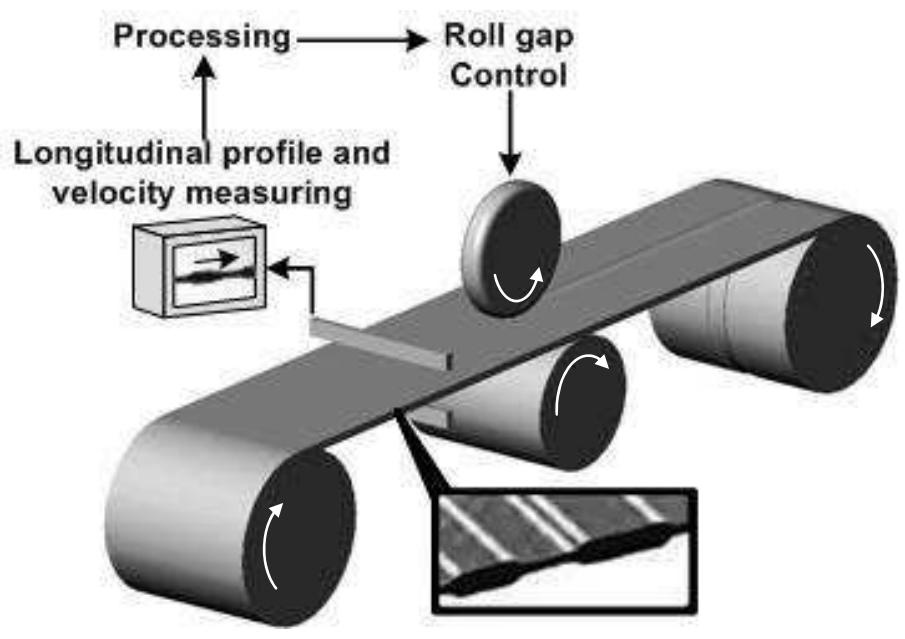

Fig. 6. Required control system to adjust the roll gap during Strip Profile Rolling of Tailor Rolled Blanks

The realisation of this concept is subject of matter of work being currently done. The new conceptual 
control system for 3D-Strip Profile Rolling focuses on the second step in the process chain where a rill is rolled in the TRB. Therefore the control system measures the thickness and velocity of the TRB which enters the roll gap. An integrated algorithm performs the adaptation of the roll gap during SPR in the second step of the process chain.

A first concept of the control system for 3D-Strip Profile Rolling is currently available and has been tested in some preliminary tests. One of the results of these experiments is presented in Fig. 7. It shows the longitudinal profile on the surface of the TRB and on the bottom of the rill. From Fig. 7 can be seen that the control system for dynamic roll gap adjustment in the second SPR step is capable to adjust the roll gap so that a rill of constant depth is rolled in the TRB.

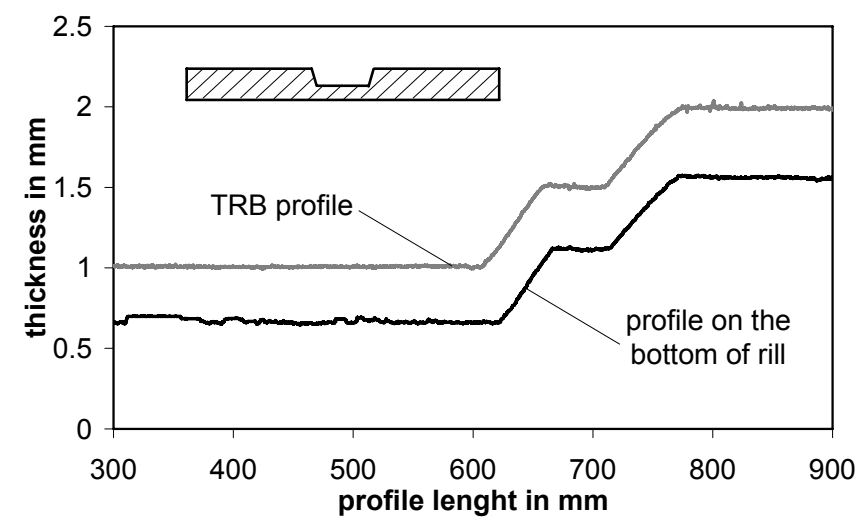

Fig. 7. Profile thickness in longitudinal direction on the surface of the TRB and on the bottom of the rill

\section{EXPERIMENTS AND SIMULATIONS}

\subsection{Experiments}

In order to investigate the latitudinal material flow in SPR of a TRB first experiments are conducted with a constant roll gap height (Fig 8). Emphasis of the experiments is put on the differences in bulge formation in the thick and thin regions (region $\mathrm{A}$ and $B$ respectively in Fig 8) of the TRB. The thickness of the TRB in the thick region (region A) is $2.0 \mathrm{~mm}$ and in the thin region (region $\mathrm{B}$ ) it measures $1.4 \mathrm{~mm}$. In the transition region (region $\mathrm{C}$ ) the thickness increase ratio equals 1:100. The width of the TRB is $100 \mathrm{~mm}$.

The latitudinal geometry of the profiled TRB was measured with aid of a Nokra thickness measuring laser. Two measured geometries are exemplarily shown in Fig. 11 and 12 for the thick and thin region respectively. The measured geometries are used for comparison with numerical simulations of the experiments.

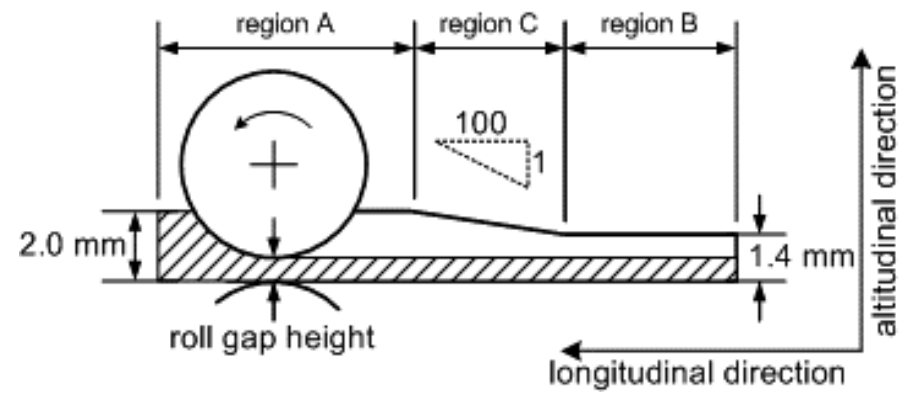

Fig. 8. SPR of a TRB with constant roll gap height

\subsection{Finite element model}

The experiments are numerically simulated with aid of finite element simulations in order to obtain detailed information about the local material flow, strains and stresses. The developed FE model (Fig. 9) consists of a cylindrical bottom roll, a profile roll and a TRB. The simulation proceeds in two steps. In the first step the blank is inducted into the roll gap with a defined velocity equal to the roll's peripheral velocity. In the second step the blank is caught up by the rolls and goes through the roll gap.

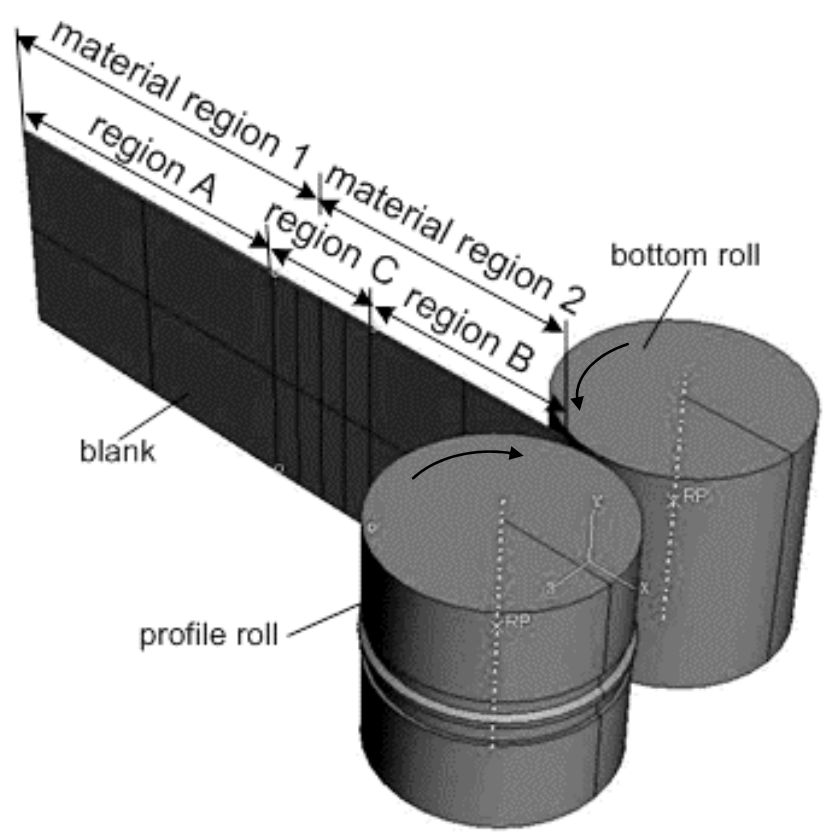

Fig. 9. The developed FE model

The material flow curve data is recorded in tensile test and is extrapolated. Because of different grades of strain hardening in the TRB, tensile experiments are conducted on specimens taken out of the thick as well as the thinner regions (Fig. 10). In the simulation model two material regions are defined. The yield curve obtained from the tensile specimens out of the thick region of the TRB are implemented in material region 1 , the one of the thin tensile specimens to material region 2 .

The profile roll and the bottom roll were constructed as analytic rigid bodies. The friction coefficient is 
assumed to be constant and measures 0.1. The geometry of the TRB is identical to the geometry used for the experiments.

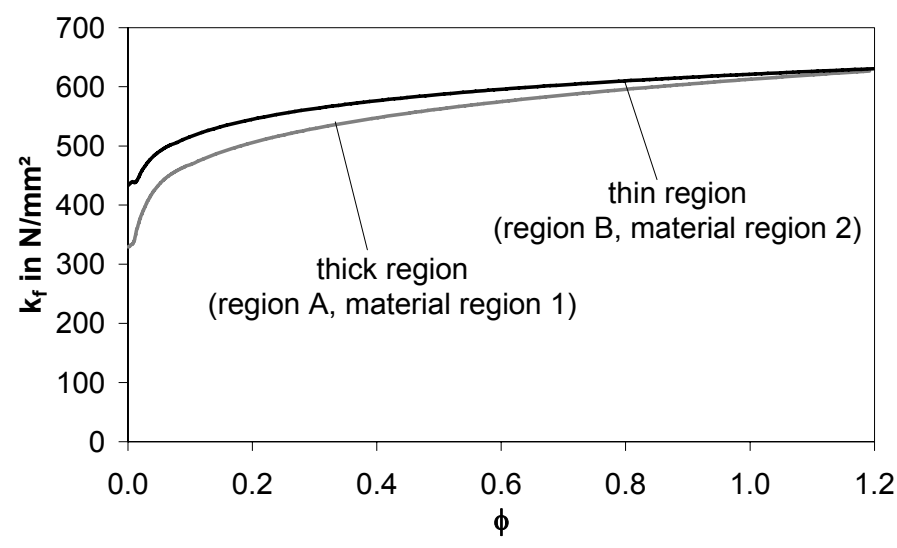

Fig. 10. Extrapolated yield curves obtained by tensile tests

\subsection{Comparison of simulation and experiment}

In order to verify the FE model, the calculated cross sectional blank geometry is compared with the one measured in the experiments. Emphasis is put on the area where the rill is rolled in the TRB. Fig 11 and 12 show the comparison between experiment and simulation for the thick and thin region respectively.

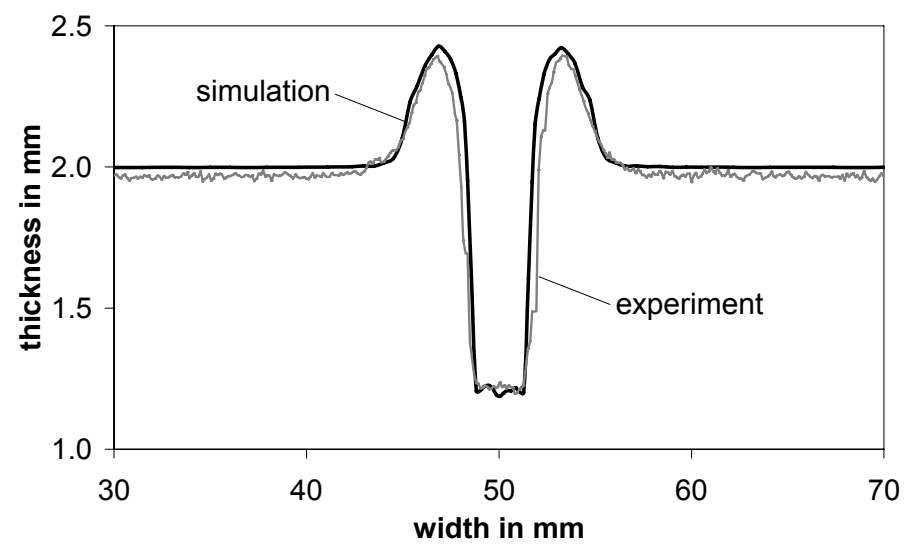

Fig. 11. Comparison of the cross sectional blank geometry in the direct environment of the rill in the thick region of the TRB

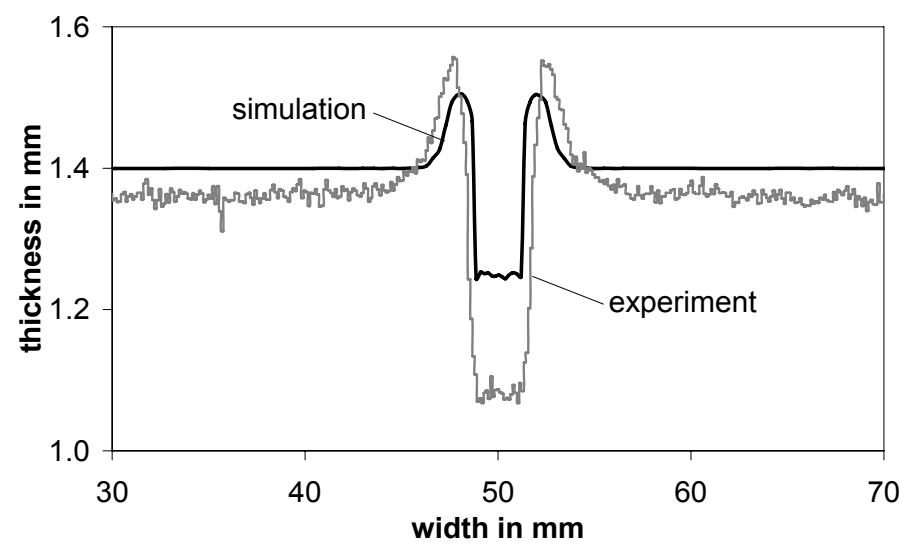

Fig. 12. Comparison of the cross sectional blank geometry in the direct environment of the rill in the thin region of the TRB
In the thick region of the TRB (region A) the cross sectional profile near the rill calculated by the numerical simulation of the SPR is in good agreement with the one measured from the experiments (Fig. 11). For the thin region of the TRB (region B) however, there exists a deviation between calculated and measured profile. This deviation can be explained by the elastic deformation of the rolling stand under load.

Due to the strain hardening imposed by the FR, the yield stress in the thinner region (region B) is significantly higher than the yield stress of the thick region (region $\mathrm{A}$ ). The height reduction is bigger in region $\mathrm{A}$ then in $\mathrm{B}$ and consequently the contact surface between roll and TRB in bigger in region A then in B. The hypothesis to explain the deviation is that despite the smaller height reduction and contact area the rolling force in region $B$ increases due to the increased yield stress and so exceeds the rolling force of in the thick region. As a consequence the elastic deformation of the stand is bigger.

\section{CONCLUSIONS}

3D-Strip Profile Rolling is a promising combination of Flexible Rolling and Strip Profile Rolling and offers the opportunity for further optimisation of products. A concept for a suitable control system is introduced and first experiments under idealised conditions have shown the feasibility. Rolling experiments and numerical simulations show coupling two rolling processes in a production chain interact and influence each other. The strain hardening in the rolling of a TRB significantly influences the bulge formation in the adjacent profile rolling step.

\section{REFERENCES}

1. Kopp R., Wiedner C., Meyer A. . 'Flexible Rolled Sheet Metal and Ist Use in Sheet Metal Forming', Advanced Material Research, Vols. 6-8, 81-92

2. Mubea, Muhr und Bender KG: Infopresentation, Atterdorn (2004)

3. Kopp R., Hirt G., Jackel F. 'Strip Profile Rolling - A New Production Process for Tailor Rolled Stripps' Proceedings of the 8th ICTP, Verona (2005) 493-494

4. Jackel F., Krückels T., Bertram F., Kopp R., Hirt G. 'Herstellung von Tailor Rolled Strips durch Bandprofilwalzen' Proceedings of the 22 Aachener Stahl Kolloquium (ASK), Aachen (2007) 205-212 


\section{The effect of the initial rolling temperature on the microstructure evolution during and after hot rolling of AA6082}

P. Sherstnev ${ }^{1}$, I. Flitta ${ }^{2}$, C. Sommitsch ${ }^{1,3}$, M. Hacksteiner ${ }^{4}$, T. Ebner ${ }^{4}$

${ }^{1}$ Christian Doppler Laboratory for Materials Modelling and Simulation, University of Leoben, Franz-JosefStrasse 18, 8700 Leoben, Austria

www.cdl-mms.at

pavel.sherstnev@,cdl-mms.at; christof.sommitsch@mu-leoben.at

${ }^{2}$ Unitec Te Whare Wananga o Wairaka, Mount Albert, Private Bag, 92025 Auckland New Zealand

${ }^{3}$ Chair of Metal Forming, University of Leoben, Franz-Josef-Strasse 18, 8700 Leoben, Austria

${ }^{4}$ AMAG rolling GmbH, P. O. Box 32, Ranshofen, Austria

ABSTRACT: In this study, the importance of the initial rolling temperature on the microstructure evolution during and after hot rolling of AA6082 was investigated. A commercial Finite Element Analysis (FE) package FORGE3 was used to predict through thickness thermal and deformation history of AA6082 undergoing multi-pass hot rolling. A physical model based on dislocation density, subgrain size and misorientation was used to calculate the grain size evolution and the recrystallized volume fraction after hot working. To validate the simulation results, homogenization and hot rolling experiments were performed. Homogenization was carried out in an air circulating furnace at temperatures of 550 and $580^{\circ} \mathrm{C}$. The homogenized samples were hot rolled in multipass process with different start temperature on a laboratory mill. The outputs from the simulation were compared with the experimental measurements.

KEYWORDS: AA6082, Hot Rolling, Microstructure Evolution, Simulation

\section{INTRODUCTION}

The homogenisation of AA6082 is necessary in order to spheroidize plate like particles and to precipitate dispersoids [1, 2]. Subsequent hot deformation activates dynamic recovery and static recrystallization, which have an important influence on the rolled product properties [3]. As well as the initial microstructure and the chemical composition, thermal changes and the deformation history i.e. strain, the strain rate and temperature experienced by the material during hot rolling, are key features that define the microstructure changes such as recovery, recrystallization and grain growth. These microstructure changes include both dynamic i.e. dynamic recovery and recrystallization during deformation and static changes i.e. static recovery and recrystallization that occur in the inter-pass region and after rolling is completed.

The FE modelling of aluminium hot rolling, coupled with microstructure models, has been proven to predict the grain size distribution and the recrystallized volume fraction in the hot rolled material after single pass rolling $[4,5]$. In the present work a FE microstructure model is applied to simulate multi-pass laboratory rolling in order to investigate the influence of initial rolling temperature and inter-pass time on the microstructure evolution of AA6082. The numerical calculation helps to optimize the hot rolling process with regard to product properties.

\section{EXPERIMENTAL PROGRAM}

\subsection{Homogenization and hot rolling experiments}

The cast material, aluminium alloy 6082 (delivered from AMAG rolling $\mathrm{GmbH}$, Table 1), was homogenized in an air circulated furnace at temperatures of 550 and $580^{\circ} \mathrm{C}$ for $10 \mathrm{~h}$ in order to investigate the influence of different homogenization temperatures on the subsequent grain structure evolution. 
Table 1: Chemical composition of AA6082 in weight per cent

\begin{tabular}{lllll}
\hline $\mathrm{Si}$ & $\mathrm{Mn}$ & $\mathrm{Zn}$ & $\mathrm{Fe}$ & $\mathrm{Mg}$ \\
$1.1-1.2$ & $0.45-0.55$ & $<0.1$ & $<0.3$ & $0.75-0.85$ \\
\hline $\mathrm{Ti}$ & $\mathrm{Cu}$ & $\mathrm{Cr}$ & $\mathrm{Al}$ & \\
$<0.05$ & $0.05-0.1$ & $<0.15$ & bal. & \\
\hline
\end{tabular}

The homogenized samples $(19 \times 150 \times 150 \mathrm{~mm})$ were hot rolled in multipass process at two different initial temperatures $\left(550\right.$ and $\left.580^{\circ} \mathrm{C}\right)$ on a laboratory mill. The experimental pass schedule is shown in table 2 . The rolling speed was set constant at $0.4 \mathrm{~m} / \mathrm{s}$.

Table 2: Pass schedule

\begin{tabular}{lc}
\hline Pass & reduction per pass, $\%$ \\
\hline 1 & 10 \\
2 & 15 \\
3 & 20 \\
4 & 30 \\
5 & 40 \\
\hline
\end{tabular}

The inter-pass time was fixed to 5 seconds. To preserve the achieved microstructure of the plate after hot rolling, it was quenched with water with a manipulation time of approximately 3 seconds.

The temperature was measured with a pyrometer in the plate centre after each pass. The result is given in table 3 .

Table 3: History plot of the measured temperature during hot rolling after homogenizations at 550 and $580^{\circ} \mathrm{C}$

\begin{tabular}{lll}
\hline Passes & $550^{\circ} \mathrm{C}$ & $580^{\circ} \mathrm{C}$ \\
\hline 1 & 491 & 520 \\
2 & 439 & 461 \\
3 & 384 & 421 \\
4 & 340 & 358 \\
5 & 318 & 338 \\
\hline
\end{tabular}

\subsection{Investigation of the substructure evolution}

Samples were upset at varying Zener-Hollomon parameter $Z$ to true strains of 0.8 and subsequently were quenched by water.

EBSD-analyses were applied in order to investigate the subgrain structure evolution as a function of $Z$. Figure 1 depicts the decreasing steady state subgrain size $\delta_{s s}$ with increasing $\ln (Z)$. Hence follows the relationship between the subgrain size and the deformation parameters in the steady-state regime

$\delta_{s s}^{-1}=-0.8274+0.0318 * \operatorname{LnZ}$

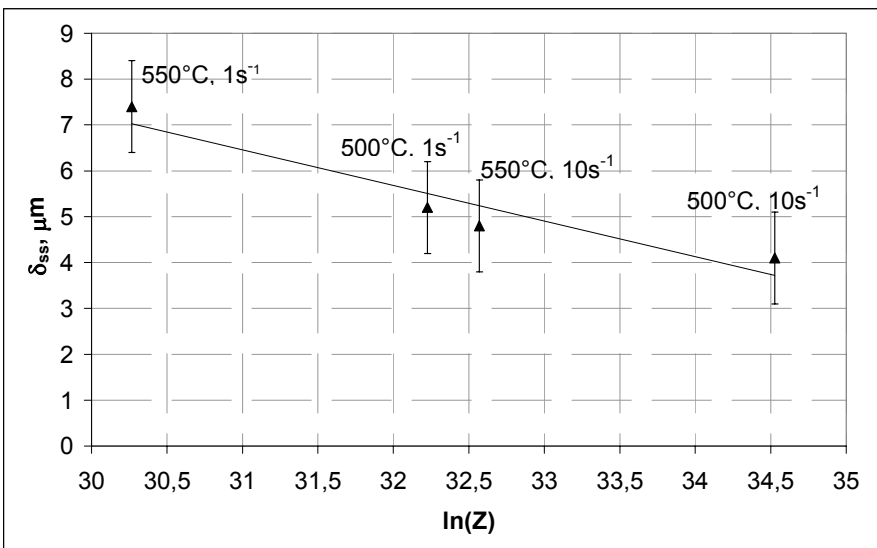

Figure 1: Subgrain size as a function of Zener-Hollomon parameter for AA6082

\section{FE SIMULATION AND MICROSTRUCTURE MODEL}

In this section a fully thermomechanical 3D FE model is adopted using FORGE3 according to the experimental procedure outlined in section 2.1. Due to the geometrical symmetry, a quarter of the plate is modelled. A very fine element size is applied to reduce any possible error caused by the mesh. Simulation has been carried out to study the substructure evolution in two dimensions.

Figure 2 presents the finite element analysis model. The workpiece is initially pushed into the roll gap by a punch. Once the net frictional force is large enough to draw the workpiece into the roll gap, the workpiece and the punch separate. A Tresca friction factor of 0.6 was used. A heat transfer coefficient between the roll and the plate of $18 \mathrm{kWm}^{-2} \mathrm{~K}^{-1}$ was chosen [4].

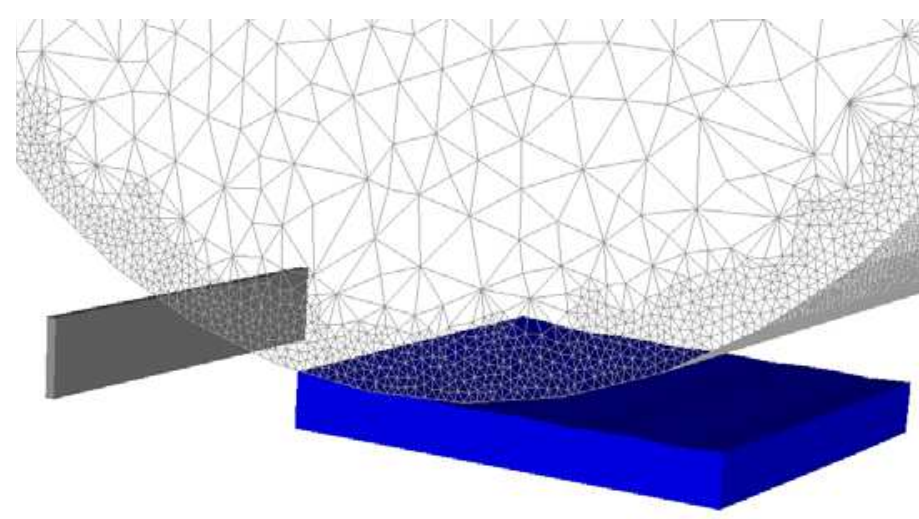

Figure 2: Finite element analysis model with the symmetrical quarter of the plate, the pushed and the roll

The material behavior is described by the following constitutive equation: 
$\sigma_{p}=\arcsin h\left(\frac{1}{A} Z^{1 / n}\right) \frac{1}{\alpha}$

and

$Z=\dot{\varphi} \exp \left(\frac{Q}{R T}\right)$

where $\sigma_{p}$ is the peak stress and $T, R$ as well as $\dot{\varphi}$ have their usually meanings.

The material constants $\alpha, n, Q$ and $A$ (table 4) were found using regression analysis of flow curves of AA6082.

Table 4: Constants for the constitutive equation

\begin{tabular}{llllc}
\hline Alloy & $\alpha$ & $\mathrm{n}$ & $\mathrm{Q}[\mathrm{J} / \mathrm{mol}]$ & $\mathrm{A}$ \\
\hline AA6082 & 0.002 & 9.209 & 148587 & $1.684^{*} 10^{19}$ \\
\hline
\end{tabular}

The relationship between the volume fraction statically recrystallised $X_{v}$ and the holding time $t$ is generally represented by the Avrami equation

$$
X_{v}=1-\exp \left(-0.693\left(\frac{t}{t_{50}}\right)^{k}\right)
$$

where $k$ is the Avrami exponent with a commonly reported value of 2 and $t_{50}$ is the time to $50 \%$ recrystallization. For the calculation of $t_{50}$, a physical model is regarded as revealing the mechanics driving the transformation. For the physical model [4], $t_{50}$ is calculated based on the stored energy $P_{D}$ and the density of recrystallization nuclei $N_{V}$

$t_{50}=\frac{C}{M P_{D}}\left(\frac{1}{N_{V}}\right)^{1 / 3}$

where $M$ is a grain boundary mobility and $C$ is a material constant. The stored energy is approximated by

$$
P_{D}=\frac{G b^{2}}{10}\left[\begin{array}{l}
\rho_{i}\left(1-\ln \left(10 b \rho_{i^{\frac{1}{2}}}\right)\right)+ \\
\frac{2 \theta}{b \delta}\left(1+\ln \left(\frac{\theta_{c}}{\theta}\right)\right)
\end{array}\right]
$$

$G$ is the shear modulus, $b$ is the Burger's vector, $\rho_{i}$ is the internal dislocation density, $\theta$ is the misorientation and $\theta_{c}$ is the critical misorientation for a high angle boundary $\left(15^{\circ}\right)$. The evolution of $\delta$, $\rho_{i}$ and $\theta$ is given by

$$
d \delta=\frac{\delta}{\varepsilon_{\delta} \delta_{s s}}\left(\delta_{s s}-\delta\right) d \varepsilon
$$

$$
d \theta=\frac{\theta}{\varepsilon_{\theta}}\left(\theta_{s s}-\theta\right) d \varepsilon
$$

and

$$
d \rho_{r}=d \rho_{r}^{+}+d \rho_{r}^{-}=\left(C_{1} \rho_{r}^{1 / 2}-C 2 \frac{\bar{\sigma}}{Z} \rho_{r}\right) d \varepsilon
$$

where $\delta_{S S}$ and $\theta_{S S}$ are respectively the subgrain size and misorientation at steady-state deformation, $\varepsilon_{\delta}$ and $\varepsilon_{\theta}$ are characteristic strains, $\rho_{r}$ is the random dislocation density, $\sigma_{f}$ is the flow stress, $C_{l}$ as well as $C_{2}$ are constants.

The initial dislocation density consists of two parts - $\rho_{r}$ and $\rho_{g}$, which is the geometrical necessary dislocation density [4]

$\rho_{i}=\rho_{r}+\rho_{g}$

For site saturated nucleation, the recrystallized grain size is simply approximated by

$d_{r e x}=D\left(N_{V}\right)^{-1 / 3}$

where $\mathrm{D}$ is constant.

\section{GRAIN STRUCTURE COMPARISON BETWEEN EXPERIMENT AND SIMULATION}

The Figure 3 shows the resulting subgrain structure in the plate center by EBSD-nalysis after the last pass. The elongated grains are located in the rolling direction. At the grain boundaries the nucleation of recrystallized grains is observable.
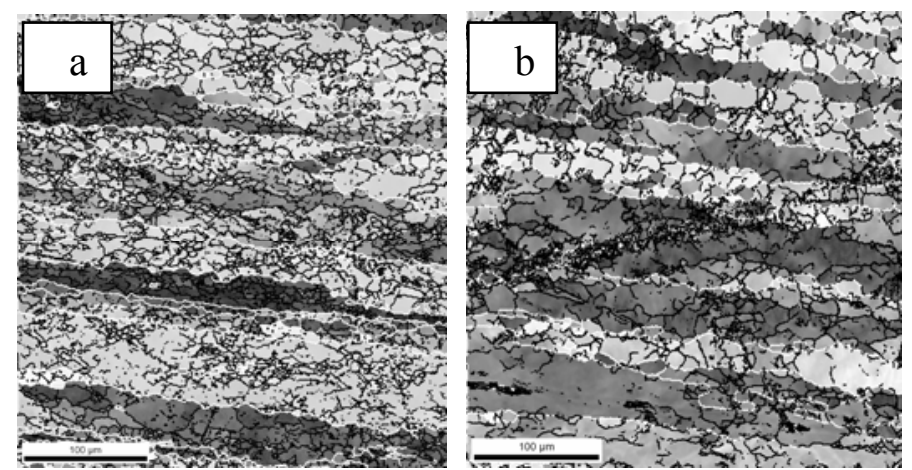

Figure 3: Subgrain structure analysis by EBSD. Low angle boundaries in black, high angle boundaries in white. Initial rolling temperature of a) $550^{\circ} \mathrm{C}$ and b) $580^{\circ} \mathrm{C}$

From EBSD-analysis the measured average subgrain sizes after the last pass were determined (table 5).

Table 5: Measured subgrain size after the last pass, $\delta_{\mathrm{ss}}[\mu \mathrm{m}]$

\begin{tabular}{ll}
\hline Initial rolling temperature $\left[{ }^{\circ} \mathrm{C}\right]$ & $\delta_{\text {ss }}$ \\
\hline $550^{\circ} \mathrm{C}$ & 2.6 \\
$580^{\circ} \mathrm{C}$ & 3.2 \\
\hline
\end{tabular}


In Figure 4 the calculated subgrain size evolution during the last pass is depicted experimentally for an initial temperature of $550^{\circ} \mathrm{C}$. Due to the contact between the roll and the plate the latter cools down, hence the subgrain size decreases. When the plate temperature increases and stabilizes because of dissipation of deformation energy, the subgrain size reaches a steady state.

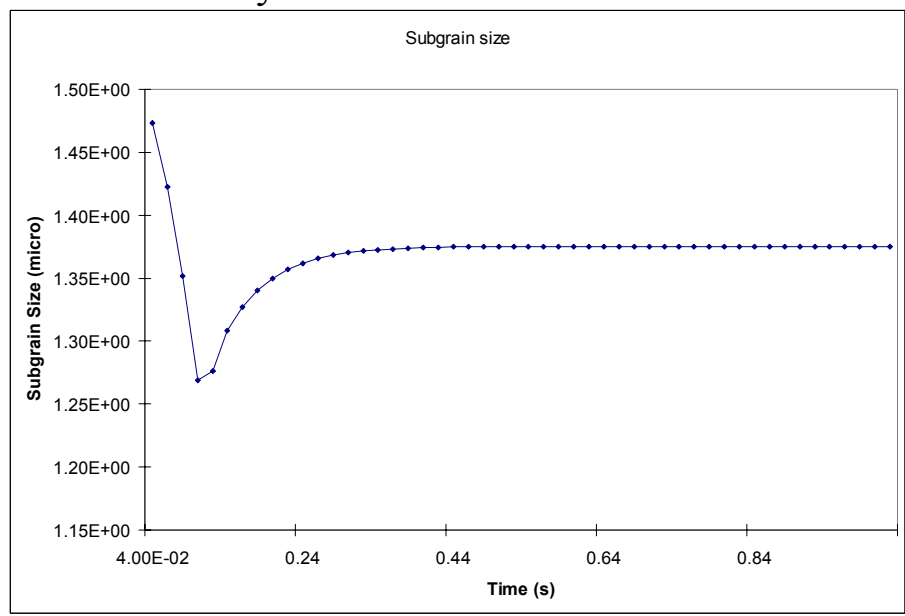

Figure 4: Subgrain size evolution in the plate center during pass 5 for an initial rolling temperature of $550^{\circ} \mathrm{C}$

The statically recrystallized volume has been analysed by light microscopy (Figure 5), therefore samples were cut from the plate center, grinded, polished and etched according to Weck $(1.90 \mathrm{ml}$ $\mathrm{H}_{2} \mathrm{O}, 10 \mathrm{ml} \mathrm{H}_{3} \mathrm{PO}_{4} ; 2$. $100 \mathrm{ml} \mathrm{H}_{2} \mathrm{O}, 4 \mathrm{~g} \mathrm{KMnO}_{4}, \mathrm{lg}$ $\mathrm{NaON})$

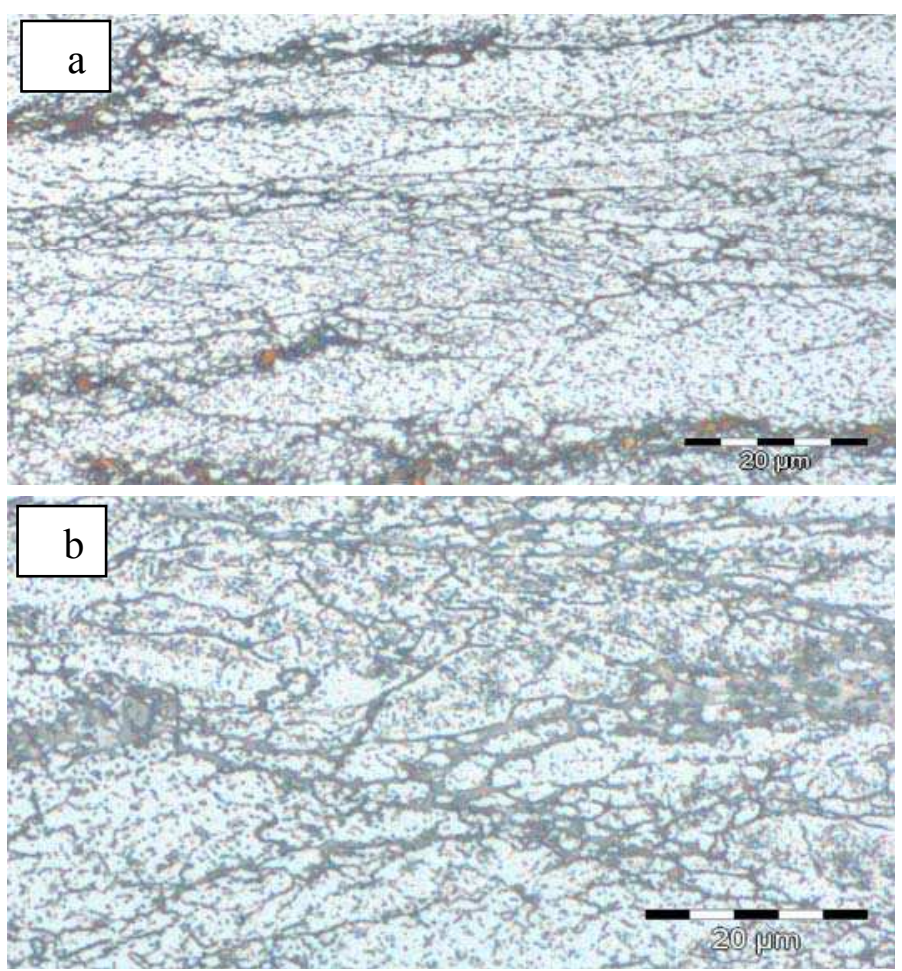

Figure 5: Microstructure in the rolled plate center after the last pass at an initial rolling temperature of a) $550^{\circ} \mathrm{C}$ and b) $580^{\circ} \mathrm{C}$. Statically recrystallized grains are located at elongated deformed grains
The microstructure after the last pass indicates the beginning of statically recrystallization $(<10 \%)$, whereas at $580^{\circ} \mathrm{C}$ the recrystallization apparently is more advanced. The calculations from the physical model also show the onset of static recrystallization, however with even smaller volume fractions $(<1 \%)$.

\section{SUMMARY}

In this work, the effect of the initial rolling temperature on the microstructure evolution during and after hot rolling of AA6082 was described. A commercial FEM package FORGE3 was used to predict the subgrain structure evolution during rolling as well as the grain structure development after multi-pass hot rolling.

It was shown that the homogenization temperature, i.e. the initial rolling temperature has a reasonable influence on the final grain structure, because the subgrain structure strongly influences the subsequent statically recrystallization. Both calculations and experimental analysis indicate a rather smaller amount of statically recrystallization.

\section{REFERENCES}

[1] P. Rometsch, S. Wang, A. Harriss, P. Gregson, M. Starik. The effect of homogenizing on the quench sensitivity of 6082 . Materials Science Forum, 396-402:655-660, 2002

[2] G. Mromka-Nowotnik, J. Sieniawski. Influence of heat treatment on the microstructure and mechanical properties of 6005 and 6082 aluminium alloys. Journal of Materials Processing and Technology. 162-163:367-372, 2005

[3] X. Duan and T. Sheppard. Simulation and control of microstructure evolution during hot extrusion of hard aluminium alloys. Materials Science and Engeneering, A351:382-292, 2003

[4] X. Duan, $T$ and Sheppard. Influence of forming parameters on static recrystallization behaviour during hot rolling aluminium alloy 5083. Modelling and Similation in Materials Science and Engineering, 10: 363-380, 2002

[5] I. Flitta, T. Sheppard, and Z. Peng. Finite element analysis to predict development of structure during extrusion and subsequent solution soak cycle. Materials Science and Technology, 23:1-11, 2007 


\title{
Numerical approach for thick plates manufacturing
}

\author{
Richard SPATARO ${ }^{1}$, Pierre KRUMPIPE ${ }^{1}$, Georges ROSSI ${ }^{2}$, Louis MATHIEU ${ }^{2}$ \\ ${ }^{1}$ CETIM (Centre Technique des Industries Mécaniques) - 7, rue de la Presse, BP 802, 42952 Saint Etienne \\ Cedex 9, France \\ URL: $\underline{\text { www.cetim.fr }}$ \\ e-mail: richard.spataro@cetim.fr; pierre.krumpipe@cetim.fr
}

${ }^{2}$ ALSTOM HYDRO - 82, Avenue Léon BLUM, 38000 Grenoble, France

URL: $\underline{w w w . h y d r o . p o w e r . a l s t o m . c o m} \quad$ e-mail:georges.rossi-ext@power.alstom.com;

louis.mathieu@power.alstom.com

\begin{abstract}
The construction of increasingly powerful hydraulic plants added to the ongoing research to cut manufacturing costs, requires the power station suppliers to develop and control new production technologies without delay. Therefore ALSTOM HYDRO in a continuous effort of $\mathrm{R}^{*} \mathrm{D}$, has turned to numerical simulation using the $\mathrm{FORGE}^{\circledR} 2005$ software to define their production process for turbine blades. Modelling the forming operation allows manufacturing difficulties and die modifications to be anticipated. We use thermo-physical measurements and the setting of thermal exchange coefficients to then simulate the blade heat treatment. The relevance of the digital approach is confirmed by comparing the numerical results to manufacturing data.
\end{abstract}

Keywords: hydraulic turbines, blade, forming, cooling, FORGE ${ }^{\circledR} 2005$, expansion coefficient

\section{INTRODUCTION}

ALSTOM HYDRO is the world leading hydro power equipment supplier and service provider. Its product range covers large, medium and small hydro plants, as well as services and rehabilitation of existing plants. For their Hydraulic turbines and pump turbines up to $900 \mathrm{MW}$, they produce a large range of blades.

Together with traditional casting production, ALSTOM HYDRO is now developing manufacturing technology using thick plate hot forming processes. This approach results from research and development of new products or supplies. In order to optimize the material used and control the final blade shape, ALSTOM HYDRO wished to simulate the complete production cycle. This means two main steps as follows:

- plate forming

- heat treatment: controlled cooling

\section{PLATE FORMING SIMULATION}

\subsection{Plate positioning at the start of forming}

The used material is a stainless steel warmed to $1150^{\circ} \mathrm{C}$. The $105-\mathrm{mm}$ thick plates are previously obtained by rolling and are then flame cut to the profile specified by ALSTOM HYDRO. The greatest length is about three metres. The blade is shown in figure 1.

The dies are made with honeycomb structure.

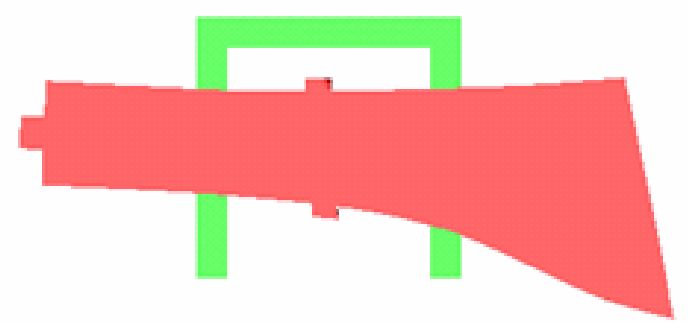

Fig. 1. initial plate shape

According to the difficulty of handling these parts in the factory with lift trucks, the plate's position and its stability on the forks of the handling machine or on the lower die, have to be ensured and easy to set up.

A simple calculation of gravity setting demonstrates the plate's instability when placed on the lower die. As shown in figure 2, the plate tips exceed $\mathrm{Y}$ axis. 


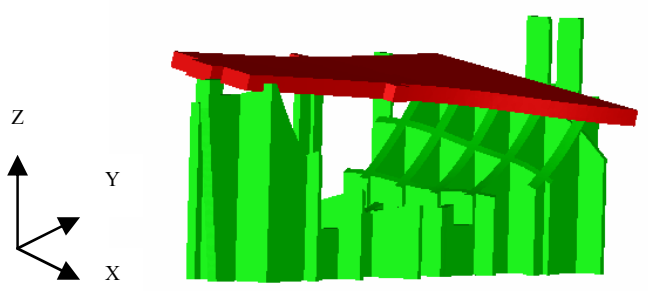

Fig. 2. Plate tipping

In order to avoid this matter, end stops are added along the $\mathrm{Z}$ axis. Figure 3 confirms that the plate's position at the start of forming is now ensured (included in the XY plan).

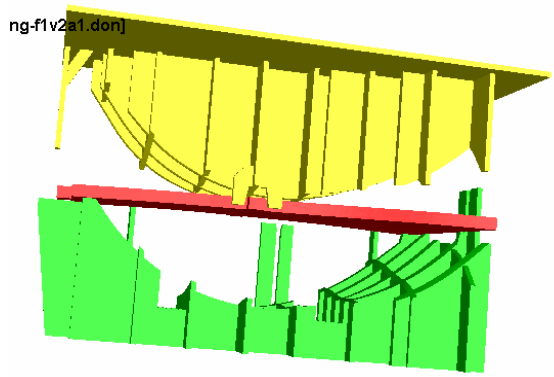

Fig. 3. Plate positioned correctly

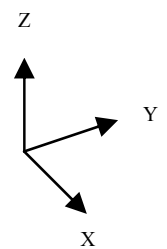

\subsection{Slipping of the plate during forming}

The dies are specified so as to obtain a shape of plate that suits to the machined blade. Thus, as a consequence of the part's curved shape, it is essential that the formed plate remains strictly in the required position.

Figure 4 shows excessive slipping of the plate and thus a wrong final position on the lower die.

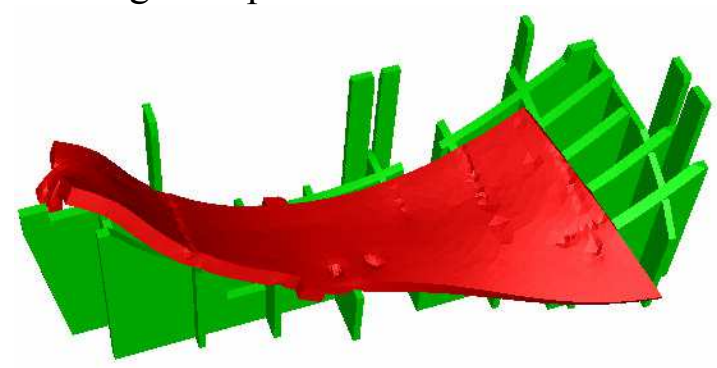

Fig. 4. Plate slipping

Because of the cut plate cost, any manufacturing scrap or over length is forbidden. Lateral stops are then settled to hold the plate during forming and hence obtain a suitable blade as shown in figure 5 .

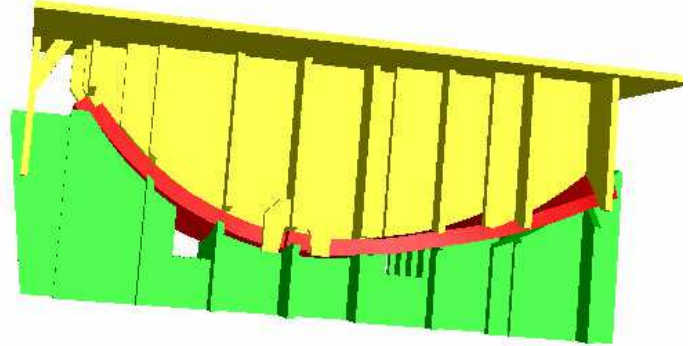

Fig. 5. Blade positioned correctly
These few die modifications, before their production, had limited the risks of plate scrapping in production.

\subsection{Forming force}

Using numerical simulation, FORGE ${ }^{\circledR} 2005$ software, we estimate the required forming force which increases very slowly to reach about 10,000 $\mathrm{kN}$ (1000 tons) at the end of forming (Fig 6).

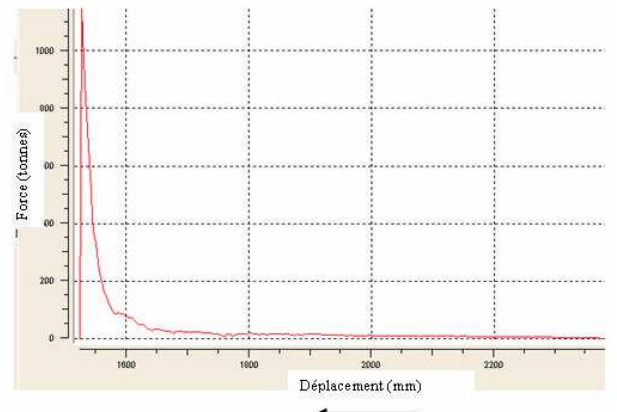

Fig. 6. Forming force

This result allows us to select the suitable production press.

These values will be confirmed later during initial blade manufacturing.

\section{AIR COOLING SIMULATION}

\subsection{Study hypothesis and thermo-physical data}

For this type of martensitic stainless steel, the heat treatment step involves a simple air cooling. We make the hypothesis that in a first approach, just taking into account the expansion coefficient change with temperature shows up the main distortions. Here micro-structural changes or other transformation plasticities are ignored.

Accurate expansion measurements are made using a NETZSCH DIL 402C "push rod" expansion meter. The results are shown in figure 7.

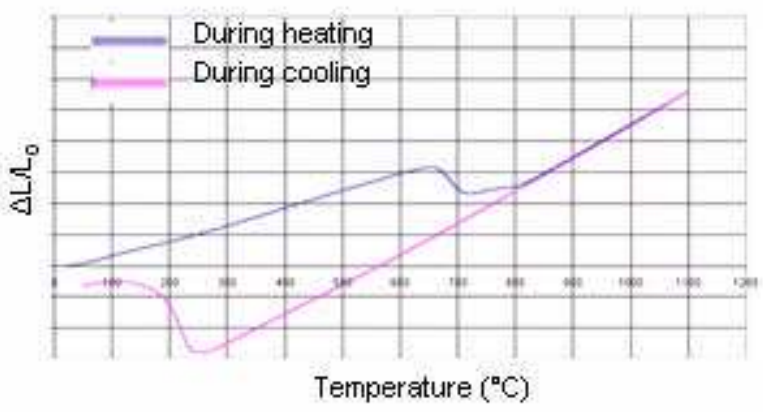

Fig. 7. Expansion measurement curves 
These data are completed with specific heat and thermal conductivity measurements.

\subsection{Setting the heat exchange coefficients}

To reproduce in the best way the cooling conditions of the formed plate, we use temperature data supplied by ALSTOM HYDRO. These curves (temperature versus time) derive from thermocouples attached to a test sample, (fig 8), of the same metal as the designed blades and heated/cooled in the same conditions as all the manufactured blades.
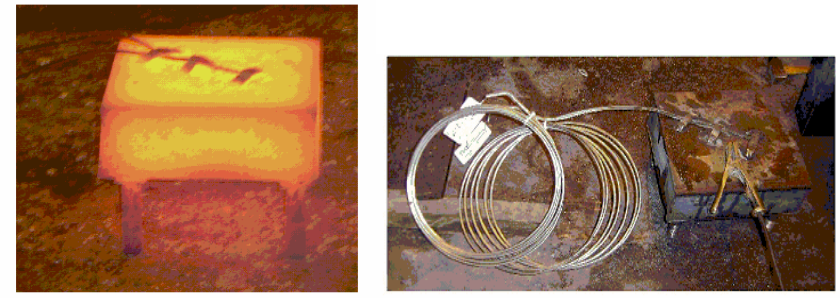

Fig. 8. Test sample

Meanwhile, we model this experimental test with FORGE $^{\circledR} 2005$. The aim is to validate simulation input data by setting the numerical temperature curves in relation to the measurements. Then we introduce thermal coefficient values depending on the temperature of the heat exchange area. In addition, these values and those of the ambient temperature are different according to the exposed surface (facing the ground or free). By successive simulations, we obtain close digital/experimental curves, as represented in figure 9 .

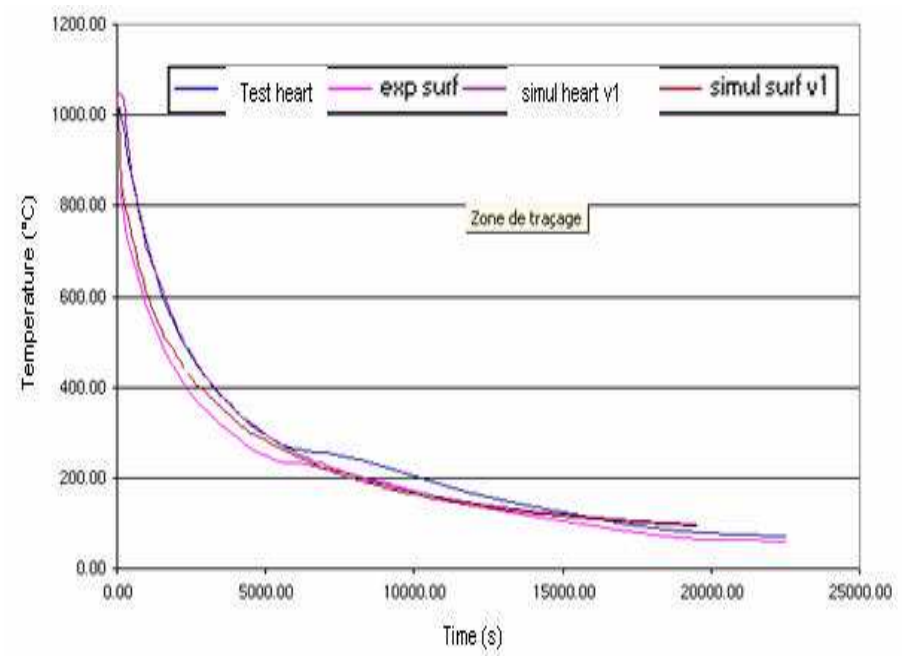

Fig. 9. Test sample

\subsection{Simulation results}

These settings, both for the material's thermophysical characteristics and for the thermal exchange coefficients, allow to simulate the formed plate's air cooling phase. We see relatively uniform deformation (shrinkage). Nevertheless, plate contraction during cooling slightly alters its curvature, as we can see in figure 10.

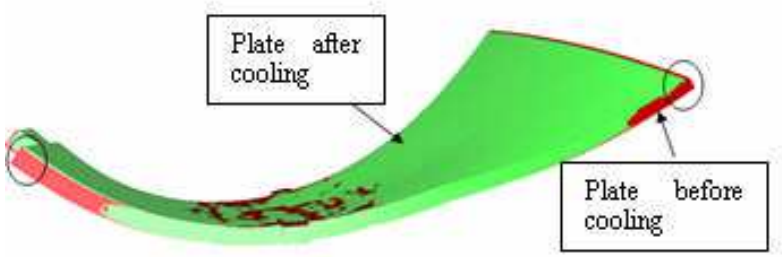

Fig. 10. Plate superimposition before (red) and after cooling (green)

Differences of about $10 \mathrm{~mm}$ appear at the ends. So, it looks important to take expansion coefficient effects into account.

\section{DIGITAL RESULTS VALIDATION}

The final geometry of the formed plate obtained by simulation is compared with the scatter plot constructed from digital sensing of the first manufactured blade. This was formed by the tools free from any manual reworking, and normally suits to the CAD specification used for the simulation.

Figures 11 below shows the differences observed on one side of the blade between the measured and theoretical values (a) and the numerical and theoretical values (b).

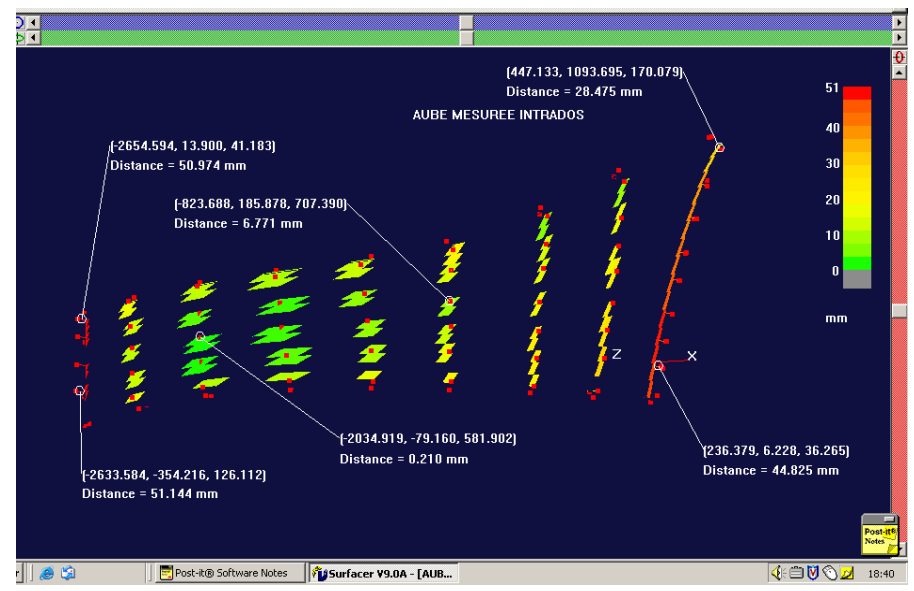

Fig. 11a Distance (mm) between the measured and theoretical blades 


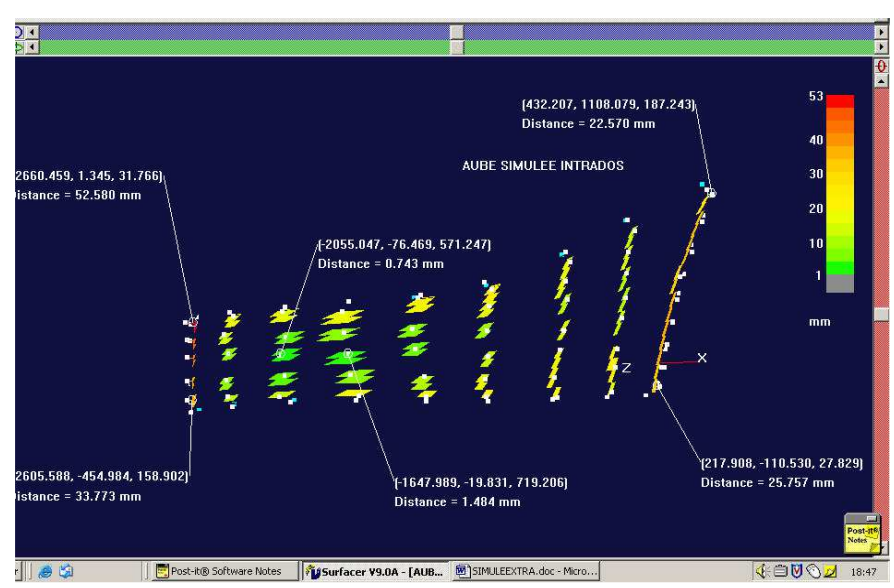

Fig. 11b Distance $(\mathrm{mm})$ between the simulated and theoretical blades

Overall, the distance readings show the same trend. For example, we find again an area of low thickness in the middle of the blade near the narrow side $(0.2 \mathrm{~mm}$ for measured blade and 0.7 for simulated blade). The maximum difference between the simulation and the measurements is about $5 \mathrm{~mm}$.

\section{CONCLUSIONS}

Blade forming simulation, as a part of the development process, enables tool modifications before even the first manufacturing step. Following this production run (February 2007), the first part was declared good and only some slight tool modifications were made, unlike previous manufactures. Thus this study enabled cost and time savings.

Experimental data of temperature change with time allows us to set the thermal exchange coefficient values as precisely as possible. Combined with the measured thermo-physical values, these input data consolidate modelling of the process.

Multiple simulation/measurement comparisons lean us to the following conclusion :

- simulated plate seems to be quite close to measured plate. Thus, even if simulation cannot perfectly represent actual forming, this model seems capable of acting as a pre-validation of the forming plate. While allowing a safety numerical margin (3-4 mm), for new blade production ALSTOM HYDRO can validate or develop stamping device shapes for new blade production even before manufacturing. 


\title{
Technological Problems of Closed- Die Forging of Powder Metallurgy Fe-Al Preforms
}

\author{
S.Szczepanik ${ }^{1}$
}

${ }^{1} A G H$ University of Science and Technology - Al. Mickiewicza 30, Pl-30-059 Kraków, Poland
e-mail: szczepan@metal.agh.edu.pl

Fe-Al PM preforms from powder mixes with 30 and 40at $\%$ Al were heated and closed-die forged at 500 or $550^{\circ} \mathrm{C}$ to yield materials with porosity lower than $10 \%$. Brinell hardness, bend and compression strengths were determined, also after $4 \mathrm{~h}$ heat treatment at $540^{\circ} \mathrm{C}$. The content of the $\mathrm{Fe}-\mathrm{Al}$ intermetallics depends on forging temperature and heat treatment. Optimum bend strength reached, $153 \mathrm{MPa}$, was for $30 \% \mathrm{Al}$ alloy, forged at $550^{\circ} \mathrm{C}$ and heat-treated. Larstran Shape program was used to simulate shape manufacturing by closed - die forging.

Key words: Fe-Al PM alloy, closed-die forging, mechanical properties, shape forging, simulation

\section{INTRODUCTION}

Various metallurgical processes, including PM routes, are used to obtain alloys with intermetallic phases [1,7]. For the synthesis of powders mechanical alloying may be used [2]. SHS, self propagation high temperature synthesis, has been employed to obtain intermetallics from homogenous powder mixtures [3]. This research deals with Fe-Al for which, considering the significant difference in their melting points, it is difficult to obtain materials with repeatable composition and structure. In this system intermetallic $\mathrm{Fe}-\mathrm{Al}$ phases obtained from powders via the SHS process and hot processing are charecterised by good high temperature corrosion resistance and adequate mechanical properties, which strongly depend on the forming conditions [4,5]. In the binary system Fe-Al two intermetallics $\mathrm{Fe}-\mathrm{Al}$ and $\mathrm{Fe}_{3} \mathrm{Al}$ can constitute the matrix for potential construction materials. The phase $\mathrm{Fe}_{3} \mathrm{Al}$ appears in alloys with 23-36 at \% aluminium, while the $\mathrm{FeAl}$ phase in 36-48at\%Al. The main disadvantage of the alloys based on $\mathrm{FeAl}$ and $\mathrm{Fe}_{3} \mathrm{Al}$ phases is low plasticity at room temperature and low strength at elevated temperatures.

\subsection{Aim and Scope of the Investigation}

The aim of this research is to determine the influence of deformation temperature of the preforms of iron and aluminium powder mixes on the flow, density and mechanical properties, taking account also of the tool shape. The chosen processing route was first to cold densify and then heat and deform at an elevated temperature. The flow of two component $\mathrm{Fe}-40 \mathrm{at} \% \mathrm{Al}$ material during forming in the shape die were to be analysed using Larstran Shape program.

\subsection{Material Characteristics}

Two powder mixtures containing 30 and 40 at $\%$ of RAl-1 aluminium, balance iron WPL, were prepared in a two-cone mixer with steel balls. The morphology of the particles is shown in Fig. $1.165 \mathrm{~g}$ samples were consolidated in an hydraulic press at $175 \mathrm{MPa}$ into preforms with diameter $\phi=48 \mathrm{~mm}$, and $20 \mathrm{~mm}$ in height. The densities of the 40 and $30 \% \mathrm{Al}$ preforms were $4,49 \pm 0,31$ and $4,56 \pm 0,23$ $\mathrm{g} / \mathrm{cm}^{3}$, respectively. 
The preforms were heated to 500 or $550{ }^{\circ} \mathrm{C}$, and then formed in closed dies using flat punches. The forming was accomplished in one stroke in a screw press at about $526 \mathrm{MPa}$. Fig. 2 shows an example of the change in forging force during deformation. The densities of the preforms were measured using the Archimedes'method.

a)

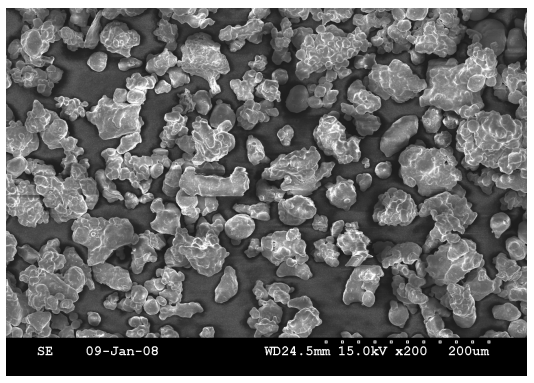

b)

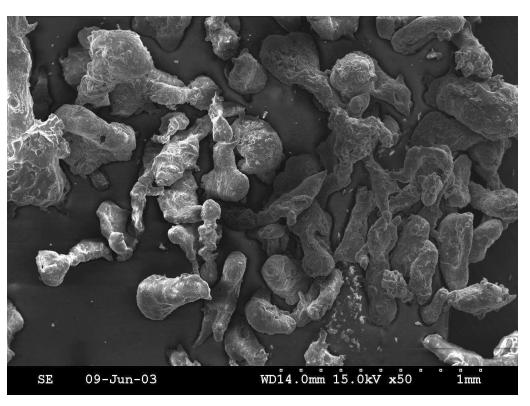

Fig. 1. Morphology of WPL -a and RAl-1 -b powder particles.

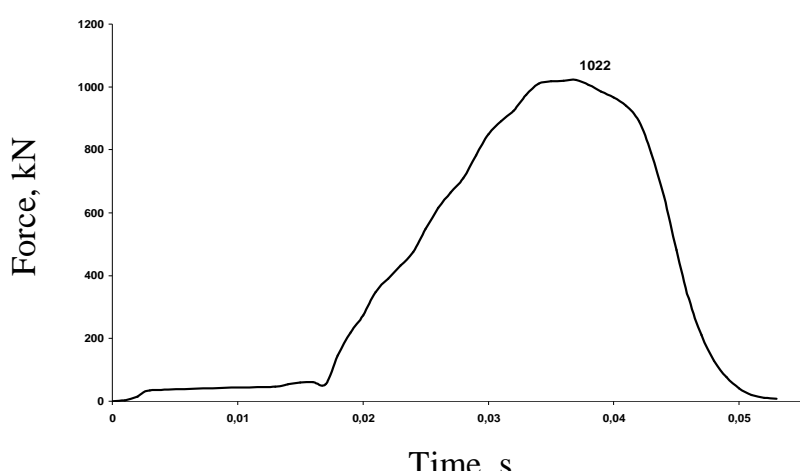

Fig. 2. Force diagram during forging of $\mathrm{Fe}-30 \%$ at $\mathrm{Al}$ preforms at 550C in closed dies with flat punches.

These were 5,16 and $5,57 \mathrm{~g} / \mathrm{cm}^{3}$ for 40 and $30 \% \mathrm{Al}$ forged at $500{ }^{\circ} \mathrm{C}$ and for forging at $550^{\circ} \mathrm{C}, 5,23$ and $5,52 \mathrm{~g} / \mathrm{cm}^{3}$, respectively. Some specimens were additionally argon annealed for $4 \mathrm{hrs}$ at $540^{\circ} \mathrm{C}$. This resulted in density increases: for 40 at $\% \mathrm{Al}$ forged at $500^{\circ} \mathrm{C}$ from 5,16 to $5,21 \mathrm{~g} / \mathrm{cm}^{3}$, for forged at $550{ }^{\circ} \mathrm{C}$ from 5,39 to $5,62 \mathrm{~g} / \mathrm{cm}^{3}$ and correspondingly for 30 at\% Al from 5,60 to $5,81 \mathrm{~g} / \mathrm{cm}^{3}$ and from 5,36 to $5,54 \mathrm{~g} / \mathrm{cm}^{3}$, respectively.

\subsection{Mechanical properties}

Brinnel hardness (indenter with diameter $\mathrm{d}=2,5 \mathrm{~mm}$ and applied force of $62,5 \mathrm{kG}$ ) and compression and bend strengths for materials processed by forging and additional annealing are presented in Table 1 . Fractographic observations of bend specimens showed that the brittle failures were associated with pores and fracture took place along prior particle boundaries, as illustrated in Figs. 3 and 4.

Table 1. Mechanical properties of the Fe-Al materials

\begin{tabular}{ccccc}
\hline Material & $\begin{array}{c}\text { Forming } \\
\text { temperature } \\
{ }^{\circ} \mathrm{C}\end{array}$ & $\begin{array}{c}\text { Brinell } \\
\text { hardness } \\
\mathrm{HB}\end{array}$ & $\begin{array}{c}\text { Bend } \\
\text { strength } \\
\mathrm{MPa}\end{array}$ & $\begin{array}{c}\text { Compression } \\
\text { strength, } \\
\mathrm{MPa}\end{array}$ \\
\hline $\begin{array}{c}\mathrm{Fe}- \\
40 \% \text { at } \mathrm{Al}\end{array}$ & 500 & $66 \pm 2$ & $130 \pm 21$ & 190 \\
\cline { 2 - 5 } & 550 & $62 \pm 3^{*}$ & $115 \pm 35^{*}$ & $201^{*}$ \\
\cline { 2 - 5 } & 500 & $68 \pm 3$ & $138 \pm 6$ & 208 \\
\hline Fe- & & $76 \pm 6$ & $120 \pm 25$ & 208 \\
\hline $30 \%$ at Al & $55 \pm 5^{*}$ & $109 \pm 28^{*}$ & $207^{*}$ \\
\cline { 2 - 5 } & 550 & $80 \pm 7$ & $153 \pm 16$ & 233 \\
\cline { 2 - 4 } & & $87 \pm 3^{*}$ & $92 \pm 8^{*}$ & $242^{*}$ \\
\hline
\end{tabular}

* after annealing: $540^{\circ} \mathrm{C} / 4 \mathrm{~h}$

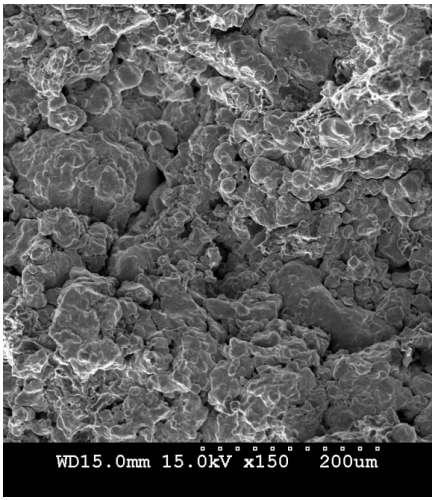

a)

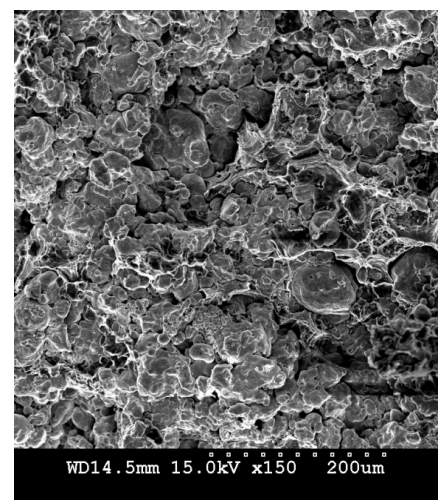

b)
Fig. 3. Fractograph of Fe-40at $\% \mathrm{Al}$ material: a- after forging at $500^{\circ} \mathrm{C}, \mathrm{b}-$ as a) and annealed at $540^{\circ} \mathrm{C}$ for $4 \mathrm{~h}$.

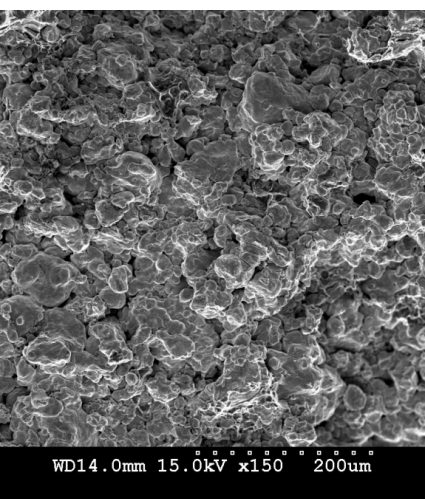

a)

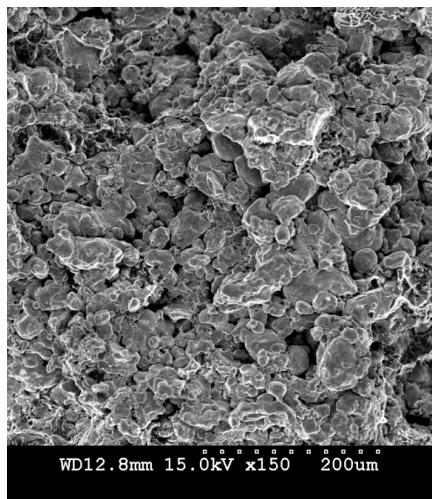

b)
Fig. 4. Fractograph of $\mathrm{Fe}-40 \mathrm{at} \% \mathrm{Al}$ material: a - after forging, b- as a) and annealed at $540{ }^{\circ} \mathrm{C}$ for $4 \mathrm{~h}$.

\subsection{Shape Forming Trials}

Shape forging of the preforms was performed at $550^{\circ} \mathrm{C}$. An example of a force - time diagram during 
forging is shown in Fig.5. Typical stages visible on the curve are: indentation of the punch into material, filling the die and filling the corner of the die with strongly increase in force. Fig. 6 illustrates the forgings; the resultant dimensions are recorded in Table 2.

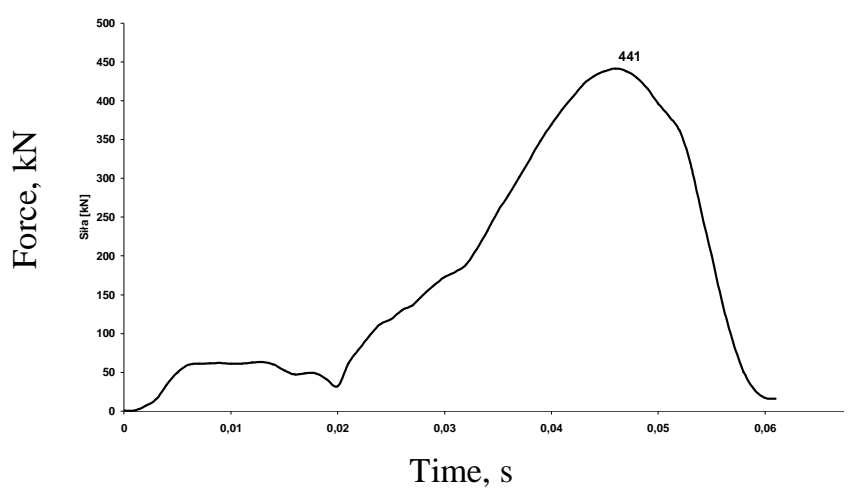

Fig. 5. Force variation during forging at $550^{\circ} \mathrm{C}$ with top and bottom shape punches with joggle of $\phi=30 \mathrm{~mm}$ diameter

a)
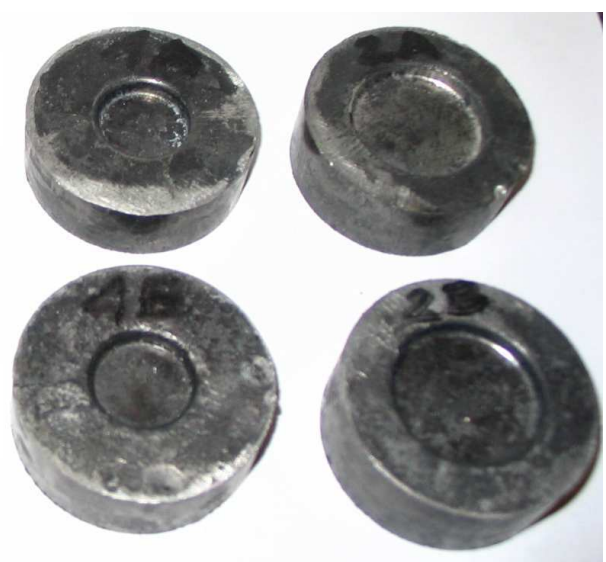

Fig. 6. Closed-die forged preforms: a-Fe-40at \%Al, b- Fe30 at $\% \mathrm{Al}$

Table 2. Shape and density of the forgings

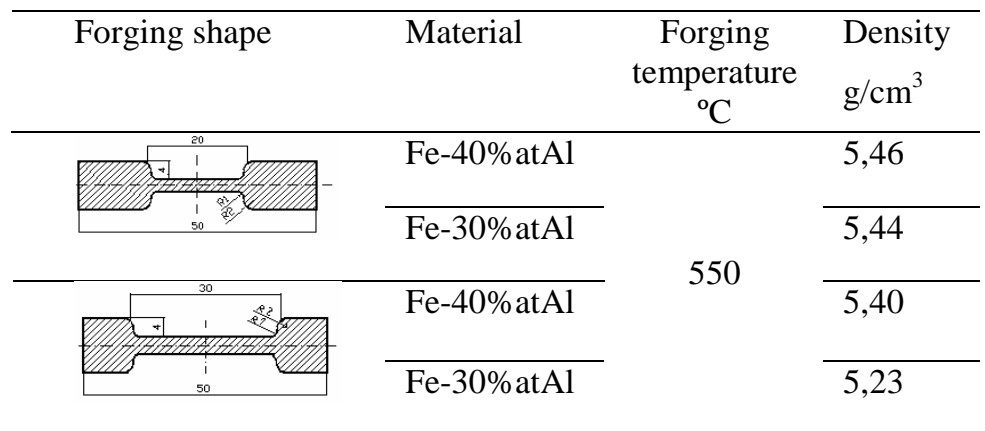

\subsection{Numerical analysis of die forging}

Larstran Shape program was used to simulate shape manufacturing by closed - die forging [8]. The simulation was of material flow during forging using shape top punch with $\phi 20 \mathrm{~mm}$ diameter of the joggle and flat bottom of the die. The boundary conditions for the die were: punch velocity - 200 $\mathrm{mm} / \mathrm{s}$, die temperature $-300^{\circ} \mathrm{C}$, friction coefficient $-0,1$ and material temperature $550^{\circ} \mathrm{C}$. The stressstrain relationship for iron and aluminium were defined by the Hensel -Spittel equation [9]. Calculations of the simulations employed a 88- step thermo-mechanical model. Die with workpiece and the shape of the forging are shown in Fig. 7.

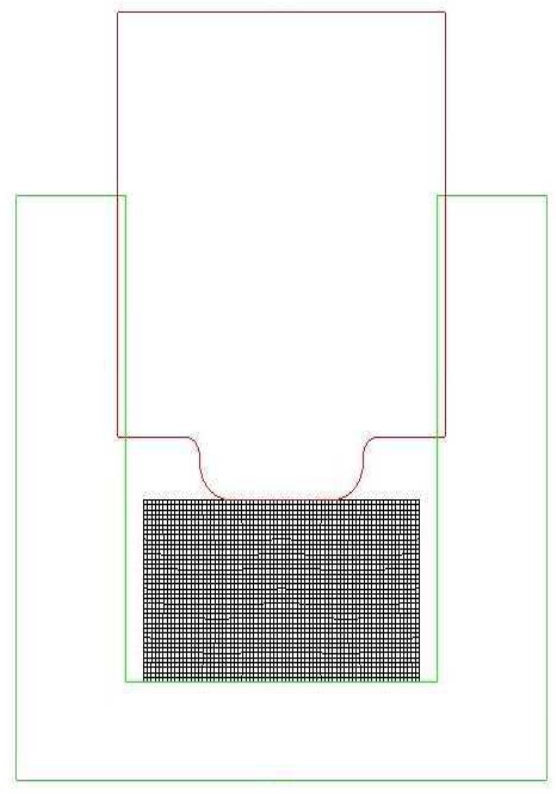

(a)

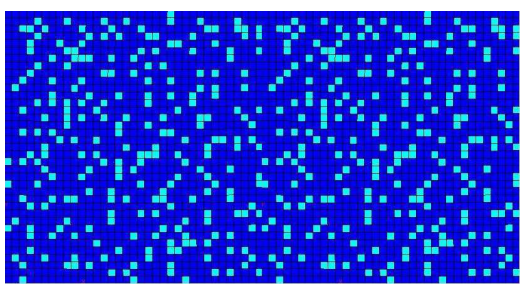

(b)

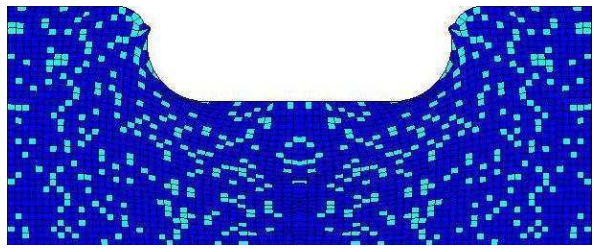

(c)

Fig. 7. Model generated for the simulation $-\mathrm{a}$, initial $\mathrm{Fe}-40 \% \mathrm{Al}$ specimen $-\mathrm{b}$ and forging $-\mathrm{c}$.

The simulation yielded information about distribution of equivalent strain, equivalent stress and temperature in material in intermediate and finished stages of forging, illustrated in Fig. 8.

During the intermediate stage of forging, higher values of equivalent strain, 2.0, appear in material in the contact zone of web of the forging with the punch. In the remainder of the forging zone, equivalent strains are smaller than 1.0. The highest values, 2.6, appear in the end stage of the deformation 
- in the forging zone under the punch. In the remainder of the forging they were smaller than 1.3.

a)

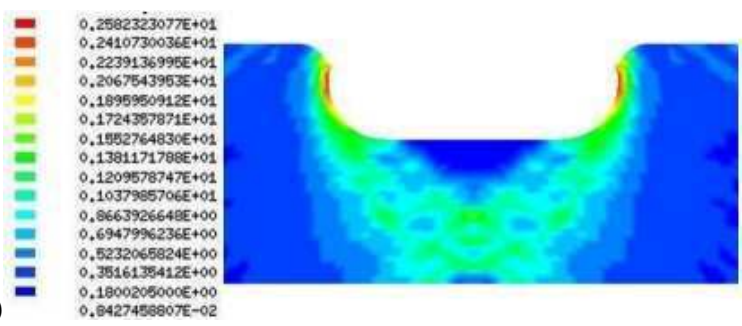

b)

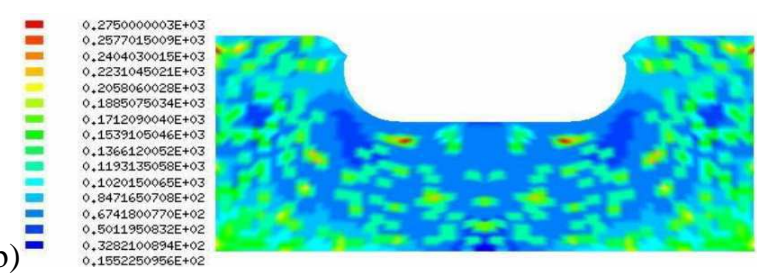

c)

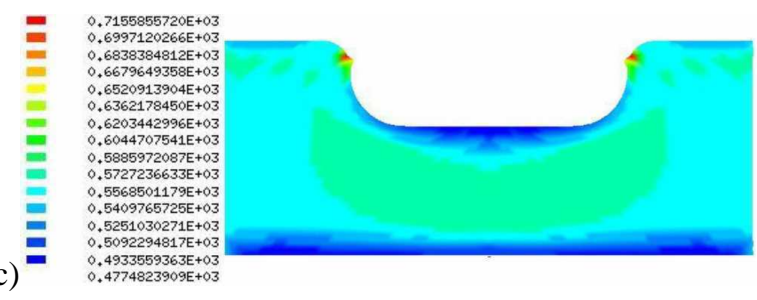

Fig. 8. Distribution of equivalent: a- strain, b- stress and $\mathrm{c}$ - temperature

In zones with higher aluminum concentration the values of equivalent stresses are higher. In these zones their value are 200 to $270 \mathrm{MPa}$ during the intermediate stage and about $275 \mathrm{MPa}$ during the finished stage of forging.

During the intermediate stage of forging temperature of $565^{\circ} \mathrm{C}$ was reached in the central zone of forging, with lower temperature of about $500{ }^{\circ} \mathrm{C}$ in the contact zone of punch and the surface of the die. In the finished stage of deformation, the highest local temperature of $715^{\circ} \mathrm{C}$ appeared in the forging zone of the highest equivalent strain. In the remainder of the forging the temperatures were 500 to $570{ }^{\circ} \mathrm{C}$.

\section{CONCLUSIONS}

The mechanical properties of $\mathrm{Fe}-\mathrm{Al}$ materials obtained by hot closed-die forging of PM preforms depend on chemical composition and forming parameters. This method of consolidation results in densities reaching nearly theoretical values. Additional annealing at $540^{\circ} \mathrm{C}$ for $4 \mathrm{~h}$ in argon causes small increases in density. As to hardness, for forging at $500^{\circ} \mathrm{C}$, it decreases, while for material forged at $550{ }^{\circ} \mathrm{C}$ it increases considerably. The highest hardness of $93 \mathrm{HB}$ was achieved after forging at $550^{\circ} \mathrm{C}$ an annealing of $\mathrm{Fe}-a t 40 \% \mathrm{Al}$.

Annealing of $\mathrm{Fe}-\mathrm{Al}$ material resulted in decreases of bend strength in comparison with only forged material, especially after forging at $550{ }^{\circ} \mathrm{C}$. The highest bend strengths were recorded for materials after forging at $550^{\circ} \mathrm{C}$, without the annealing. Compression strengths were higher for forged materials after annealing; the highest value, $242 \mathrm{MPa}$, was attained by $\mathrm{Fe}-30 \% \mathrm{Al}$ after forging at $550^{\circ} \mathrm{C}$.

Qualitative and quantitative data about the flow of compound, two component materials were obtained by sing Larstran Shape program to simulate shape manufacturing by closed-die forging. This information was adapted to manufacturing of forgings from $\mathrm{Fe}-40 \% \mathrm{Al}$ performs.

\section{ACKNOWLEDGEMENTS}

The experimental part of this research forms part of the AGH Statutory Work Programme 11.11.110.795. The author is grateful to Dipl.-Ing. G. Barton from Acut Aachen and Mgr inż. K. Fludzińska for co-operation in the simulation part, and to Prof. A. Wroński of the University of Bradford for editing the MS.

\section{REFERENCES}

1. J. Barcik, J. Cebulski, Intermetallic Compound Based Fe40Al as Cast Alloy- Chemical Composition, Microstructure and Properties. Inżynieria Materiałowa 4(1998) 901-904

2. D. Oleszak, Proszki kompozytowe FeAl-Al2O3 i NiAlAl2O3 otrzymywane metodą mechanicznej syntezy: Kompozyty 1(2001) 76-78.

3. E. Godlewska, R. Mania, S. Szczepanik, S. Koziński, J. Krawiarz, Some useful properties of FeAl intermetallic obtained by self-propagating high-temperature synthesis. Inżynieria Materiałowa, 4 (2001) 354-357.

4. S. Szczepanik, E. Godlewska, R. Mania, Influence of hot forming on the properties of $\mathrm{Fe}-\mathrm{Al}$ intermetallic materials. In Proc. of the $8^{\text {th }}$ Inter. Conf. on Metal Forming Metal forming 2000, ed. Pietrzyk et al, Balkema, Rotterdam (2000) 477-484

5. E. Godlewska, R. Mania, S. Szczepanik, Selected properties of $\mathrm{Fe}-\mathrm{Al}$ intermetallics prepared by various processsing routes. In Proc. Int. Conf. Enviromental Degradation of Engineering Materials, Gdańsk - Gdańsk Jurata (1999) 347-352

6. S.Szczepanik, E. Godlewska, R. Mania, Materiały Fe-Al otrzymane z proszków. Kompozyty 4 (2002) 242-247

7. M. Kupka: Struktura $i$ wtaściwości stopów na osnowie fazy FeAl otrzymanych $w$ procesach metalurgicznych. Wydawnictwo Uniwersytetu Śląskiego, Katowice (2005)

8. Larstran Shape. Acut Aachener Umformtechnik GmbH, Aachen, Germany

9. A. Hensel, T. Spittel: Kraft und Arbeitsbedarf bildsamer Formgebungsverfahren. VEB Deutsche Verlag für Grundstoffindustrie, Leipzig (1978) 


\title{
Quasi-static versus dynamic explicit scheme for the modeling of an energy-driven thermo-mechanical forming process
}

\author{
E. Vidal-Sallé ${ }^{1}$ S. Boutabba ${ }^{2}$, J.C. Boyer ${ }^{1}$
}

${ }^{1}$ Département de Génie Mécanique Conception, Institut National des Sciences Appliquées, 20 Av A. Einstein, 69621 Villeurbanne Cedex, France

URL: $\underline{w w w . i n s a-l y o n . f r \quad e-m a i l: E m m a n u e l l e . V i d a l-S a l l e @ i n s a-l y o n . f r ; J e a n-C l a u d e . B o y e r @ i n s a-l y o n . f r ~}$

${ }^{2}$ Département de Génie Mécanique, Université de Guelma, Guelma, Algérie

e-mail: boutabba_s_lpg@yahoo.fr;

\begin{abstract}
Two finite element plane strain models of the same closed die forming process are compared with ABAQUS software. This work is prepared in the frame work of Work Package $n^{\circ} 3$ of the Virtual Intelligent Forging Coordination Action. The subject of this benchmark is a thermo mechanical upsetting with a screw press of an Inconel workpiece with an initial temperature equal to $1230^{\circ} \mathrm{C}$ between two warm shaped dies. The first simulation uses the classical implicit quasi static algorithm, the second one uses an explicit scheme without mass scaling with the actual kinematic conditions of the process. Significant discrepancies in the final shape of the workpiece are found.
\end{abstract}

Key words: Forging, Finite element, Explicit, Implicit

\section{INTRODUCTION}

The choice of the right software for the modelling of dynamic thermo mechanical forming processes remains tricky. Many papers deal with finite element simulation of quasi-static forming processes but as industrial plants are still using drop machines as power hammers or forging presses, numerical simulation has to be suited to these dynamic forgings. This paper describes two plane strain finite element models of the upsetting of a simple cylindrical workpiece with an energy driven press. In the first part of this paper, the actual definitions of the process as well as the material behaviour of the workpiece and tools are described. The second and third parts deal with the results of, respectively, the quasi static implicit and dynamic explicit schemes applied to the modelling of the process. The last part is devoted to the comparison of the results and to some explanations of the discrepancies found.

\section{PROCESS DEFINITION}

\subsection{Geometry}

Following the definition of the Work Package $n^{\circ} 3$ of

the Virtual Intelligent Forging Coordination Action, the billet is a $35 \mathrm{~mm}$ long cylinder with a radius of $14 \mathrm{~mm}$, made of Inconel 690. The upper and lower dies are identical with a circular concave shape with a radius of $65 \mathrm{~mm}$ and a $10 \mathrm{~mm}$ long flat part, (see figure 1). Both tools are machined in a $100 \mathrm{~mm}$ large and $50 \mathrm{~mm}$ thick rectangular block of AISI H11 steel.

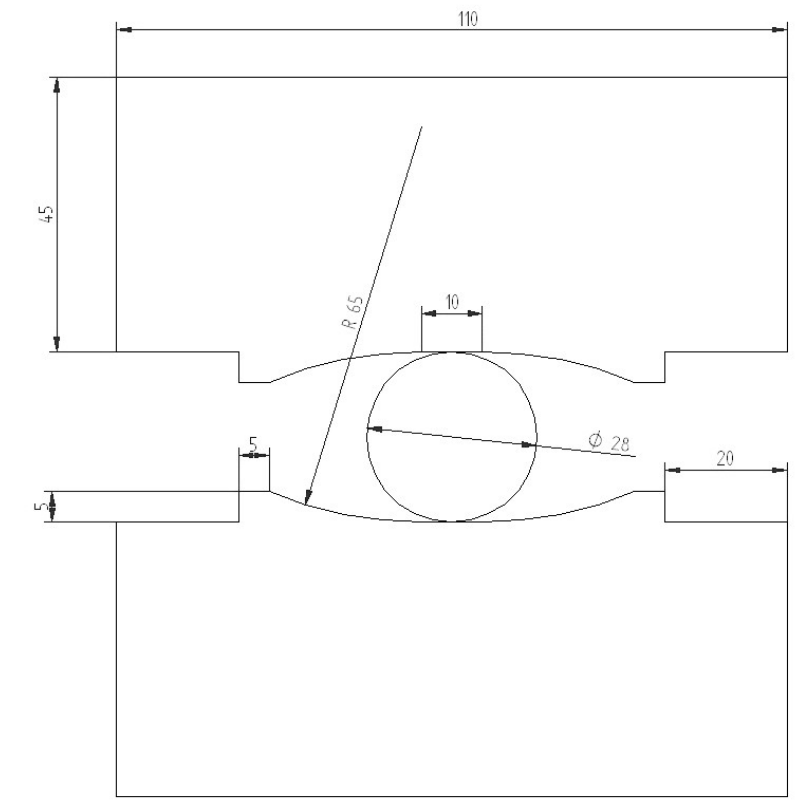

Fig. 1. Tool and billet geometries 


\subsection{Billet material}

As no data about the constitutive law of the Inco 690 was defined by the Work Package $\mathrm{n}^{\circ} 3$, some mix of thermal and mechanical properties of the Inco 718 and Inco690 are used for the modelling of this forming process. The elastic behaviour is assumed to be linear and temperature dependent with values of the Young modulus and the Poisson ratio defined in Table 1

Table1. Elastic properties of the Inconel 718

\begin{tabular}{ccc}
\hline $\begin{array}{c}\text { Temperature } \\
(\mathrm{K})\end{array}$ & $\begin{array}{c}\text { Young Modulus } \\
(\mathrm{MPa})\end{array}$ & $\begin{array}{c}\text { Poisson } \\
\text { ratio }\end{array}$ \\
\hline 294 & 207000 & 0.3 \\
477 & 196000 & 0.3 \\
700 & 183000 & 0.31 \\
892 & 165000 & 0.28 \\
1144 & 147000 & 0.3 \\
1366 & 125000 & 0.36 \\
1503 & 112000 & 0.4 \\
\hline
\end{tabular}

Existing data for the plastic behaviour of this material are bounded to $1000 \mathrm{~K}$ when this process considers an initial billet temperature close to $1500 \mathrm{~K}$. Below this temperature, the available data for high plastic strain rates presented by Lee et al. [1] are used as the screw press can induce plastic strain rates in the range of 10 to $100 \mathrm{~s}^{-1}$. For higher temperatures as well as lower strain rates, some extension of the known visco-plastic properties of the Inco718 is introduced following a power law.

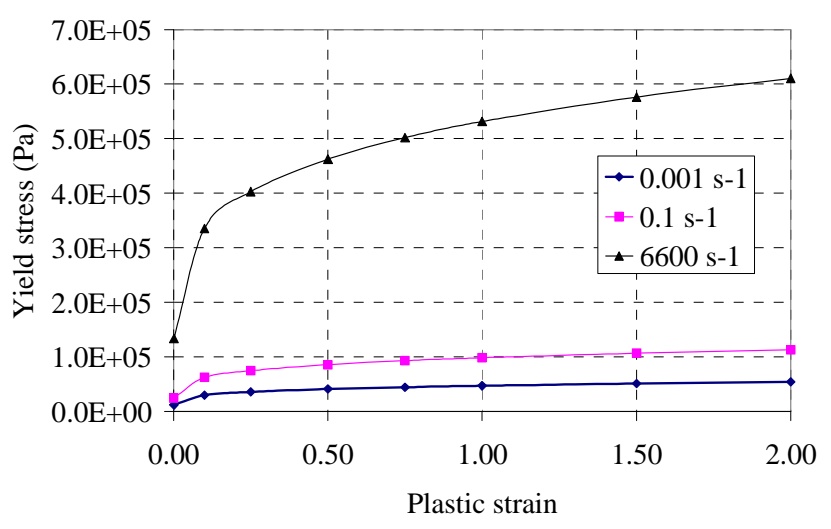

Fig. 2. Yield strength of the billet material at $1500 \mathrm{~K}$

Figure 2, presents the values of yield strength for the initial temperature of the billet and three plastic strain rates. For others temperature, the data has been calculated with the following constitutive visco-plastic law:

$\sigma_{\mathrm{e}}=\mathrm{Ke}^{\beta / \mathrm{T}} \bar{\varepsilon}_{\mathrm{p}}{ }^{\mathrm{m}} \dot{\bar{\varepsilon}}_{\mathrm{p}}{ }^{\mathrm{n}}$

with $\mathrm{K}$ a material parameter proportional to the actual consistency set to $10 \mathrm{MPa}$ in this case. $\mathrm{T}$ is the absolute temperature of the material, the coefficient $\beta$ for the Inco718 is set equal to $4000 \mathrm{~K}$. $\bar{\varepsilon}_{\mathrm{p}}$ and $\dot{\bar{\varepsilon}}_{\mathrm{p}}$ are respectively the equivalent plastic strain and the equivalent plastic strain rate. Exponents $\mathrm{m}$ and $\mathrm{n}$ are two constitutive constants of the material are set respectively to the values 0.16 and 0.2 .

Thermal properties of the billet material are also considered temperature dependent although the process lasts less than $0.2 \mathrm{~s}$ but provisions are made for some quenching effects on the skin of the billet with the thermal shock induced by the difference between temperatures of the dies and of the part close to $1000^{\circ} \mathrm{C}$. The inner part of the billet might be considered as isothermal but this assumption is coarse in the vicinity of the billet surface where high residual stress will be generated by the steep temperature gradient. Table 2 summarizes those thermal values

Table2. Thermal properties of the Inconel 718

\begin{tabular}{cccc}
\hline $\begin{array}{c}\text { Temperature } \\
(\mathrm{K})\end{array}$ & $\begin{array}{c}\text { Conductivity } \\
(\mathrm{W} / \mathrm{m} / \mathrm{K})\end{array}$ & $\begin{array}{c}\text { Specific Heat } \\
(\mathrm{J} / \mathrm{kg} / \mathrm{K})\end{array}$ & $\begin{array}{c}\text { Expansion } \\
\text { Coefficient }\end{array}$ \\
\hline 373 & 15.4 & 471 & $1.406 \mathrm{E}-05$ \\
573 & 19.1 & 525 & $1.453 \mathrm{E}-05$ \\
773 & 21. & 578 & $1.519 \mathrm{E}-05$ \\
973 & 24.8 & 631 & $1.618 \mathrm{E}-05$ \\
1173 & 28.5 & 684 & $1.701 \mathrm{E}-05$ \\
1373 & 32. & 738 & $1.779 \mathrm{E}-05$ \\
1503 & 33.78 & 773 & $1.828 \mathrm{E}-05$ \\
\hline
\end{tabular}

The coupling between the thermal and mechanical phenomena is controlled with the inelastic heat fraction of the mechanical dissipated power producing a heat source in the material. This fraction is set arbitrarily to 0.9 .

\subsection{Die material}

As no data are available for the constitutive law of the AISI H11 steel in the definition of the Work Package $\mathrm{n}^{\circ} 3$, the die material is considered at $200^{\circ} \mathrm{C}$ as elastic plastic with a Young modulus close to $210000 \mathrm{MPa}$, a Poisson ratio equal to 0.3 , a density close to $7800 \mathrm{~kg} / \mathrm{m}^{3}$, and an initial yield strength close to $1000 \mathrm{MPa}$. A linear hardening law is assumed with a hardening coefficient equal to $250 \mathrm{MPa}$. These assumed values of the mechanical properties are not temperature dependent and may have significant consequences on the mechanical behaviour of the tools in the area of the print. The specific heat is considered as constant and equal to $460 \mathrm{~J} / \mathrm{kg} / \mathrm{K}$. The conductivity and the expansion 
coefficient of the die material are defined in Table 3. No data have been found for temperature greater than $1088 \mathrm{~K}$ even though the tools will have contact with a hot billet with an initial temperature close to $1500 \mathrm{~K}$.

Table3. Conductivity and expansion coefficient of the AISI H11 steel

\begin{tabular}{cccc}
\hline $\begin{array}{c}\text { Temperature } \\
(\mathrm{K})\end{array}$ & $\begin{array}{c}\text { Conductivity } \\
(\mathrm{W} / \mathrm{m} / \mathrm{K})\end{array}$ & $\begin{array}{c}\text { Temperatures } \\
(\mathrm{K})\end{array}$ & $\begin{array}{c}\text { Expansion } \\
\text { coefficient }\end{array}$ \\
\hline 373 & 42.2 & 373 & $1.19 \mathrm{E}-05$ \\
533 & 36.3 & 473 & $1.24 \mathrm{E}-05$ \\
813 & 31.5 & 698 & $1.28 \mathrm{E}-05$ \\
948 & 30.1 & 813 & $1.29 \mathrm{E}-05$ \\
1088 & 28.6 & 923 & $1.33 \mathrm{E}-05$ \\
\hline
\end{tabular}

\subsection{Loading}

The data for the loading are also scarce, the screw press has a maximum energy equal to $10 \mathrm{~kJ}$ and the maximum initial velocity of the upper tool is equal to $0.4 \mathrm{~m} / \mathrm{s}$, no information about the moving mass and the actual energy used in the actual process is indicated, these figures lead to an equivalent moving mass equal to $125000 \mathrm{~kg}$. On the first hand, the material behaviour of the billet is strain rate sensitive at high temperature, on the second hand, the process is energy driven, so some kinematic law is necessary in order to model this actual process. An estimation of the plastic strain energy dissipated in the forming process leads to $1 \mathrm{~kJ}$ with an homogeneous yield stress close to $50 \mathrm{MPa}$ every where in the billet. If the screw press worked at its maximum energy, its velocity would be reduced from $0.4 \mathrm{~m} / \mathrm{s}$ to $0.392 \mathrm{~m} / \mathrm{s}$. So the kinematic law would be quite simple with a constant velocity of the upper tool, but it is not worthwhile to notice that $90 \%$ of the initial energy would be lost in the anvil and the press frame. The simulation presented in this paper uses this assumption that seems not realistic.

\subsection{Boundary conditions}

Mechanical boundary conditions are simple with the lower die supported on the vertical direction and the upper die impelled with a vertical movement. The geometrical rugosity of the tools and billet is not introduced in the simulation. As the tools are lubricated with graphite, no friction is considered on the interface with the billet (perfect slinding). Heat transfer boundary conditions are three fold. As the initial temperature of the billet is close to $1500 \mathrm{~K}$, radiation must be considered. An estimation of the power induced in this kind of heat transfer leads to a flux close to $170 \mathrm{~kW} / \mathrm{m}^{2}$. This is more than the convection contribution that is evaluated to $25 \mathrm{~kW} / \mathrm{m}^{2}$, but much less than the conduction heat transfer. Assuming a heat transfer coefficient lying in the range $1000-10000 \mathrm{~W} /\left(\mathrm{m}^{2} . \mathrm{K}\right)$, the heat flux between the billet and the die in the area of contact may be estimated between 1000 and $10000 \mathrm{~kW} / \mathrm{m}^{2}$. In this paper, only conductive heat transfer will be considered as a model with radiating and convection heat transfers confirmed the negligible contribution of these phenomena.

\section{DYNAMIC EXPLICIT SCHEME}

Both simulations presented in this paper are conducted with Abaqus software, release 6.5. with coupled temperature-displacement procedures, the results obtained with Abaqus/Explicit are presented first. In both cases, the results are presented at the same instant, $0.04 \mathrm{~s}$ after the first contact. Further displacements would need remeshing as many elements degenerate with plastic strain reaching $250 \%$ in few area of the billet.

\subsection{Meshing and loading}

The geometries of the dies and billet are meshed with CPE4RT, 4-node plane strain thermally coupled quadrilateral elements with bilinear displacement and temperature shape functions, reduced integration, and hourglass control. In a first attempt of the modelling of this process, coarse meshes are used for the billet as well as for the dies, see figure 3. The same meshes are used for the quasi static implicit integration scheme in order to have the same geometry approximations in both simulations.

The upper die is linked to a point mass, the value of which set to $125000 \mathrm{~kg}$ and this moving mass has an initial velocity equal to $0.4 \mathrm{~m} / \mathrm{s}$ when the contact between the billet and the upper die takes place.

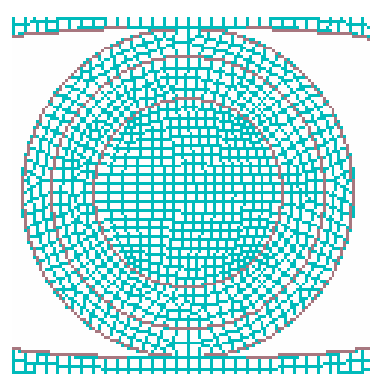

Fig. 3. Billet mesh 


\subsection{Results}

With such coarse meshes, temperature distribution in the deformed billet indicates that only a thin layer of the billet is affected by the conduction heat transfer with the die contact. With the value of the heat transfer coefficient set for the billet-die contact, the surface temperature of the billet decreases from $1500 \mathrm{~K}$ to $1200 \mathrm{~K}$ when the surface temperature of the die increases from $473 \mathrm{~K}$ to $800 \mathrm{~K}$. These temperature changes take place in a $2 \mathrm{~mm}$ thick layer under the surfaces of the deformed billet and the dies. If better predictions of the residual stress in the billet are necessary, finer mesh under the billet surface must be built on the geometry as the heat transfer is very hard with a temperature difference between the dies and the billet close to $1000^{\circ} \mathrm{C}$.

In this range of temperatures, the billet material keeps low yield strength. In this case, $0.04 \mathrm{~s}$ after the first contact, the maximum equivalent von Mises stress is equal to $5 \mathrm{MPa}$ but the maximum equivalent plastic strain reaches $250 \%$, see figure 4 .

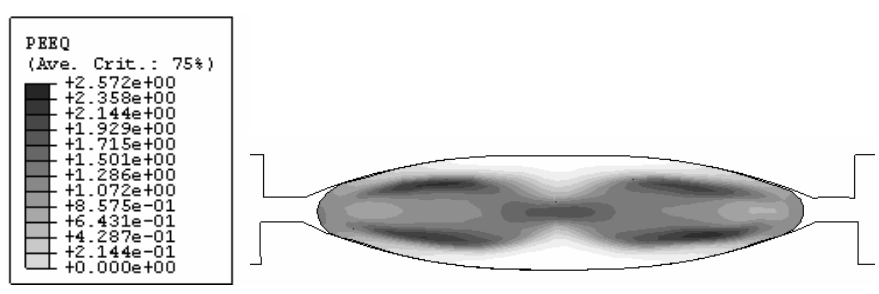

Fig. 4. Plastic strain distribution in the billet

The most significant feature of this modelling is the deformed shape of the billet without any start of flash forming. The small plastic strain of the dies has to be noticed.

\section{QUASI STATIC IMPLICIT SCHEME}

In this case, the loading is a displacement with a constant velocity equal to $0.4 \mathrm{~m} / \mathrm{s}$. The temperature distribution is very similar to the explicit integration scheme simulation as heat transfer is mainly controlled by time. $0.04 \mathrm{~s}$ after the first contact, this modelling predicts a large flash on the symmetry plane of the billet. Figure 5 shows the shape differences between those two simulations.

At this instant, the maximum equivalent von Mises stress is only equal to $1.5 \mathrm{MPa}$ and the maximum equivalent plastic strain remains under $140 \%$. Nevertheless, plastic strain distribution in the deformed billet is not realistic as no remeshing was carried out. In the flash, elements are highly distorted and such a result can only give an idea of the final shape.

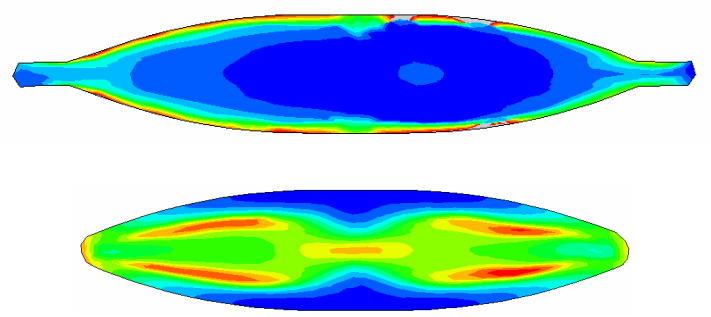

Fig. 5. Billet shape after forging

Those differences can partially be explained with volume changes. Initial billet volume is identical for implicit and explicit model. A the end of forming simulations, the loss of volume is $0.8 \%$ using the implicit scheme and $2.8 \%$ using the explicit scheme.

\section{CONCLUSIONS}

This simple example shows that the choice between a quasi static implicit scheme and a dynamic explicit one is not straightforward. In this paper, two simulations of the closed die forming of a cylindrical bar with a screw press are carried out with the same material data and the same meshes and lead to different result on the deformation process. It has been checked that he thermal effects are reduced to conduction heat transfer between the deformed billet and the dies. The quasi static implicit integration scheme predicts a blade with a flash when the dynamic explicit integration scheme forecasts larger strain in the dies induced by dynamic effects and a blade without any flash. This important discrepancy of the two predictions must be scrutinized once the actual conditions of the process will be defined for a better numerical analysis of the different phenomenon.

\section{REFERENCES}

1. W. S. Lee, C.Y. Liu, and T.N. Sun, Journal of Material Processing Technology, 153-154, 2004, 219-225. 